Article

\title{
Analogues of Muraymycin Nucleoside Antibiotics with Epimeric Uridine-Derived Core Structures
}

\author{
Anatol P. Spork ${ }^{1,+}$, Stefan Koppermann ${ }^{2,+}$, Stephanie Schier (née Wohnig) ${ }^{1,2}$, Ruth Linder ${ }^{1,2}$ \\ and Christian Ducho $1,2, *$ (D) \\ 1 Department of Chemistry, Institute of Organic and Biomolecular Chemistry, Georg-August-University \\ Göttingen, Tammannstr. 2, 37077 Göttingen, Germany; anatolspork@gmx.de (A.P.S.); \\ swohnig@web.de (S.S.W.); ruth.linder@uni-saarland.de (R.L.) \\ 2 Department of Pharmacy, Pharmaceutical and Medicinal Chemistry, Saarland University, Campus C2 3, \\ 66123 Saarbrücken, Germany; stefan.koppermann@uni-saarland.de \\ * Correspondence: christian.ducho@uni-saarland.de; Tel.: +49-(0)681-302-70343 \\ + These authors contributed equally to this work.
}

Academic Editor: Derek J. McPhee

Received: 21 September 2018; Accepted: 30 October 2018; Published: 3 November 2018

\begin{abstract}
Nucleoside analogues have found widespread application as antiviral and antitumor agents, but not yet as antibacterials. Naturally occurring uridine-derived 'nucleoside antibiotics' target the bacterial membrane protein MraY, an enzyme involved in peptidoglycan biosynthesis and a promising target for the development of novel antibacterial agents. Muraymycins represent a nucleoside-peptide subgroup of such MraY-inhibiting natural products. As part of detailed structure-activity relationship (SAR) studies on muraymycins and their analogues, we now report novel insights into the effects of stereochemical variations in the nucleoside core structure. Using a simplified version of the muraymycin scaffold, it was shown that some formal inversions of stereochemistry led to about one order of magnitude loss in inhibitory potency towards the target enzyme MraY. In contrast, epimers of the core motif with retained inhibitory activity were also identified. These $5^{\prime}, 6^{\prime}$-anti-configured analogues might serve as novel chemically tractable variations of the muraymycin scaffold for the future development of uridine-derived drug candidates.
\end{abstract}

Keywords: antibiotics; natural products; nucleoside analogues; structure-activity relationships.

\section{Introduction}

Infections with bacterial strains that have developed resistance against clinically used antibiotics are on the rise and represent a major challenge in healthcare [1,2]. New targets and new modes of action are needed to fight back such infections. Such novel targets can also be found in bacterial pathways that have already been addressed by many antibiotics [3]. MraY (translocase I) represents an example of a yet unexploited target, as it is part of bacterial peptidoglycan biosynthesis, i.e., one of the main pathways addressed by established antibiotics [4,5]. MraY catalyses the first membrane-associated step of peptidoglycan formation: the reaction of UDP-MurNAc pentapeptide ('Park's nucleotide') 1 with the isoprenoid membrane anchor undecaprenyl phosphate 2 , thus yielding membrane-bound lipid I 3 (Scheme 1) [6-12]. 


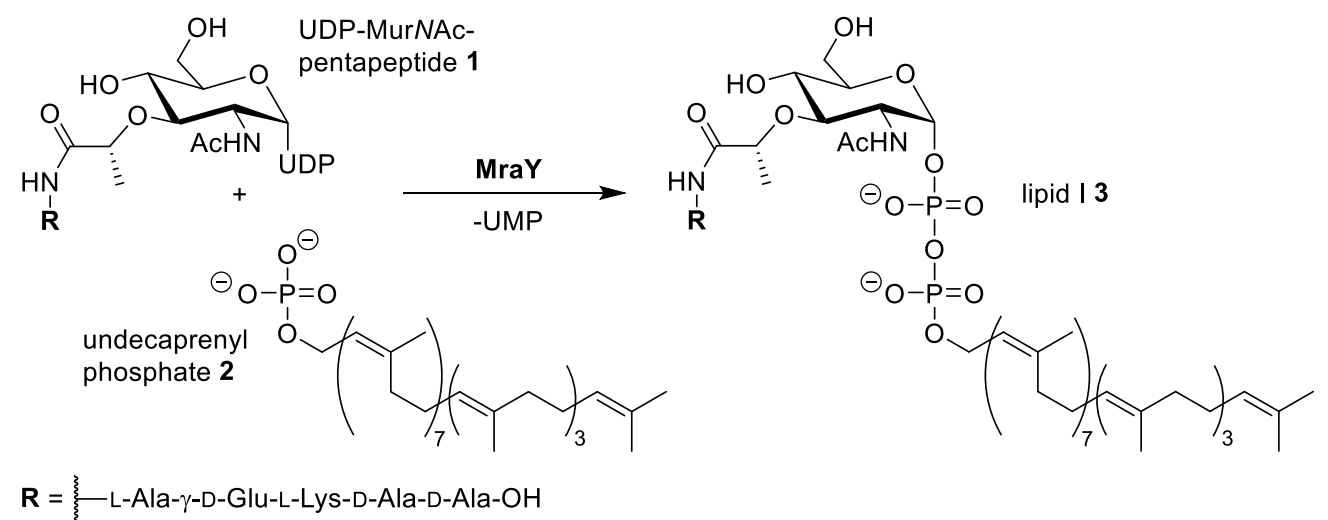

Scheme 1. Reaction of Park's nucleotide 1 with undecaprenyl phosphate $\mathbf{2}$ yielding lipid I 3 catalysed by translocase I (MraY). UDP = uridine diphosphate, UMP = uridine monophosphate. The exact composition of the pentapeptide moiety (residue $\mathbf{R}$ ) can vary among different bacteria [11].

MraY is a membrane protein with ten transmembrane helices and five cytosolic loops $[13,14]$. Methods for overexpression and isolation of the protein are available [15-17]. Several classes of natural products that inhibit MraY have been found over the years ('nucleoside antibiotics', e.g., muraymycins, caprazamycins, liposidomycins, capuramycins, and mureidomycins) [12,18-20]. We are mainly interested in muraymycins and their synthetic analogues, as they represent promising lead structures for antibacterial drug development. Muraymycins were originally discovered as a group of 19 structurally related secondary metabolites from Streptomyces [21,22]. Very recently, new and more active members of the muraymycins were isolated from the same strains [23]. The principle structure of muraymycins consists of a $\left(5^{\prime} S, 6^{\prime} S\right)$-glycyluridine (GlyU) motif (representing a 'high-carbon' nucleoside) and a urea peptide moiety containing the arginine-derived non-proteinogenic amino acid epicapreomycidine, with both units connected by an alkyl linker (Figure 1). Many naturally occurring muraymycins carry an $O$-aminoribosyl residue at the nucleosidic $5^{\prime}$-position. Muraymycins have been assigned to four subclasses with respect to the central L-leucine motif: classes A-C feature a (3S)-3-hydroxyl-L-leucine that is further functionalised with fatty acyl motifs in the A- and B-series. The A-series has $\omega$-functionalised fatty acyl units bearing a terminal ( $N$-hydroxy-)guanidine group (e.g., A1 4 and A5 5), whereas the B-series has branched alkyl chains instead (e.g., B9 6). The C-series (e.g., C4 7) is not $\mathrm{O}$-acylated in the 3-hydroxyl-L-leucine moiety, and the D-series (e.g., D1 8) is characterised by a nonhydroxylated L-leucine residue.

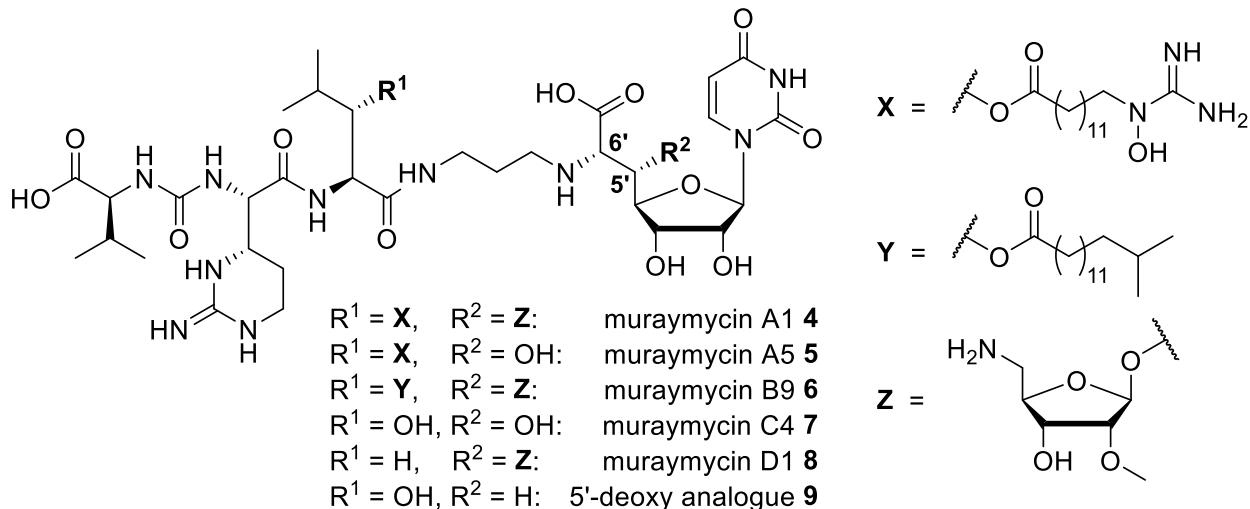

Figure 1. Structures of selected naturally occurring muraymycins 4-8 [21,23] and the previously reported synthetic 5'-deoxy analogue 9 [24].

In 2016, Chung et al. reported an X-ray crystal structure of MraY from the extremophile Aquifex aeolicus in complex with muraymycin D2 (which differs from D1 8 by the lack of the methyl ether at the amino ribose (Z), Figure 1) [25]. By comparison of this co-crystal structure with the previously 
described ligand-free apo enzyme structure [14], a pronounced conformational plasticity of the enzyme was revealed, with some amino acids moving up to $17 \AA$ upon inhibitor binding [25,26]. In combination with the complex structures of the inhibitors, this makes computer-aided drug design approaches challenging and less reliable for the prediction of binding modes and structure-activity relationship (SAR) for other muraymycins and their analogues. Thus, the synthesis and biological testing of novel analogues represents a crucial approach in obtaining additional and more detailed insights into the interactions of muraymycin-type inhibitors with their bacterial target MraY.

The total synthesis of naturally occurring muraymycins is challenging with respect to several unusual structural motifs in the muraymycin scaffold (in particular, the $5^{\prime}$-O-aminoribosylated 'high-carbon' nucleoside core, the epicapreomycidine, and the (3S)-3-hydroxyl-L-leucine units). Important contributions to the total synthesis of muraymycins and/or the aforementioned structural motifs were made by Ichikawa and Matsuda, Kurosu, and our group [12,24,27-34]. Several SAR studies on muraymycin analogues (including structurally simplified congeners) have already been conducted [12,24,35-39]. For instance, Ichikawa, Matsuda, and coworkers showed that the epicapreomycidine unit can be substituted with simpler amino acids without being deprived of antibacterial activity. This finding was solely based on antibacterial minimum inhibitory concentrations (MIC values), i.e., no in vitro data on MraY inhibition were reported for such analogues [38]. We have recently re-investigated selected naturally occurring muraymycins for their properties as MraY inhibitors. By that, we showed that the lack of the fatty acid moiety (such as in 7 or 8 ) eliminates antimicrobial activity (likely due to hampered cellular uptake) but hardly affects the target interaction [40]. Regarding structural simplifications of the muraymycin scaffold, we have reported $5^{\prime}$-defunctionalised (' 5 '-deoxy') analogues of the uridine-derived muraymycin core unit, i.e., congeners not only lacking the aminoribosyl motif, but any substituent in the $5^{\prime}$-position $[24,41,42]$. For the 5'-deoxy analogue 9 of muraymycin C4 7 (Figure 1), it was demonstrated that a corresponding full-length muraymycin derivative of this type can still be a fairly potent inhibitor of $\mathrm{MraY}\left(\mathrm{IC}_{50}=\right.$ $95 \pm 19 \mathrm{nM}$ for 9) [40]. Thus, the $5^{\prime}$-deoxy variation might be useful to derive novel chemically more tractable lead structures for antibacterial drug development. It might also serve as a simplified scaffold for further SAR studies, for instance, on the muraymycin peptide unit.

However, it has been unknown so far if further variations of the nucleoside core structure might be feasible without hampering inhibition of the target enzyme MraY. In particular, stereochemical variations have only scarcely been studied. It was therefore the goal of this work to investigate simplified muraymycin analogues with epimeric configurations in the 'high-carbon' uridine-derived nucleoside core. During our studies on $5^{\prime}$-deoxy analogue 9 , we have made the unexpected observation that $5^{\prime}$-hydroxylated synthetic intermediates (i.e., protected uridine-derived building blocks with the native (5'S,6 $\left.6^{\prime} S\right)$-syn-configuration) were fairly unstable and therefore prone to decomposition [24]. Based on the assumption that the intrinsic instability of these intermediates originates from their $5^{\prime}, 6^{\prime}$-syn-configuration, we turned to the respective $5^{\prime}, 6^{\prime}$-anti-configured congeners. Thus, another objective was to investigate if epimeric anti-configured variations $\left(\left(5^{\prime} R, 6^{\prime} S\right)\right.$ and $\left(5^{\prime} S, 6^{\prime} R\right)$, respectively) might be sufficiently stable for the synthesis of full-length muraymycins and if the resultant analogues would be MraY inhibitors. Finally, we also aimed to study the interplay of stereochemical variations in the nucleoside core and an epimeric configuration in the peptide unit. We therefore decided to include D-leucine derivatives (in contrast to the native L-configuration in this position) in our studies.

The aforementioned considerations led to the design of target structures 10-17 (Scheme 2). In order to limit synthetic effort, the scaffold of the previously reported 5'-deoxy analogue 9 was further simplified (L-lysine instead of the cyclic arginine derivative epicapreomycidine, nonhydroxylated L-leucine (as in muraymycin D1 8) in the central section), thus furnishing analogue 10 with the native $\left(6^{\prime} S\right)$-configuration in the nucleoside core. Compound 11 represents the leucine (i.e., $2^{\prime \prime \prime}$ ) epimer of 10, and target structures 12 and $\mathbf{1 3}$ are the $6^{\prime}$-epimers of $\mathbf{1 0}$ and 11, respectively. Compounds 14-17 are anti-configured $5^{\prime}$-hydroxylated analogues with one epimeric configuration (relative to the $5^{\prime}, 6^{\prime}$-syn-configured natural products) in either the $5^{\prime}$ - or the $6^{\prime}$-position. In the case of 15 and 
$\mathbf{1 7}$, this variation was combined with the non-natural D-leucine (i.e., $\left(2^{\prime \prime \prime} R\right)$ ) motif. It was our goal to prepare this series of muraymycin analogues in an efficient manner and to subject them to an established fluorescence-based in vitro assay for MraY inhibition [15,40,43]. Thus, we wanted to identify stereochemical variations of the muraymycin scaffold with potentially retained inhibitory activities towards the bacterial target enzyme MraY.

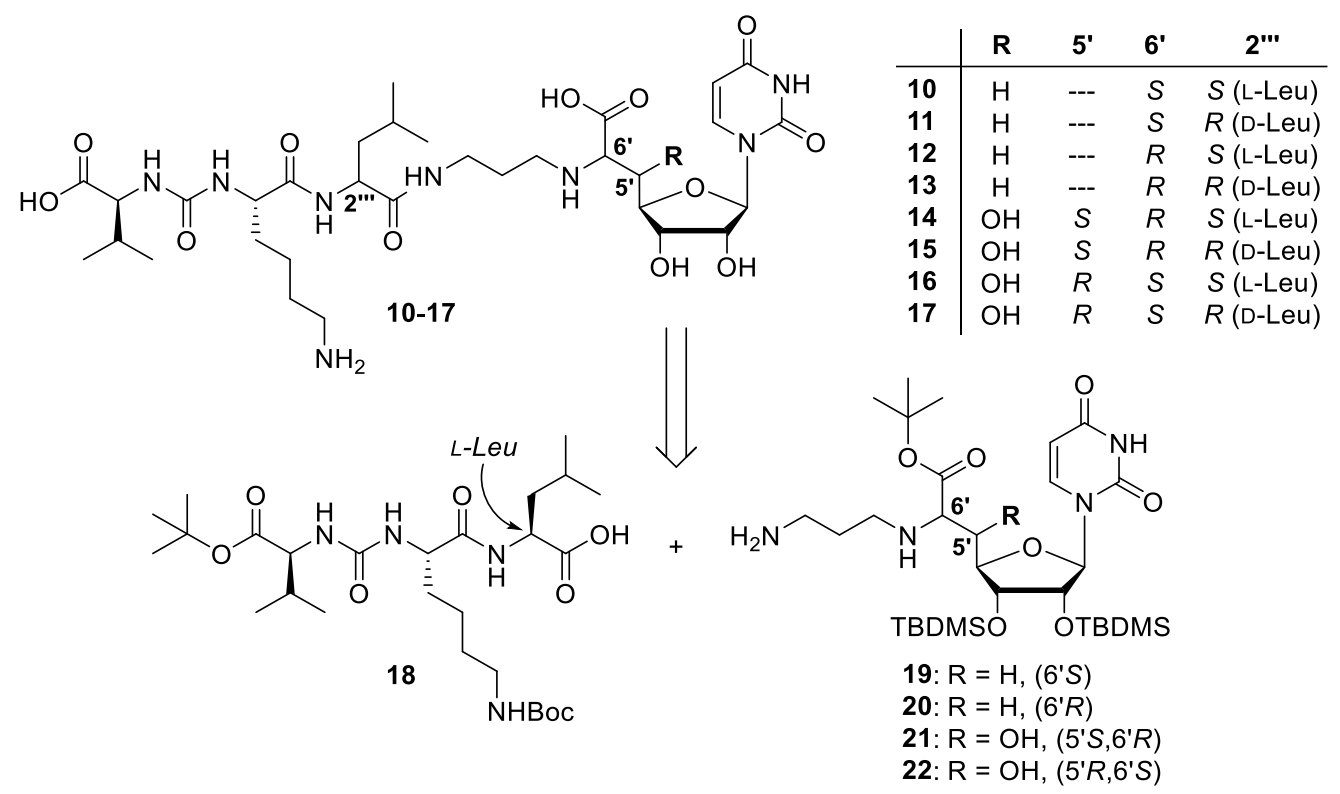

Scheme 2. Target structures $\mathbf{1 0 - 1 7}$ of this study and retrosynthetic strategy for their preparation.

\section{Results}

\subsection{Synthesis of Muraymycin Epimers}

For our previous synthesis of 5'-deoxy muraymycin analogue 9, we had reported a tripartite approach using protected building blocks for the uridine-derived nucleoside core, the terminal urea dipeptide motif and the central section [24]. However, for the sake of efficiency, we have decided to pursue a bipartite strategy in this work as most of the structural variations would be in the nucleoside core. Hence, such a bipartite approach was envisioned to be more convergent. The dissection of target structures 10-17 into two principle building blocks led to the protected urea tripeptide $\mathbf{1 8}$ and aminoalkylated nucleosyl amino acids 19-22 (Scheme 2). Peptide coupling and subsequent global acidic deprotection of the two building blocks was envisaged to afford the target compounds. It was initially unclear if the peptide coupling of 18 with either uridine derivative 19-22 proceeds without epimerisation. Hence, it was decided to prepare the L-leucine-containing tripeptide 18 first in order to initially elucidate the stereochemical outcome of the key coupling reaction before preparing the D-leucine-containing derivative of $\mathbf{1 8 .}$

Protected urea tripeptide 18 was synthesised from corresponding amino acid building blocks (Scheme 3). Commercially available $N^{\alpha}-\mathrm{Cbz}-N^{\varepsilon}$-Boc-protected L-lysine 23 was converted into its 2-(trimethylsilyl)ethyl (TMSE) ester using a sequence of 1-ethyl-3-(3-dimethylaminopropyl)carbodiimide hydrochloride (EDC)-mediated esterification and $N^{\alpha}-\mathrm{Cbz}$ deprotection (77\% yield over two steps). The resultant product 24 was coupled with $\mathrm{N}$-(S-methyl thiocarbonyl)-L-valine-tert-butyl ester 25 [28] in the presence of silver triflate to give 26 in $76 \%$ yield. TMSE deprotection with tetrabutylammonium fluoride (TBAF) then afforded the free carboxylic acid 27 in 93\% yield. Urea dipeptide 27 was coupled with L-leucine TMSE ester 28 (TFA salt) to give urea tripeptide ester 29 in $80 \%$ yield. Subsequent cleavage of the TMSE ester furnished the urea tripeptide building block 18 in 92\% yield. The L-leucine TMSE ester 28 had been obtained in a 
similar manner as its L-lysine congener from $\mathrm{N}$-Cbz-L-leucine $\mathbf{3 0}$ via a sequence of EDC-mediated esterification and $\mathrm{N}$-Cbz deprotection ( $86 \%$ yield over 2 steps, Scheme 3$)$.

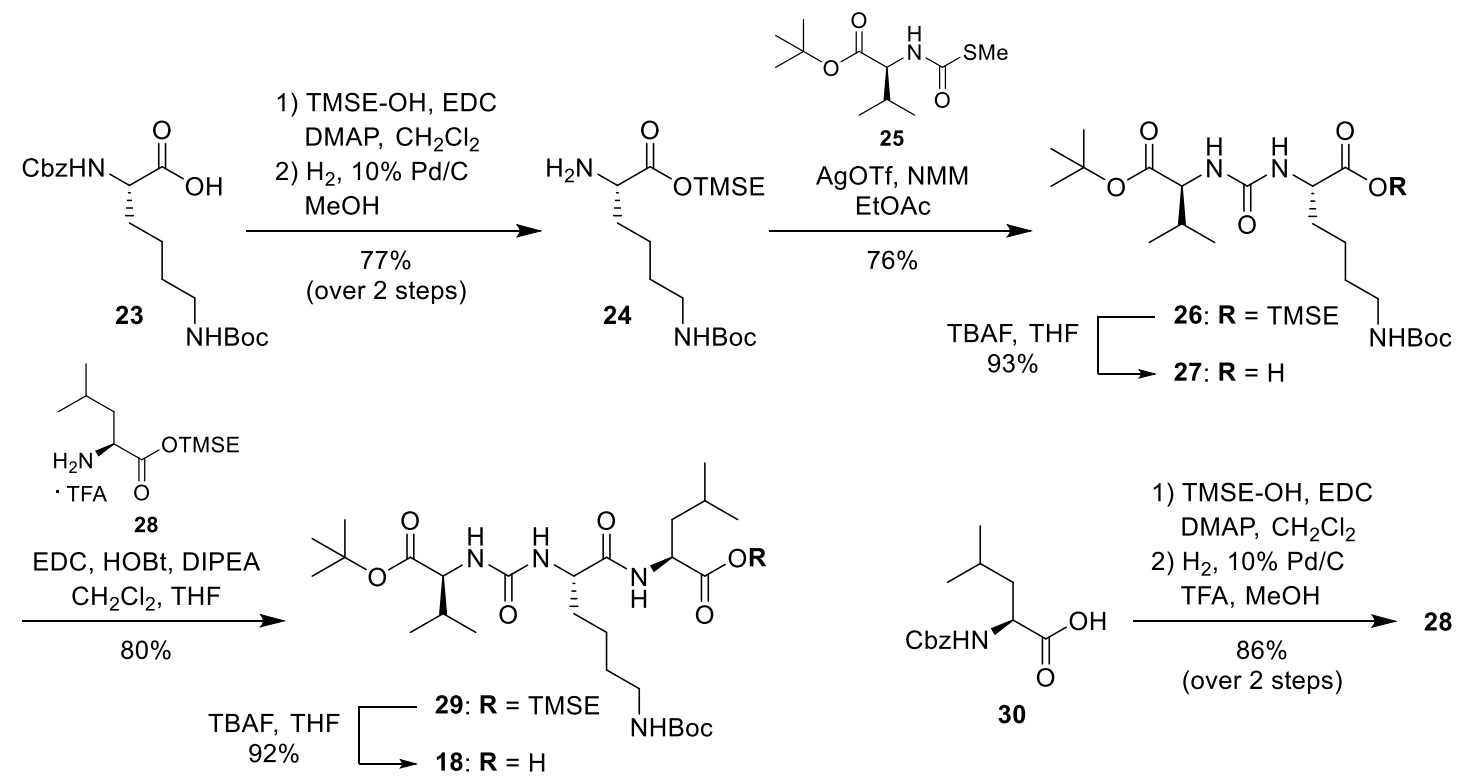

Scheme 3. Synthesis of the urea tripeptide building block 18. TMSE = 2-(trimethylsilyl)ethyl.

The stereocontrolled synthesis of the aminoalkylated $5^{\prime}$-deoxy nucleosyl amino acids $\mathbf{1 9}$ and $\mathbf{2 0}$ has been reported before [41]. For the preparation of the $5^{\prime}$-hydroxylated building blocks $\mathbf{2 1}$ and 22, we have employed our previously described stereocontrolled syntheses of corresponding epoxy ester precursors [44]. In the case of $6^{\prime}$-epimer 21, epoxy ester 31 was obtained via stereoselective reaction of a sulphur ylide with a uridine- $5^{\prime}$-aldehyde precursor (reactions not shown) [31,45-47]. Epoxide 31 was then reacted with $N^{1}-(\mathrm{Cbz})-1,3$-diaminopropane 32 in a regioselective $\mathrm{S}_{\mathrm{N}} 2$-type transformation affording amino alcohol 33 in 77\% yield (Scheme 4). Subsequent $N$-Cbz deprotection ( $99 \%$ yield) gave the $6^{\prime}$-epi building block 21. For $5^{\prime}$-epimer 22, epoxy ester 34 was obtained via Sharpless epoxidation (reactions not shown) [44,47]. Epoxide 34 was then subjected to a similar sequence of regioselective $\mathrm{S}_{\mathrm{N}}$ 2-type ring opening (product 35, 89\% yield) and $\mathrm{N}$-Cbz deprotection (99\% yield) to afford the $5^{\prime}$-epi building block 22 (Scheme 4).
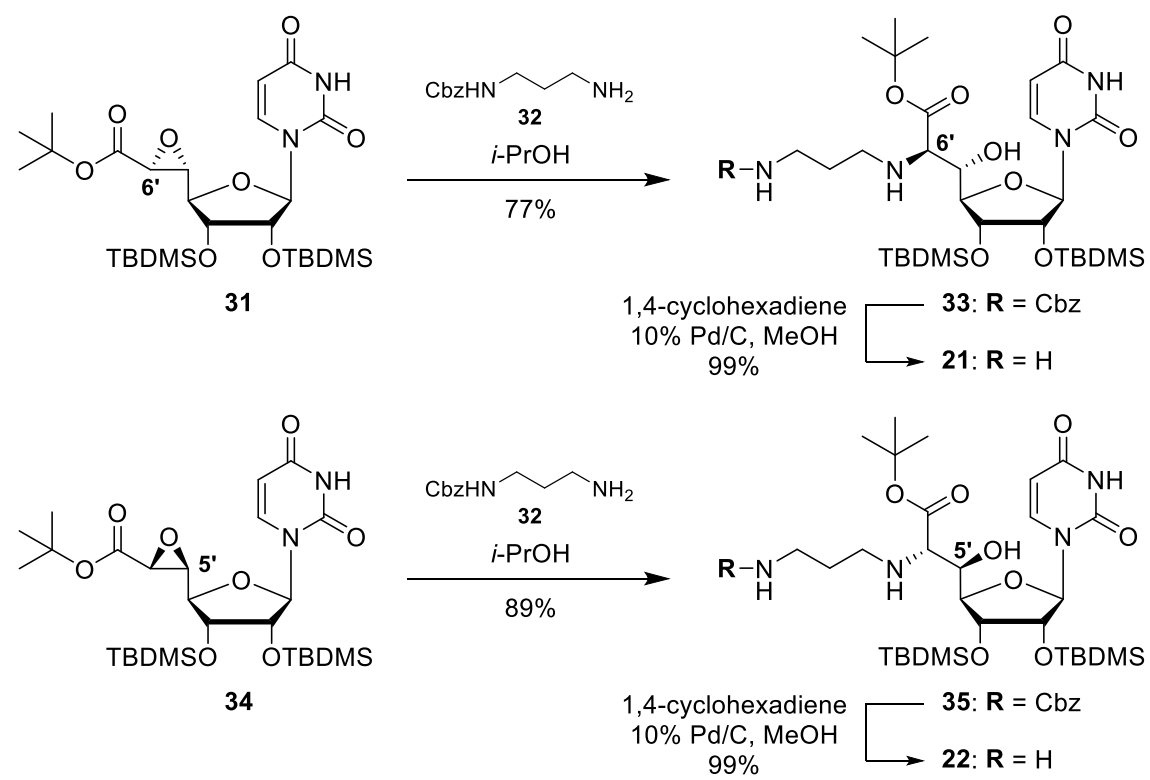

Scheme 4. Synthesis of uridine-derived building blocks 21 and 22. 
With all required building blocks in hand, the target structures could be prepared. The urea tripeptide building block 18 was activated with EDC in the presence of HOBt and then treated with amines 19-22 (Scheme 5). Corresponding coupling products were not characterised but directly employed in global acidic deprotections with 80\% TFA in water. For each two-step transformation of this type, two compounds were isolated by preparative HPLC, showing identical masses and connectivities (as proven by NMR spectroscopy). It was concluded that the activated leucine unit in tripeptide 18 must have undergone epimerisation in the coupling step, which implied that the respective L-leucine and D-leucine epimers were isolated in pure form (after HPLC) from just one two-step transformation for every variation of the nucleoside core. This was unambiguously proven by acidic hydrolysis of the respective stereoisomerically pure peptidic products, subsequent derivatisation with Marfey's reagent and HPLC analysis, which also furnished the stereochemical assignment of the leucine unit (see Supplementary Materials). Hence, it was not necessary to prepare the D-leucine epimer of 18 as all target structures (10-17) were synthesised from one urea tripeptide precursor in a highly efficient manner (Scheme 5).

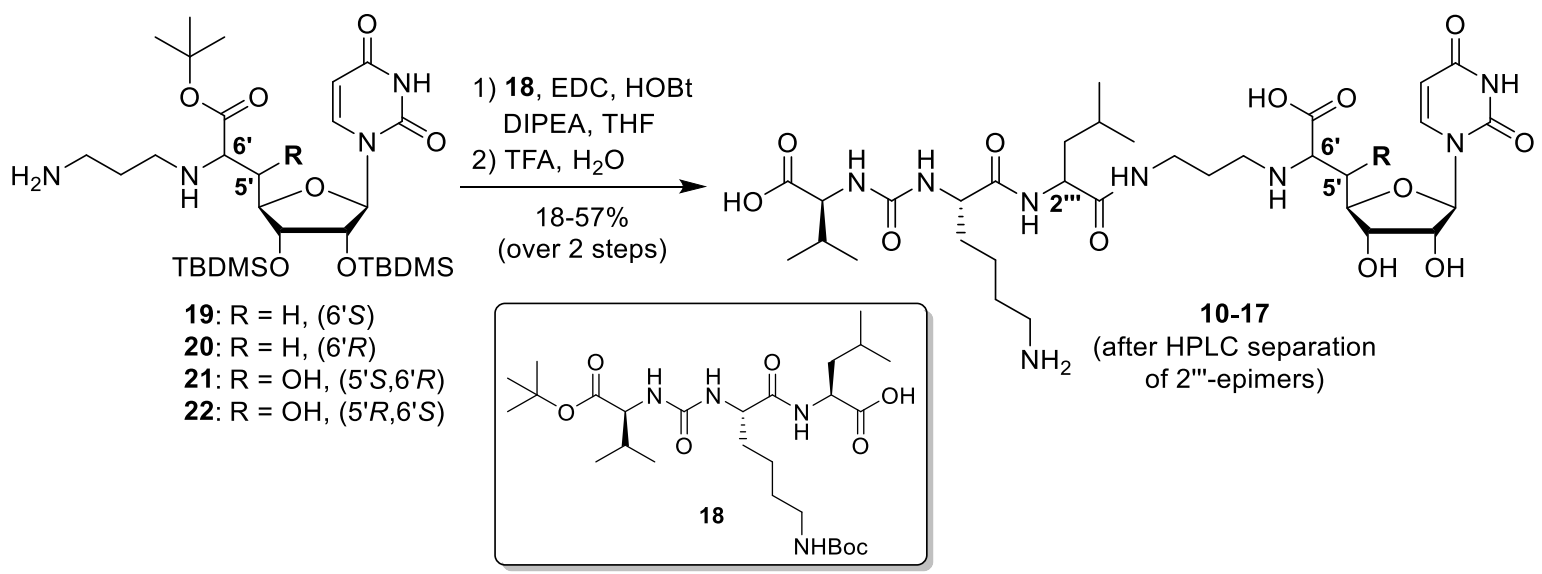

Scheme 5. Synthesis of target structures 10-17.

\subsection{Biological Evaluation}

Target compounds 10-17 were tested in vitro for their inhibitory potency towards the bacterial target enzyme MraY. Therefore, a previously reported fluorescence-based assay was employed, using dansylated Park's nucleotide and MraY from S. aureus (recombinantly overexpressed in E. coli) $[15,23,40,43,48]$. None of the tested muraymycin analogues showed any interfering autofluorescence at the employed wavelength $\left(\lambda_{\mathrm{ex}}=355 \mathrm{~nm}\right)$. The thus obtained inhibitory activities ( $\mathrm{IC}_{50}$ values) are listed in Table 1.

Muraymycin analogues 10-17 were also studied for their antibacterial activities against E. coli, but were not active (MIC $>50 \mu \mathrm{g} / \mathrm{mL}$ ). This was in agreement with the results obtained for previously reported 5'-deoxy analogue 9 (which proved to be more potent as an MraY inhibitor) which was weakly active against bacterial growth [24]. 
Table 1. In vitro inhibitory activities of muraymycin analogues 10-17 against MraY from S. aureus.

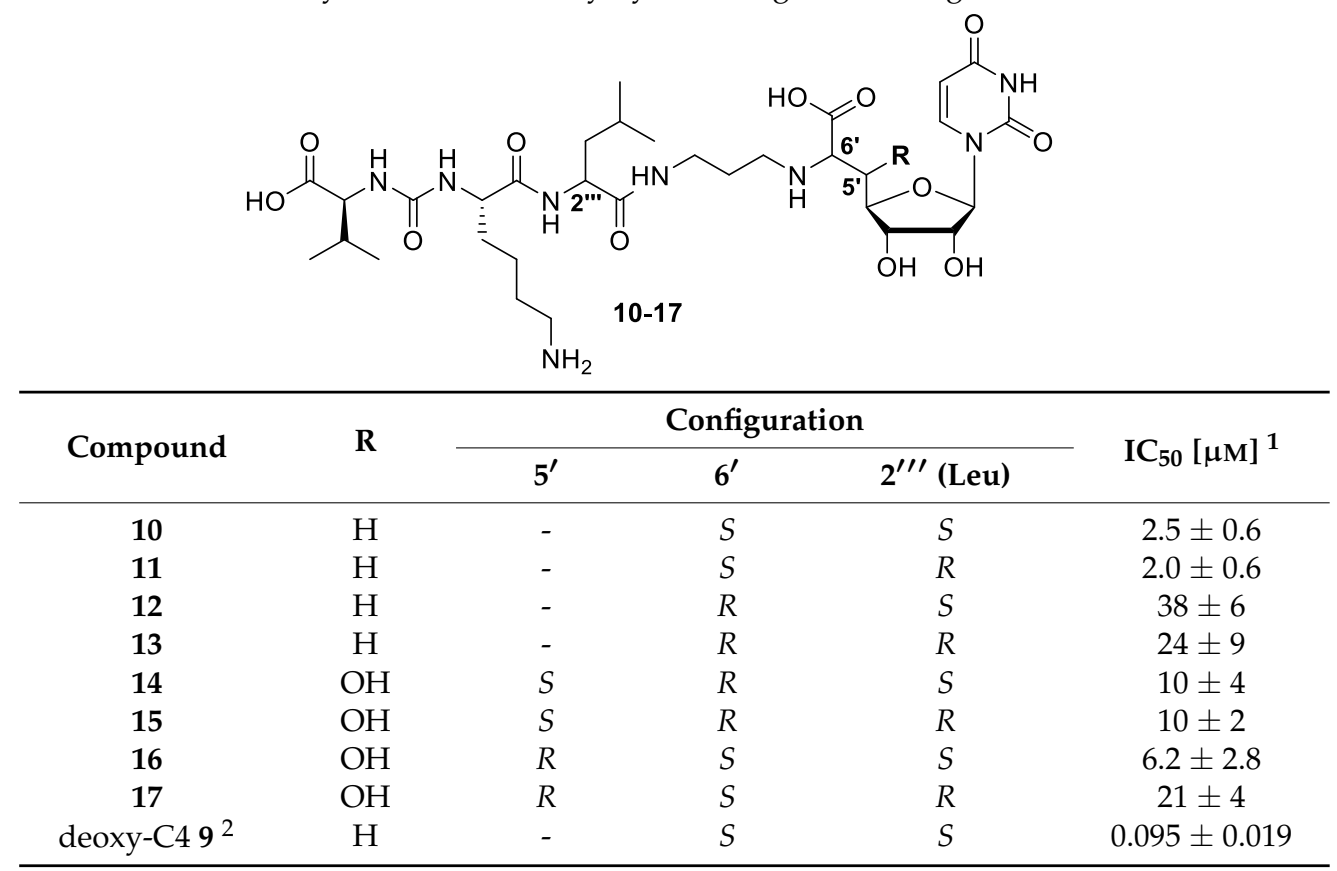

${ }^{1}$ A crude membrane preparation of MraY from S. aureus, heterologously overexpressed in E. coli, was used. All measurements were carried out in triplicates. Shown data represent mean values \pm standard deviations. ${ }^{2}$ Structure shown in Figure 1.

\section{Discussion}

All newly synthesised muraymycin epimers $\mathbf{1 0}-\mathbf{1 7}$ showed $\mu \mathrm{M}$ inhibitory activities in vitro against the bacterial target protein MraY. This is in accordance with previously reported observations that exchanging the epicapreomycidine moiety to simpler amino acids preserves inhibitor potency to a large extent, even though this finding was mainly based on antibacterial activities (MIC values) [38]. In our series of 5'-deoxy analogues, replacing epicapreomycidine for L-lysine and inserting nonhydroxylated L-leucine in the central position led to a 26 -fold loss in inhibitory potency (compounds 10 vs. 9). However, this implied that $\mathbf{1 0}$ was still a reasonably potent (i.e., low $\mu \mathrm{M}) \mathrm{MraY}$ inhibitor.

A comparison of MraY inhibitory activities of 10-17 (Table 1) revealed that the configuration of the leucine moiety had only a weak influence on inhibitory potencies, with the notable exception of 16 vs. 17. In this case, the native L-configuration was preferred as 16 was $\sim 3$-fold more active than 17. The reason for this is not fully clear, but it is possible that the non-native $\left(5^{\prime} R\right)$-configuration in 16 and 17 might lead to a slightly different binding mode of these MraY inhibitors relative to 10-13 (5'-deoxy) as well as 14 and $\mathbf{1 5}\left(5^{\prime} S\right)$. The influence of the configuration in the $6^{\prime}$-position was much more pronounced with the most distinct difference for the $5^{\prime}$-deoxy $\left(6^{\prime} R\right)$-derivatives 12 and $\mathbf{1 3}$ (which were 15 -fold and 12 -fold weaker inhibitors than their $\left(6^{\prime} S\right)$-counterparts $\mathbf{1 0}$ and $\mathbf{1 1}$, respectively). This decrease in inhibitory potency of the $\left(6^{\prime} R\right)$-configured analogues was largely compensated by the presence of a $5^{\prime}$-hydroxy group if the latter was oriented in the native $\left(5^{\prime} S\right)$-configuration (analogues 14 and 15). Interestingly, the $\left(5^{\prime} R, 6^{\prime} S\right)$-analogue 16 also showed almost completely retained activity, suggesting that at least one of the two substituents at the $5^{\prime}$ - and $6^{\prime}$-position needs to be in its natural orientation (in the $5^{\prime}$-hydroxylated series of compounds).

In conclusion, these results indicate that the effect of formal stereochemical inversions in the muraymycin nucleoside core (relative to the native scaffold) on MraY inhibition can be limited if a suitable structural motif is chosen. This is particularly the case for $5^{\prime}, 6^{\prime}$-anti-configured $5^{\prime}$-hydroxy analogues (except for D-leucine congener 17). This series of compounds turned out to be stable and chemically tractable, in contrast to the previously reported native $\left(5^{\prime} S, 6^{\prime} S\right)$-syn-configured motif and its 
intrinsic lability [24]. The synthesis of $\left(5^{\prime} S, 6^{\prime} R\right)$-derivatives 14 and 15 was particularly straightforward and efficient, as their epoxy ester precursor 31 is readily accessible [44].

The primary goal of the reported study was to further elucidate MraY inhibition and not to obtain analogues with strong antibacterial potencies. It was anticipated that the target structures 10-17 would only show very weak antibacterial activities at best, as previously reported derivative $\mathbf{9}$ (which was a stronger MraY inhibitor) had already only been moderately active in inhibiting bacterial cell growth [24]. Indeed, 10-17 were devoid of activity against $E$. coli (MIC $>50 \mu \mathrm{g} / \mathrm{mL}$ ). The comparison with 9 as well as with naturally occurring muraymycins [40] indicates that a low-nM (or stronger) inhibitory potency of this compound class against MraY appears to be a prerequisite for reasonable antibacterial activity. It needs to be taken into account that the polar muraymycin scaffold surely hampers cellular uptake, thus making it a decisive bottleneck for antibacterial potency. However, the novel variations of the muraymycin structure identified in this work will be highly useful for future SAR studies and the development of muraymycin analogues with improved MraY inhibition. In a second step, one can then aim to improve bacterial cellular uptake, for instance, by lipophilisation of the polar muraymycin scaffold. Such a strategy is envisioned to finally provide antibacterially active muraymycin analogues with improved chemical tractability as antimicrobial drug candidates.

\section{Materials and Methods}

\subsection{Synthesis of Muraymycin Epimers}

General methods: All chemicals were purchased from standard suppliers. Reactions involving oxygen and/or moisture sensitive reagents were carried out under an atmosphere of argon using anhydrous solvents. Anhydrous solvents were obtained in the following manner. THF was dried over sodium/benzophenone and distilled, $\mathrm{CH}_{2} \mathrm{Cl}_{2}$ was dried over $\mathrm{CaH}_{2}$ and distilled, $\mathrm{MeOH}$ was dried over activated molecular sieves $(3 \AA)$ and degassed. The obtained solvents were stored over molecular sieves ( $4 \AA$; in case of $\mathrm{MeOH} 3 \AA$ ). All other solvents were of technical quality and distilled prior to use, and deionised water was used throughout. Column chromatography was carried out on silica gel 60 (0.040-0.063 mm, 230-400 mesh ASTM, VWR, Darmstadt, Germany) under flash conditions except where indicated. TLC was performed on aluminium plates precoated with silica gel $60 \mathrm{~F}_{254}$ (VWR, Darmstadt, Germany). Visualisation of the spots was carried out using UV light $(254 \mathrm{~nm})$ and/or staining under heating $\left(\mathrm{H}_{2} \mathrm{SO}_{4}\right.$ staining solution: $4 \mathrm{~g}$ vanillin, $25 \mathrm{~mL}$ conc. $\mathrm{H}_{2} \mathrm{SO}_{4}, 80 \mathrm{~mL}$ $\mathrm{AcOH}$, and $680 \mathrm{~mL} \mathrm{MeOH} ; \mathrm{KMnO}_{4}$ staining solution: $1 \mathrm{~g} \mathrm{KMnO}_{4}, 6 \mathrm{~g} \mathrm{~K}_{2} \mathrm{CO}_{3}$, and $1.5 \mathrm{~mL} 1.25 \mathrm{M}$ $\mathrm{NaOH}$ solution, all dissolved in $100 \mathrm{~mL} \mathrm{H}_{2} \mathrm{O}$; ninhydrin staining solution: $0.3 \mathrm{~g}$ ninhydrin, $3 \mathrm{~mL}$ $\mathrm{AcOH}$, and $100 \mathrm{~mL}$ 1-butanol). Analytical HPLC was performed on a VWR-Hitachi system equipped with an L-2300 pump, an L-2200 autosampler, an L-2300 column oven $\left(24^{\circ} \mathrm{C}\right)$, an L-2455 Diode Array Detector $(\mathrm{DAD})$, and a LiChroCart ${ }^{\mathrm{TM}}$ column $(4 \times 125 \mathrm{~mm})$ containing reversed phase silica gel Purospher ${ }^{\mathrm{TM}}$ RP18e $(5 \mu \mathrm{m})$ purchased from VWR (Darmstadt, Germany). The exact HPLC method is given in the Supplementary Materials. Preparative HPLC was carried out on a Jasco system equipped with a DG-2080-53 degasser, two PU-2080 Plus pumps, a UV-2075 Plus UV/Vis detector (detection at $260 \mathrm{~nm})$, and a column $(21 \times 250 \mathrm{~mm})$ containing reversed phase silica gel Nucleodur ${ }^{\mathrm{TM}} 100-5 \mathrm{C} 18 \mathrm{ec}$ $(5 \mu \mathrm{m})$ purchased from Macherey-Nagel (Düren, Germany). Method: eluent A water $(+0.1 \% \mathrm{TFA})$, eluent B 80:20 MeCN:water (+0.1\% TFA); 0-30 min gradient of B (10-60\%), 30-32 min gradient of B (60-100\%), 32-40 min 100\% B, 40-42 min gradient of B (100-5\%), 42-51 min 5\% B; flow $10 \mathrm{~mL} / \mathrm{min}$. $300 \mathrm{MHz}-$ and $600 \mathrm{MHz}^{-1} \mathrm{H}$, and $75 \mathrm{MHz}-$ and $126 \mathrm{MHz}^{-13} \mathrm{C}$, as well as $282 \mathrm{MHz}^{-19} \mathrm{~F}$ NMR spectra were recorded on Varian MERCURY 300, UNITY 300, and INOVA 600 spectrometers (Varian, Palo Alto, CA, USA). All ${ }^{13} \mathrm{C}$ and ${ }^{19} \mathrm{~F}$ NMR spectra were ${ }^{1} \mathrm{H}$-decoupled. All spectra were recorded at room temperature except of samples in DMSO- $d_{6}$ and $\mathrm{D}_{2} \mathrm{O}$ (standard $35^{\circ} \mathrm{C}$ ) and where indicated otherwise and were referenced internally to solvent reference frequencies wherever possible. Chemical shifts $(\delta)$ are quoted in ppm and coupling constants $(J)$ are reported in $\mathrm{Hz}$. Assignment of signals was carried out using $\mathrm{H}, \mathrm{H}-\mathrm{COSY}, \mathrm{HSQC}$, and $\mathrm{HMBC}$ spectra obtained on the spectrometers mentioned above. 
The numbering of atoms of muraymycin target structure is depicted in the Supplementary Material (Figure S20). Mass spectra of small molecules were measured on a Finnigan LCQ ion-trap mass spectrometer or on a Bruker microTOF spectrometer (Bremen, Germany). For ESI measurements in the negative mode, solutions of the compounds in pure $\mathrm{MeOH}$ were used, whereas for measurements in the positive mode, solutions in $\mathrm{MeOH}$ containing $0.1 \%$ formic acid were used. High resolution spectra were measured on a Bruker 7 Tesla Fourier transform ion cyclotron resonance (FTICR) mass spectrometer (Bruker, Bremen, Germany). Melting points (mp) were measured on a Büchi instrument (Büchi, Essen, Germany) and are not corrected. Optical rotations were recorded on a PerkinElmer polarimeter 241 (Perkin-Elmer, Hamburg, Germany) with a Na source using a $10 \mathrm{~cm}$ cell. Solutions of the compounds $(10 \mathrm{mg})$ in $\mathrm{CHCl}_{3}, \mathrm{MeOH}$, or water $(1 \mathrm{~mL})$ were used, and concentrations are given in $\mathrm{g} / 100 \mathrm{~mL}$. Infrared spectroscopy (IR) was performed on a Jasco (Pfungstadt, Germany) FT/IR-4100 spectrometer equipped with an integrated ATR unit (GladiATR ${ }^{\mathrm{TM}}$, PIKE Technologies, Madison WI, USA). Wavenumbers $(v)$ are quoted in $\mathrm{cm}^{-1}$. UV spectroscopy of small molecules was carried out on a PerkinElmer (Hamburg, Germany) Lambda 2 spectrometer. Measurements were performed with solutions of $\sim 0.1 \mathrm{mg}$ of the compound in $10 \mathrm{~mL} \mathrm{MeCN}, \mathrm{MeOH}$, or water and in the range of 190 to $500 \mathrm{~nm}$. Wavelengths of maximum absorption $\left(\lambda_{\max }\right)$ are reported in $\mathrm{nm}$ with the corresponding logarithmic molar extinction coefficient $\left(\log \varepsilon, \varepsilon / \mathrm{dm}^{3} \mathrm{~mol}^{-1} \mathrm{~cm}^{-1}\right)$ given in parenthesis.

5'-deoxy-L-Leu muraymycin analogue (10) and 5'-deoxy-D-Leu muraymycin analogue (11): To a solution of the urea tripeptide $18(10 \mathrm{mg}, 0.018 \mathrm{mmol})$ in THF $(2.5 \mathrm{~mL}), 1$-hydroxybenzotriazole (HOBt, $2.4 \mathrm{mg}, 0.018 \mathrm{mmol}$ ), 1-ethyl-3-(3-dimethylaminopropyl)carbodiimide hydrochloride (ECD, $3.5 \mathrm{mg}, 0.018 \mathrm{mmol}$ ), and $N, N$-diisopropylethylamine (DIPEA, $3.1 \mu \mathrm{L}, 0.018 \mathrm{mmol}$ ) were added and the mixture was stirred at room temperature for $30 \mathrm{~min}$. It was then added to a solution of amine 19 $(15 \mathrm{mg}, 0.023 \mathrm{mmol})$ in THF $(2 \mathrm{~mL})$ and stirred at room temperature for $20 \mathrm{~h}$. EtOAc $(30 \mathrm{~mL}) \mathrm{was}$ added and the solution was washed with sat. $\mathrm{NaHCO}_{3}(30 \mathrm{~mL})$. The organic layer was dried over $\mathrm{Na}_{2} \mathrm{SO}_{4}$ and the solvent was removed under reduced pressure. The protected analogues of $\mathbf{1 0}$ and 11 were obtained after column chromatography (98:2-95:5, $\left.\mathrm{CH}_{2} \mathrm{Cl}_{2}-\mathrm{MeOH}\right)$ as colourless solids. This material was dissolved in TFA $(80 \%$ in water, $2.7 \mathrm{~mL})$ and stirred at room temperature for $24 \mathrm{~h}$. Water $(10 \mathrm{~mL})$ was added and the solvent was removed under reduced pressure. The muraymycin analogues $10(10 \mathrm{mg}, 57 \%)$ and $11(3.1 \mathrm{mg}, 17 \%)$ were separated by preparative HPLC (10: $t_{\mathrm{R}}=17.9 \mathrm{~min}, \mathbf{1 1}: t_{\mathrm{R}}=$ $16.5 \mathrm{~min})$ and obtained as colourless solids. 10: ${ }^{1} \mathrm{H} \mathrm{NMR}\left(600 \mathrm{MHz}, \mathrm{D}_{2} \mathrm{O}, 35{ }^{\circ} \mathrm{C}\right): \delta[\mathrm{ppm}]=0.99(\mathrm{~d}, J=$ $\left.6.0 \mathrm{~Hz}, 3 \mathrm{H}, 5^{\prime \prime \prime}-\mathrm{H}_{\mathrm{a}}\right), 1.04\left(\mathrm{~d}, J=6.0 \mathrm{~Hz}, 3 \mathrm{H}, 5^{\prime \prime \prime}-\mathrm{H}_{\mathrm{b}}\right), 1.05\left(\mathrm{~d}, J=7.1 \mathrm{~Hz}, 3 \mathrm{H}, 4^{\prime \prime \prime \prime \prime}-\mathrm{H}_{\mathrm{a}}\right), 1.08(\mathrm{~d}, J=6.6 \mathrm{~Hz}$, $\left.3 \mathrm{H}, 4^{\prime \prime \prime \prime \prime}-\mathrm{H}_{\mathrm{b}}\right), 1.51-1.60\left(\mathrm{~m}, 2 \mathrm{H}, 4^{\prime \prime \prime \prime}-\mathrm{H}\right), 1.66-1.83\left(\mathrm{~m}, 6 \mathrm{H}, 3^{\prime \prime \prime}-\mathrm{H}, 4^{\prime \prime \prime}-\mathrm{H}, 3^{\prime \prime \prime \prime}-\mathrm{H}_{\mathrm{a}}, 5^{\prime \prime \prime \prime}-\mathrm{H}\right), 1.88-1.94(\mathrm{~m}$, $\left.1 \mathrm{H}, 3^{\prime \prime \prime \prime}-\mathrm{H}_{\mathrm{b}}\right), 2.04\left(\mathrm{dddd}, J=7.4,7.2,6.6,6.4 \mathrm{~Hz}, 2 \mathrm{H}, 2^{\prime \prime}-\mathrm{H}\right), 2.28\left(\mathrm{dqq}, J=7.1,6.6,6.2 \mathrm{~Hz}, 1 \mathrm{H}, 3^{\prime \prime \prime \prime \prime}-\mathrm{H}\right)$, $2.43\left(\mathrm{ddd}, J=15.0,9.7,6.2 \mathrm{~Hz}, 1 \mathrm{H}, 5^{\prime}-\mathrm{H}_{\mathrm{a}}\right), 2.59\left(\mathrm{ddd}, J=15.0,6.7,2.3 \mathrm{~Hz}, 1 \mathrm{H}, 5^{\prime}-\mathrm{H}_{\mathrm{b}}\right), 3.12(\mathrm{dd}, J=7.6$, $\left.7.6 \mathrm{~Hz}, 2 \mathrm{H}, 6^{\prime \prime \prime \prime}-\mathrm{H}\right), 3.22\left(\mathrm{dd}, J=7.4,7.2 \mathrm{~Hz}, 2 \mathrm{H}, 1^{\prime \prime}-\mathrm{H}\right), 3.37\left(\mathrm{ddd}, J=14.1,6.6,6.4 \mathrm{~Hz}, 1 \mathrm{H}, 3^{\prime \prime}-\mathrm{H}_{\mathrm{a}}\right)$, $3.44\left(\mathrm{ddd}, J=14.1,6.6,6.4 \mathrm{~Hz}, 1 \mathrm{H}, 3^{\prime \prime}-\mathrm{H}_{\mathrm{b}}\right), 4.10\left(\mathrm{dd}, J=6.7,6.2 \mathrm{~Hz}, 1 \mathrm{H}, 6^{\prime}-\mathrm{H}\right), 4.20-4.23\left(\mathrm{~m}, 2 \mathrm{H}, 3^{\prime}-\mathrm{H}\right.$, $\left.2^{\prime \prime \prime \prime \prime \prime}-\mathrm{H}\right), 4.24\left(\mathrm{dd}, J=8.7,5.4 \mathrm{~Hz}, 1 \mathrm{H}, 2^{\prime \prime \prime \prime}-\mathrm{H}\right), 4.29\left(\mathrm{ddd}, J=9.7,6.0,2.3 \mathrm{~Hz}, 1 \mathrm{H}, 4^{\prime}-\mathrm{H}\right), 4.38(\mathrm{dd}, J=10.8$, $\left.4.6 \mathrm{~Hz}, 1 \mathrm{H}, 2^{\prime \prime \prime}-\mathrm{H}\right), 4.56\left(\mathrm{dd}, J=5.8,4.0 \mathrm{~Hz}, 1 \mathrm{H}, 2^{\prime}-\mathrm{H}\right), 5.87\left(\mathrm{~d}, J=4.0 \mathrm{~Hz}, 1 \mathrm{H}, 1^{\prime}-\mathrm{H}\right), 6.01(\mathrm{~d}, J=8.1 \mathrm{~Hz}$, $1 \mathrm{H}, 5-\mathrm{H}), 7.76(\mathrm{~d}, J=8.1 \mathrm{~Hz}, 1 \mathrm{H}, 6-\mathrm{H}) .{ }^{13} \mathrm{C} \mathrm{NMR}\left(126 \mathrm{MHz}, \mathrm{D}_{2} \mathrm{O}, 35^{\circ} \mathrm{C}\right): \delta[\mathrm{ppm}]=19.69\left(\mathrm{C}_{\mathrm{a}}-4^{\prime \prime \prime \prime \prime \prime}\right)$, $21.18\left(\mathrm{C}_{\mathrm{b}}-4^{\prime \prime \prime \prime \prime}\right), 23.37\left(\mathrm{C}_{\mathrm{a}}-5^{\prime \prime \prime}\right), 24.71\left(\mathrm{C}-4^{\prime \prime \prime \prime}\right), 24.79\left(\mathrm{C}_{\mathrm{b}}-5^{\prime \prime \prime}\right), 27.09\left(\mathrm{C}-4^{\prime \prime \prime}\right), 28.30\left(\mathrm{C}-2^{\prime \prime}\right), 28.93\left(\mathrm{C}-5^{\prime \prime \prime \prime}\right)$, $32.64\left(\mathrm{C}-3^{\prime \prime \prime \prime \prime \prime}\right), 33.41\left(\mathrm{C}-3^{\prime \prime \prime \prime}\right), 35.29\left(\mathrm{C}-5^{\prime}\right), 38.64\left(\mathrm{C}-3^{\prime \prime}\right), 41.92\left(\mathrm{C}-6^{\prime \prime \prime \prime}\right), 42.23\left(\mathrm{C}-3^{\prime \prime \prime}\right), 46.93\left(\mathrm{C}-1^{\prime \prime}\right), 55.20$ $\left(\mathrm{C}-2^{\prime \prime \prime}\right), 56.75\left(\mathrm{C}-2^{\prime \prime \prime \prime}\right), 61.50\left(\mathrm{C}-2^{\prime \prime \prime \prime \prime \prime}\right), 61.73\left(\mathrm{C}-6^{\prime}\right), 75.18\left(\mathrm{C}-2^{\prime}\right), 75.55\left(\mathrm{C}-3^{\prime}\right), 82.46\left(\mathrm{C}-4^{\prime}\right), 94.41\left(\mathrm{C}-1^{\prime}\right)$, $104.84(\mathrm{C}-5), 118.93\left(\mathrm{q}^{1}{ }^{1} \mathrm{~J}_{\mathrm{CF}}=292.3 \mathrm{~Hz}, \mathrm{TFA}-\mathrm{CF}_{3}\right), 145.32(\mathrm{C}-6), 153.89(\mathrm{C}-2), 161.95(\mathrm{NC}(=\mathrm{O}) \mathrm{N}), 165.36$ $\left(\mathrm{q}^{2} \mathrm{~J}_{\mathrm{CF}}=35.3 \mathrm{~Hz}\right.$, TFA-COO), $168.58(\mathrm{C}-4), 173.96\left(\mathrm{C}-7^{\prime}\right), 177.32\left(\mathrm{C}-1^{\prime \prime \prime}\right), 177.79\left(\mathrm{C}-1^{\prime \prime \prime \prime}\right), 179.05\left(\mathrm{C}-1^{\prime \prime \prime \prime \prime}\right)$. ${ }^{19} \mathrm{~F}$ NMR $\left(282 \mathrm{MHz}, \mathrm{D}_{2} \mathrm{O}, 35^{\circ} \mathrm{C}\right): \delta[\mathrm{ppm}]=-72.86\left(\mathrm{TFA}_{-} \mathrm{CF}_{3}\right) . \mathrm{MS}\left(\mathrm{ESI}^{-}\right): \mathrm{m} / z=741.4[\mathrm{M}-\mathrm{H}]^{-}$. HRMS (ESI) ${ }^{-}$: calcd.: 741.3788 [M - H] ${ }^{-}$, found: 741.3792. IR (ATR): $v=1638,1551,1198,1182,1131$, $799,720,551,519$. UV $\left(\mathrm{H}_{2} \mathrm{O}\right): \lambda_{\max }(\log \varepsilon)=260$ (4.01). Optical rotation: $[\alpha]_{\mathrm{D}}{ }^{25}=-1.1\left(\mathrm{c}=0.46, \mathrm{H}_{2} \mathrm{O}\right)$. m.p. $=208{ }^{\circ} \mathrm{C} .11:{ }^{1} \mathrm{H}$ NMR $\left(600 \mathrm{MHz}, \mathrm{D}_{2} \mathrm{O}, 35^{\circ} \mathrm{C}\right): \delta[\mathrm{ppm}]=0.98\left(\mathrm{~d}, J=6.1 \mathrm{~Hz}, 3 \mathrm{H}, 5^{\prime \prime \prime}-\mathrm{H}_{\mathrm{a}}\right), 1.04(\mathrm{~d}, J$ $\left.=5.9 \mathrm{~Hz}, 3 \mathrm{H}, 5^{\prime \prime \prime}-\mathrm{H}_{\mathrm{b}}\right), 1.04\left(\mathrm{~d}, J=6.9 \mathrm{~Hz}, 3 \mathrm{H}, 4^{\prime \prime \prime \prime \prime \prime}-\mathrm{H}_{\mathrm{a}}\right), 1.08\left(\mathrm{~d}, J=6.7 \mathrm{~Hz}, 3 \mathrm{H}, 4^{\prime \prime \prime \prime \prime}-\mathrm{H}_{\mathrm{b}}\right), 1.50-1.63(\mathrm{~m}$, $\left.2 \mathrm{H}, 4^{\prime \prime \prime \prime}-\mathrm{H}\right), 1.66-1.85\left(\mathrm{~m}, 6 \mathrm{H}, 3^{\prime \prime \prime}-\mathrm{H}, 4^{\prime \prime \prime}-\mathrm{H}, 3^{\prime \prime \prime \prime}-\mathrm{H}_{\mathrm{a}}, 5^{\prime \prime \prime \prime}-\mathrm{H}\right), 1.87-1.93\left(\mathrm{~m}, 1 \mathrm{H}, 3^{\prime \prime \prime \prime}-\mathrm{H}_{\mathrm{b}}\right), 1.97-2.07(\mathrm{~m}$, 
$\left.2 \mathrm{H}, 2^{\prime \prime}-\mathrm{H}\right), 2.27\left(\mathrm{dqq}, J=6.9,6.7,5.7 \mathrm{~Hz}, 1 \mathrm{H}, 3^{\prime \prime \prime \prime \prime \prime}-\mathrm{H}\right), 2.36\left(\mathrm{ddd}, J=15.1,10.0 \mathrm{~Hz}, 6.6 \mathrm{~Hz}, 1 \mathrm{H}, 5^{\prime}-\mathrm{H}_{\mathrm{a}}\right)$, $2.54\left(\mathrm{ddd}, J=15.1,6.5 \mathrm{~Hz}, 3.0 \mathrm{~Hz}, 1 \mathrm{H}, 5^{\prime}-\mathrm{H}_{\mathrm{b}}\right), 3.11\left(\mathrm{dd}, J=7.6,7.6 \mathrm{~Hz}, 2 \mathrm{H}, 6^{\prime \prime \prime \prime}-\mathrm{H}\right), 3.16(\mathrm{ddd}, J=13.2$, $\left.8.8,7.9 \mathrm{~Hz}, 1 \mathrm{H}, 1^{\prime \prime}-\mathrm{H}_{\mathrm{a}}\right), 3.21\left(\mathrm{ddd}, J=13.2,8.0,6.5 \mathrm{~Hz}, 1 \mathrm{H}, 1^{\prime \prime}-\mathrm{H}_{\mathrm{b}}\right), 3.38(\mathrm{ddd}, J=14.2,6.5,6.4 \mathrm{~Hz}, 1 \mathrm{H}$, $\left.3^{\prime \prime}-\mathrm{H}_{\mathrm{a}}\right), 3.41\left(\mathrm{ddd}, J=14.2,7.0,6.5 \mathrm{~Hz}, 1 \mathrm{H}, 3^{\prime \prime}-\mathrm{H}_{\mathrm{b}}\right), 3.93\left(\mathrm{dd}, J=6.6,6.5 \mathrm{~Hz}, 1 \mathrm{H}, 6^{\prime}-\mathrm{H}\right), 4.17(\mathrm{~d}, J=5.7 \mathrm{~Hz}$, $\left.1 \mathrm{H}, 2^{\prime \prime \prime \prime \prime}-\mathrm{H}\right), 4.20\left(\mathrm{dd}, J=6.4,5.9 \mathrm{~Hz}, 1 \mathrm{H}, 3^{\prime}-\mathrm{H}\right), 4.24\left(\mathrm{dd}, J=8.2,6.0 \mathrm{~Hz}, 1 \mathrm{H}, 2^{\prime \prime \prime \prime}-\mathrm{H}\right), 4.28(\mathrm{ddd}, J=10.0$, 6.4, 3.0 Hz, 1H, $\left.4^{\prime}-\mathrm{H}\right), 4.35\left(\mathrm{dd}, J=10.4,4.1 \mathrm{~Hz}, 1 \mathrm{H}, 2^{\prime \prime \prime}-\mathrm{H}\right), 4.54\left(\mathrm{dd}, J=5.9,3.8 \mathrm{~Hz}, 1 \mathrm{H}, 2^{\prime}-\mathrm{H}\right), 5.88(\mathrm{~d}$, $\left.J=3.8 \mathrm{~Hz}, 1 \mathrm{H}, 1^{\prime}-\mathrm{H}\right), 6.01(\mathrm{~d}, J=8.1 \mathrm{~Hz}, 1 \mathrm{H}, 5-\mathrm{H}), 7.77(\mathrm{~d}, J=8.1 \mathrm{~Hz}, 1 \mathrm{H}, 6-\mathrm{H}) .{ }^{13} \mathrm{C}$ NMR $(126 \mathrm{MHz}$, $\left.\mathrm{D}_{2} \mathrm{O}, 35^{\circ} \mathrm{C}\right): \delta[\mathrm{ppm}]=19.74\left(\mathrm{C}_{\mathrm{a}}-4^{\prime \prime \prime \prime \prime \prime}\right), 21.23\left(\mathrm{C}_{\mathrm{b}}-4^{\prime \prime \prime \prime \prime \prime}\right), 22.99\left(\mathrm{C}_{\mathrm{a}}-5^{\prime \prime \prime}\right), 24.78\left(\mathrm{C}-4^{\prime \prime \prime \prime}\right), 24.94\left(\mathrm{C}_{\mathrm{b}}-5^{\prime \prime \prime}\right)$, $27.13\left(\mathrm{C}-4^{\prime \prime \prime}\right), 28.33\left(\mathrm{C}-2^{\prime \prime}\right), 28.93\left(\mathrm{C}-5^{\prime \prime \prime \prime}\right), 32.65\left(\mathrm{C}-3^{\prime \prime \prime \prime \prime \prime}\right), 33.50\left(\mathrm{C}-3^{\prime \prime \prime \prime}\right), 35.77\left(\mathrm{C}-5^{\prime}\right), 38.53\left(\mathrm{C}-3^{\prime \prime}\right), 41.90$ $\left(\mathrm{C}-6^{\prime \prime \prime \prime}\right), 42.18\left(\mathrm{C}-3^{\prime \prime \prime}\right), 46.87\left(\mathrm{C}-1^{\prime \prime}\right), 55.21\left(\mathrm{C}-2^{\prime \prime \prime}\right), 56.84\left(\mathrm{C}-2^{\prime \prime \prime \prime}\right), 61.77\left(\mathrm{C}-2^{\prime \prime \prime \prime \prime \prime}\right), 62.91\left(\mathrm{C}-6^{\prime}\right), 75.22\left(\mathrm{C}-2^{\prime}\right)$, $75.51\left(\mathrm{C}-3^{\prime}\right), 82.94\left(\mathrm{C}-4^{\prime}\right), 94.32\left(\mathrm{C}-1^{\prime}\right), 104.87(\mathrm{C}-5), 118.93\left(\mathrm{q},{ }^{1} \mathrm{~J}_{\mathrm{CF}}=292.3 \mathrm{~Hz}, \mathrm{TFA}^{\left.-\mathrm{CF}_{3}\right),} 145.32(\mathrm{C}-6)\right.$, $153.91(\mathrm{C}-2), 161.82(\mathrm{NC}(=\mathrm{O}) \mathrm{N}), 165.41\left(\mathrm{q},{ }^{2} \mathrm{~J}_{\mathrm{CF}}=34.0 \mathrm{~Hz}\right.$, TFA-COO), $168.59(\mathrm{C}-4), 174.75\left(\mathrm{C}-7^{\prime}\right), 177.53$ $\left(\mathrm{C}-1^{\prime \prime \prime}\right), 178.10\left(\mathrm{C}-1^{\prime \prime \prime \prime}\right), 179.42\left(\mathrm{C}-1^{\prime \prime \prime \prime \prime \prime}\right) .{ }^{19} \mathrm{~F}$ NMR $\left(282 \mathrm{MHz}, \mathrm{D}_{2} \mathrm{O}, 35^{\circ} \mathrm{C}\right): \delta[\mathrm{ppm}]=-72.87\left(\mathrm{TFA}-\mathrm{CF}_{3}\right)$. MS $\left(\mathrm{ESI}^{+}\right): \mathrm{m} / \mathrm{z}=743.5[\mathrm{M}+\mathrm{H}]^{+}$. HRMS $\left(\mathrm{ESI}^{+}\right)$: calcd.: $743.3934[\mathrm{M}+\mathrm{H}]^{+}$, found: 743.3926 . IR (ATR): $v\left[\mathrm{~cm}^{-1}\right]=1641,1552,1200,1182,1131,799,720,550,517 . \mathrm{UV}\left(\mathrm{H}_{2} \mathrm{O}\right): \lambda_{\max }(\log \varepsilon)=261$ (4.07). Optical rotation: $[\alpha]_{\mathrm{D}}{ }^{25}=+31.4\left(\mathrm{c}=0.14, \mathrm{H}_{2} \mathrm{O}\right)$. m.p. $=211^{\circ} \mathrm{C}$.

$5^{\prime}$-deoxy-6'-epi-L-Leu muraymycin analogue (12) and 5'-deoxy-6'-epi-D-Leu muraymycin analogue (13): To a solution of the urea tripeptide $18(10 \mathrm{mg}, 0.018 \mathrm{mmol})$ in THF $(2.5 \mathrm{~mL})$, HOBt $(2.4 \mathrm{mg}$, $0.018 \mathrm{mmol}), \mathrm{ECD}(3.5 \mathrm{mg}, 0.018 \mathrm{mmol})$, and DIPEA $(3.1 \mu \mathrm{L}, 0.018 \mathrm{mmol})$ were added and the mixture was stirred at room temperature for $30 \mathrm{~min}$. It was then added to a solution of amine $\mathbf{2 0}(15 \mathrm{mg}$, $0.023 \mathrm{mmol})$ in THF $(2 \mathrm{~mL})$ and stirred at room temperature for $20 \mathrm{~h}$. EtOAc $(30 \mathrm{~mL})$ was added and the solution was washed with sat. $\mathrm{NaHCO}_{3}(30 \mathrm{~mL})$. The organic layer was dried over $\mathrm{Na}_{2} \mathrm{SO}_{4}$ and the solvent was removed under reduced pressure. The protected analogues of $\mathbf{1 2}$ and $\mathbf{1 3}$ were obtained after column chromatography $\left(98: 2-95: 5, \mathrm{CH}_{2} \mathrm{Cl}_{2}-\mathrm{MeOH}\right)$ as colourless solids. This material was dissolved in TFA $(80 \%$ in water, $2.7 \mathrm{~mL})$ and stirred at room temperature for $24 \mathrm{~h}$. Water $(10 \mathrm{~mL})$ was added and the solvent was removed under reduced pressure. The muraymycin analogues 12 $(10 \mathrm{mg}, 57 \%)$ and $13(3.3 \mathrm{mg}, 19 \%)$ were separated by preparative HPLC (12: $t_{\mathrm{R}}=17.8 \mathrm{~min}, 13: t_{\mathrm{R}}=$ $16.4 \mathrm{~min})$ and obtained as colourless solids. $12:{ }^{1} \mathrm{H} \mathrm{NMR}\left(600 \mathrm{MHz}, \mathrm{D}_{2} \mathrm{O}, 35^{\circ} \mathrm{C}\right): \delta[\mathrm{ppm}]=0.99(\mathrm{~d}, J=$ $\left.5.8 \mathrm{~Hz}, 3 \mathrm{H}, 5^{\prime \prime \prime}-\mathrm{H}_{\mathrm{a}}\right), 1.04\left(\mathrm{~d}, J=5.4 \mathrm{~Hz}, 3 \mathrm{H}, 5^{\prime \prime \prime}-\mathrm{H}_{\mathrm{b}}\right), 1.05\left(\mathrm{~d}, J=6.7 \mathrm{~Hz}, 3 \mathrm{H}, 4^{\prime \prime \prime \prime \prime}-\mathrm{H}_{\mathrm{a}}\right), 1.08(\mathrm{~d}, J=6.8 \mathrm{~Hz}$, $\left.3 \mathrm{H}, 4^{\prime \prime \prime \prime \prime \prime}-\mathrm{H}_{\mathrm{b}}\right), 1.51-1.61\left(\mathrm{~m}, 2 \mathrm{H}, 4^{\prime \prime \prime \prime \prime}-\mathrm{H}\right), 1.66-1.84\left(\mathrm{~m}, 6 \mathrm{H}, 3^{\prime \prime \prime}-\mathrm{H}, 4^{\prime \prime \prime}-\mathrm{H}, 3^{\prime \prime \prime \prime}-\mathrm{H}_{\mathrm{a}}, 5^{\prime \prime \prime \prime}-\mathrm{H}\right), 1.88-1.94(\mathrm{~m}$, $\left.1 \mathrm{H}, 3^{\prime \prime \prime \prime}-\mathrm{H}_{\mathrm{b}}\right), 1.96-2.04\left(\mathrm{~m}, 2 \mathrm{H}, 2^{\prime \prime}-\mathrm{H}\right), 2.26\left(\mathrm{dqq}, J=6.8,6.7,6.1 \mathrm{~Hz}, 1 \mathrm{H}, 3^{\prime \prime \prime \prime \prime \prime}-\mathrm{H}\right), 2.47$ (ddd, $J=15.5$, $\left.10.1,4.8 \mathrm{~Hz}, 1 \mathrm{H}, 5^{\prime}-\mathrm{H}_{\mathrm{a}}\right), 2.59\left(\mathrm{ddd}, J=15.5,5.3,2.9 \mathrm{~Hz}, 1 \mathrm{H}, 5^{\prime}-\mathrm{H}_{\mathrm{b}}\right), 3.12\left(\mathrm{dd}, J=7.6,7.5 \mathrm{~Hz}, 2 \mathrm{H}, 6^{\prime \prime \prime \prime}-\mathrm{H}\right)$, $3.16\left(\mathrm{ddd}, J=12.2,8.8,7.6 \mathrm{~Hz}, 1 \mathrm{H}, 1^{\prime \prime}-\mathrm{H}_{\mathrm{a}}\right), 3.21\left(\mathrm{ddd}, J=12.2,8.6,7.3 \mathrm{~Hz}, 1 \mathrm{H}, 1^{\prime \prime}-\mathrm{H}_{\mathrm{b}}\right), 3.35(\mathrm{ddd}, J=$ $\left.14.3,8.0,6.7 \mathrm{~Hz}, 1 \mathrm{H}, 3^{\prime \prime}-\mathrm{H}_{\mathrm{a}}\right), 3.40\left(\mathrm{ddd}, J=14.3,7.5,6.8 \mathrm{~Hz}, 1 \mathrm{H}, 3^{\prime \prime}-\mathrm{H}_{\mathrm{b}}\right), 4.08(\mathrm{dd}, J=5.3,4.8 \mathrm{~Hz}, 1 \mathrm{H}$, $\left.6^{\prime}-\mathrm{H}\right), 4.16\left(\mathrm{ddd}, J=10.1,7.9,2.9 \mathrm{~Hz}, 1 \mathrm{H}, 4^{\prime}-\mathrm{H}\right), 4.21-4.25\left(\mathrm{~m}, 3 \mathrm{H}, 3^{\prime}-\mathrm{H}, 2^{\prime \prime \prime \prime}-\mathrm{H}, 2^{\prime \prime \prime \prime \prime \prime}-\mathrm{H}\right), 4.37(\mathrm{dd}, J=9.7$, $\left.4.7 \mathrm{~Hz}, 1 \mathrm{H}, 2^{\prime \prime \prime}-\mathrm{H}\right), 4.56\left(\mathrm{dd}, J=5.6,3.8 \mathrm{~Hz}, 1 \mathrm{H}, 2^{\prime}-\mathrm{H}\right), 5.84\left(\mathrm{~d}, J=3.8 \mathrm{~Hz}, 1 \mathrm{H}, 1^{\prime}-\mathrm{H}\right), 6.00(\mathrm{~d}, J=8.1 \mathrm{~Hz}$, $1 \mathrm{H}, 5-\mathrm{H}), 7.78(\mathrm{~d}, J=8.1 \mathrm{~Hz}, 1 \mathrm{H}, 6-\mathrm{H}) .{ }^{13} \mathrm{C}$ NMR $\left(126 \mathrm{MHz}, \mathrm{D}_{2} \mathrm{O}, 35^{\circ} \mathrm{C}\right): \delta[\mathrm{ppm}]=19.68\left(\mathrm{C}_{\mathrm{a}}-4^{\prime \prime \prime \prime \prime \prime}\right)$, $21.18\left(\mathrm{C}_{\mathrm{b}}-4^{\prime \prime \prime \prime \prime \prime}\right), 23.37\left(\mathrm{C}_{\mathrm{a}}-5^{\prime \prime \prime}\right), 24.73\left(\mathrm{C}-4^{\prime \prime \prime \prime}\right), 24.79\left(\mathrm{C}_{\mathrm{b}}-5^{\prime \prime \prime}\right), 27.09\left(\mathrm{C}-4^{\prime \prime \prime}\right), 28.21\left(\mathrm{C}-2^{\prime \prime}\right), 28.94\left(\mathrm{C}-5^{\prime \prime \prime \prime}\right)$, $32.66\left(\mathrm{C}-3^{\prime \prime \prime \prime \prime}\right), 33.42\left(\mathrm{C}-3^{\prime \prime \prime \prime}\right), 34.63\left(\mathrm{C}-5^{\prime}\right), 38.65\left(\mathrm{C}-3^{\prime \prime}\right), 41.92\left(\mathrm{C}-6^{\prime \prime \prime \prime}\right), 42.23\left(\mathrm{C}-3^{\prime \prime \prime}\right), 47.29\left(\mathrm{C}-1^{\prime \prime}\right), 55.21$ $\left(\mathrm{C}-2^{\prime \prime \prime}\right), 56.77\left(\mathrm{C}-2^{\prime \prime \prime \prime}\right), 61.51\left(\mathrm{C}-2^{\prime \prime \prime \prime \prime \prime}\right), 62.56\left(\mathrm{C}-6^{\prime}\right), 75.00\left(\mathrm{C}-2^{\prime}\right), 75.39\left(\mathrm{C}-3^{\prime}\right), 82.26\left(\mathrm{C}-4^{\prime}\right), 94.93\left(\mathrm{C}-1^{\prime}\right)$, $104.85(\mathrm{C}-5), 118.93\left(\mathrm{q},{ }^{1} \mathrm{~J}_{\mathrm{CF}}=292.3 \mathrm{~Hz}, \mathrm{TFA}-\mathrm{CF}_{3}\right), 145.71(\mathrm{C}-6), 153.92(\mathrm{C}-2), 161.94(\mathrm{NC}(=\mathrm{O}) \mathrm{N}), 165.37$ $\left(\mathrm{q},{ }^{2} \mathrm{~J}_{\mathrm{CF}}=35.3 \mathrm{~Hz}, \mathrm{TFA}-\mathrm{COO}\right), 168.53(\mathrm{C}-4), 174.09\left(\mathrm{C}-7^{\prime}\right), 177.31\left(\mathrm{C}-1^{\prime \prime \prime}\right), 177.82\left(\mathrm{C}-1^{\prime \prime \prime \prime}\right), 179.08\left(\mathrm{C}-1^{\prime \prime \prime \prime \prime \prime}\right)$.

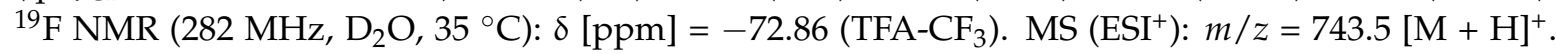
HRMS (ESI ${ }^{+}$): calcd.: $743.3934[\mathrm{M}+\mathrm{H}]^{+}$, found: 743.3926 . IR (ATR): $v\left[\mathrm{~cm}^{-1}\right]=1633,1551,1198,1182$, $1131,1054,799,720,551$. UV $\left(\mathrm{H}_{2} \mathrm{O}\right): \lambda_{\max }(\log \varepsilon)=261(4.00)$. Optical rotation: $[\alpha]_{\mathrm{D}}{ }^{25}=-3.8(\mathrm{c}=0.45$, $\left.\mathrm{H}_{2} \mathrm{O}\right)$. m.p. $=208^{\circ} \mathrm{C} .13:{ }^{1} \mathrm{H}$ NMR $\left(600 \mathrm{MHz}, \mathrm{D}_{2} \mathrm{O}, 35^{\circ} \mathrm{C}\right): \delta[\mathrm{ppm}]=0.99\left(\mathrm{~d}, J=5.6 \mathrm{~Hz}, 3 \mathrm{H}, 5^{\prime \prime \prime}-\mathrm{H}_{\mathrm{a}}\right)$, $1.05\left(\mathrm{~d}, J=6.1 \mathrm{~Hz}, 3 \mathrm{H}, 5^{\prime \prime \prime}-\mathrm{H}_{\mathrm{b}}\right), 1.05\left(\mathrm{~d}, J=7.1 \mathrm{~Hz}, 3 \mathrm{H}, 4^{\prime \prime \prime \prime \prime \prime}-\mathrm{H}_{\mathrm{a}}\right), 1.08\left(\mathrm{~d}, J=6.6 \mathrm{~Hz}, 3 \mathrm{H}, 4^{\prime \prime \prime \prime \prime \prime}-\mathrm{H}_{\mathrm{b}}\right)$,

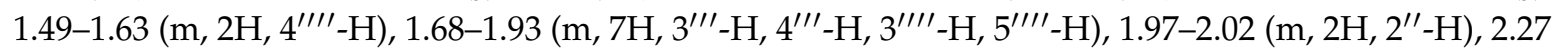
$\left(\mathrm{dqq}, J=7.1,6.6,5.8 \mathrm{~Hz}, 1 \mathrm{H}, 3^{\prime \prime \prime \prime \prime}-\mathrm{H}\right), 2.47\left(\mathrm{ddd}, J=15.3,10.1,4.7 \mathrm{~Hz}, 1 \mathrm{H}, 5^{\prime}-\mathrm{H}_{\mathrm{a}}\right), 2.59(\mathrm{ddd}, J=15.3$, $\left.5.3,2.8 \mathrm{~Hz}, 1 \mathrm{H}, 5^{\prime}-\mathrm{H}_{\mathrm{b}}\right), 3.11\left(\mathrm{dd}, J=8.0,7.8 \mathrm{~Hz}, 2 \mathrm{H}, 6^{\prime \prime \prime \prime}-\mathrm{H}\right), 3.14\left(\mathrm{ddd}, J=12.7,7.7,7.3 \mathrm{~Hz}, 1 \mathrm{H}, 1^{\prime \prime}-\mathrm{H}_{\mathrm{a}}\right)$, 
$3.20\left(\mathrm{ddd}, J=12.3,7.2,7.0 \mathrm{~Hz}, 1 \mathrm{H}, 1^{\prime \prime}-\mathrm{H}_{\mathrm{b}}\right), 3.38\left(\mathrm{dd}, J=6.7,6.6 \mathrm{~Hz}, 2 \mathrm{H}, 3^{\prime \prime}-\mathrm{H}\right), 4.03(\mathrm{dd}, J=5.3,4.7 \mathrm{~Hz}$, $\left.1 \mathrm{H}, 6^{\prime}-\mathrm{H}\right), 4.16\left(\mathrm{ddd}, J=10.1,7.1,2.8 \mathrm{~Hz}, 1 \mathrm{H}, 4^{\prime}-\mathrm{H}\right), 4.18\left(\mathrm{~d}, J=5.8 \mathrm{~Hz}, 1 \mathrm{H}, 2^{\prime \prime \prime \prime \prime}-\mathrm{H}\right), 4.24(\mathrm{dd}, J=9.2$, $\left.6.3 \mathrm{~Hz}, 1 \mathrm{H}, 3^{\prime}-\mathrm{H}\right), 4.24\left(\mathrm{dd}, J=5.9,2.1 \mathrm{~Hz}, 1 \mathrm{H}, 2^{\prime \prime \prime \prime}-\mathrm{H}\right), 4.36\left(\mathrm{dd}, J=10.3,4.0 \mathrm{~Hz}, 1 \mathrm{H}, 2^{\prime \prime \prime}-\mathrm{H}\right), 4.55(\mathrm{dd}, J$ $\left.=9.2,3.8 \mathrm{~Hz}, 1 \mathrm{H}, 2^{\prime}-\mathrm{H}\right), 5.85\left(\mathrm{~d}, J=3.8 \mathrm{~Hz}, 1 \mathrm{H}, 1^{\prime}-\mathrm{H}\right), 6.00(\mathrm{~d}, J=8.1 \mathrm{~Hz}, 1 \mathrm{H}, 5-\mathrm{H}), 7.79(\mathrm{~d}, J=8.1 \mathrm{~Hz}$, $1 \mathrm{H}, 6-\mathrm{H}) .{ }^{13} \mathrm{C}$ NMR $\left(126 \mathrm{MHz}, \mathrm{D}_{2} \mathrm{O}, 35^{\circ} \mathrm{C}\right): \delta[\mathrm{ppm}]=19.72\left(\mathrm{C}_{\mathrm{a}}-4^{\prime \prime \prime \prime \prime \prime}\right), 21.19\left(\mathrm{C}_{\mathrm{b}}-4^{\prime \prime \prime \prime \prime \prime}\right), 23.00\left(\mathrm{C}_{\mathrm{a}}-5^{\prime \prime \prime}\right)$, $24.79\left(\mathrm{C}-4^{\prime \prime \prime \prime}\right), 24.93\left(\mathrm{C}_{\mathrm{b}}-5^{\prime \prime \prime}\right), 27.14\left(\mathrm{C}-4^{\prime \prime \prime}\right), 28.28\left(\mathrm{C}-2^{\prime \prime}\right), 28.94\left(\mathrm{C}-5^{\prime \prime \prime \prime}\right), 32.61\left(\mathrm{C}-3^{\prime \prime \prime \prime \prime}\right), 33.48\left(\mathrm{C}-3^{\prime \prime \prime \prime}\right)$, $34.72\left(\mathrm{C}-5^{\prime}\right), 38.58\left(\mathrm{C}-3^{\prime \prime}\right), 41.90\left(\mathrm{C}-6^{\prime \prime \prime \prime}\right), 42.16\left(\mathrm{C}-3^{\prime \prime \prime}\right), 47.30\left(\mathrm{C}-1^{\prime \prime}\right), 55.21\left(\mathrm{C}-2^{\prime \prime \prime}\right), 56.87\left(\mathrm{C}-2^{\prime \prime \prime \prime}\right), 61.63$ $\left(\mathrm{C}-2^{\prime \prime \prime \prime \prime \prime}\right), 62.96\left(\mathrm{C}-6^{\prime}\right), 75.00\left(\mathrm{C}-2^{\prime}\right), 75.41\left(\mathrm{C}-3^{\prime}\right), 82.35\left(\mathrm{C}-4^{\prime}\right), 94.78\left(\mathrm{C}-1^{\prime}\right), 104.88(\mathrm{C}-5), 118.94\left(\mathrm{q}^{1}{ }^{1} \mathrm{~J}_{\mathrm{CF}}=\right.$ $\left.291.1 \mathrm{~Hz}, \mathrm{TFA}-\mathrm{CF}_{3}\right), 145.67(\mathrm{C}-6), 153.96(\mathrm{C}-2), 161.81(\mathrm{NC}(=\mathrm{O}) \mathrm{N}), 165.40\left(\mathrm{q},{ }^{2} \mathrm{~J}_{\mathrm{CF}}=35.3 \mathrm{~Hz}, \mathrm{TFA}-\mathrm{COO}\right)$, $168.55(\mathrm{C}-4), 174.33\left(\mathrm{C}-7^{\prime}\right), 177.55\left(\mathrm{C}-1^{\prime \prime \prime}\right), 178.10\left(\mathrm{C}-1^{\prime \prime \prime \prime}\right), 179.23\left(\mathrm{C}-1^{\prime \prime \prime \prime \prime \prime}\right) .{ }^{19} \mathrm{~F}$ NMR $\left(282 \mathrm{MHz}, \mathrm{D}_{2} \mathrm{O}\right.$, $\left.35^{\circ} \mathrm{C}\right): \delta[\mathrm{ppm}]=-72.87\left(\mathrm{TFA}-\mathrm{CF}_{3}\right)$. MS $\left(\mathrm{ESI}^{+}\right): m / z=743.5[\mathrm{M}+\mathrm{H}]^{+}$. HRMS $\left(\mathrm{ESI}^{+}\right)$: calcd.: 743.3934 $[\mathrm{M}+\mathrm{H}]^{+}$, found: 743.3928. IR (ATR): $v\left[\mathrm{~cm}^{-1}\right]=1633,1552,1198,1181,1130,1053,720,550,518$. UV $\left(\mathrm{H}_{2} \mathrm{O}\right): \lambda_{\max }(\log \varepsilon)=260$ (4.01). Optical rotation: $[\alpha]_{\mathrm{D}}{ }^{25}=+28.7\left(\mathrm{c}=0.15, \mathrm{H}_{2} \mathrm{O}\right)$. m.p. $=209^{\circ} \mathrm{C}$.

$6^{\prime}$-epi-L-Leu muraymycin analogue (14) and 6'-epi-D-Leu muraymycin analogue (15): To a solution of the urea tripeptide 18 (13 mg, $0.024 \mathrm{mmol})$ in THF ( $3 \mathrm{~mL})$, HOBt $(3.2 \mathrm{mg}, 0.024 \mathrm{mmol})$, EDC ( $4.6 \mathrm{mg}$, $0.024 \mathrm{mmol})$, and DIPEA $(4.2 \mu \mathrm{L}, 0.024 \mathrm{mmol})$ were added and the mixture was stirred at room temperature for $45 \mathrm{~min}$. It was then added to a solution of amine $21(20 \mathrm{mg}, 0.030 \mathrm{mmol})$ in THF $(2 \mathrm{~mL})$ and stirred at room temperature for $18 \mathrm{~h}$. EtOAc $(30 \mathrm{~mL})$ was added and the solution was washed with sat. $\mathrm{NaHCO}_{3}(30 \mathrm{~mL})$. The organic layer was dried over $\mathrm{Na}_{2} \mathrm{SO}_{4}$ and the solvent was removed under reduced pressure. The protected analogues of $\mathbf{1 4}$ and $\mathbf{1 5}$ were obtained after column chromatography (98:2-96:4, $\left.\mathrm{CH}_{2} \mathrm{Cl}_{2}-\mathrm{MeOH}\right)$ as colourless solids. This material was dissolved in TFA ( $80 \%$ in water, $3.6 \mathrm{~mL})$ and stirred at room temperature for $24 \mathrm{~h}$. Water $(10 \mathrm{~mL})$ was added and the solvent was removed under reduced pressure. The muraymycin analogues 14 (14 mg, 59\%) and 15 (5.6 mg, 24\%) were separated by preparative HPLC (14: $\left.t_{\mathrm{R}}=17.5 \mathrm{~min}, 15: t_{\mathrm{R}}=16.1 \mathrm{~min}\right)$ and obtained as colourless solids. 14: ${ }^{1} \mathrm{H}$ NMR $\left(600 \mathrm{MHz}, \mathrm{D}_{2} \mathrm{O}, 35^{\circ} \mathrm{C}\right): \delta[\mathrm{ppm}]=0.99\left(\mathrm{~d}, J=5.8 \mathrm{~Hz}, 3 \mathrm{H}, 5^{\prime \prime \prime}-\mathrm{H}_{\mathrm{a}}\right), 1.04(\mathrm{~d}, J=$ $\left.5.7 \mathrm{~Hz}, 3 \mathrm{H}, 5^{\prime \prime \prime}-\mathrm{H}_{\mathrm{b}}\right), 1.05\left(\mathrm{~d}, J=6.6 \mathrm{~Hz}, 3 \mathrm{H}, 4^{\prime \prime \prime \prime \prime \prime}-\mathrm{H}_{\mathrm{a}}\right), 1.09\left(\mathrm{~d}, J=6.8 \mathrm{~Hz}, 3 \mathrm{H}, 4^{\prime \prime \prime \prime \prime \prime}-\mathrm{H}_{\mathrm{b}}\right), 1.51-1.60(\mathrm{~m}$, $\left.2 \mathrm{H}, 4^{\prime \prime \prime \prime}-\mathrm{H}\right), 1.66-1.85\left(\mathrm{~m}, 6 \mathrm{H}, 3^{\prime \prime \prime}-\mathrm{H}, 4^{\prime \prime \prime}-\mathrm{H}, 3^{\prime \prime \prime \prime}-\mathrm{H}_{\mathrm{a}}, 5^{\prime \prime \prime \prime}-\mathrm{H}\right), 1.89-1.94\left(\mathrm{~m}, 1 \mathrm{H}, 3^{\prime \prime \prime \prime}-\mathrm{H}_{\mathrm{b}}\right), 2.04$ (dddd, $\left.=7.4,7.3,6.7,6.5 \mathrm{~Hz}, 2 \mathrm{H}, 2^{\prime \prime}-\mathrm{H}\right), 2.28\left(\mathrm{dqq}, J=6.8,6.6,6.4 \mathrm{~Hz}, 1 \mathrm{H}, 3^{\prime \prime \prime \prime \prime}-\mathrm{H}\right), 3.12(\mathrm{dd}, J=7.7,7.6 \mathrm{~Hz}$, $\left.2 \mathrm{H}, 6^{\prime \prime \prime \prime}-\mathrm{H}\right), 3.18\left(\mathrm{ddd}, J=12.9,7.4,7.3 \mathrm{~Hz}, 1 \mathrm{H}, 1^{\prime \prime}-\mathrm{H}_{\mathrm{a}}\right), 3.25\left(\mathrm{ddd}, J=12.9,7.4,7.3 \mathrm{~Hz}, 1 \mathrm{H}, 1^{\prime \prime}-\mathrm{H}_{\mathrm{b}}\right), 3.38$ $\left(\mathrm{ddd}, J=14.3,6.5,6.5 \mathrm{~Hz}, 1 \mathrm{H}, 3^{\prime \prime}-\mathrm{H}_{\mathrm{a}}\right), 3.45\left(\mathrm{ddd}, J=14.3,6.7,6.7 \mathrm{~Hz}, 1 \mathrm{H}, 3^{\prime \prime}-\mathrm{H}_{\mathrm{b}}\right), 4.10(\mathrm{~d}, J=4.5 \mathrm{~Hz}$, $\left.1 \mathrm{H}, 6^{\prime}-\mathrm{H}\right), 4.22-4.25\left(\mathrm{~m}, 3 \mathrm{H}, 4^{\prime}-\mathrm{H}, 2^{\prime \prime \prime \prime}-\mathrm{H}, 2^{\prime \prime \prime \prime \prime \prime}-\mathrm{H}\right), 4.37\left(\mathrm{dd}, J=9.6,4.9 \mathrm{~Hz}, 1 \mathrm{H}, 2^{\prime \prime \prime}-\mathrm{H}\right), 4.46(\mathrm{dd}, J=5.8$, $\left.5.3 \mathrm{~Hz}, 1 \mathrm{H}, 3^{\prime}-\mathrm{H}\right), 4.48\left(\mathrm{dd}, J=5.3,4.0 \mathrm{~Hz}, 1 \mathrm{H}, 2^{\prime}-\mathrm{H}\right), 4.58\left(\mathrm{dd}, J=4.5,1.1 \mathrm{~Hz}, 1 \mathrm{H}, 5^{\prime}-\mathrm{H}\right), 5.99(\mathrm{~d}, J=$ $8.1 \mathrm{~Hz}, 1 \mathrm{H}, 5-\mathrm{H}), 6.00\left(\mathrm{~d}, J=4.0 \mathrm{~Hz}, 1 \mathrm{H}, 1^{\prime}-\mathrm{H}\right), 8.14(\mathrm{~d}, J=8.1 \mathrm{~Hz}, 1 \mathrm{H}, 6-\mathrm{H}) .{ }^{13} \mathrm{C} \mathrm{NMR}\left(126 \mathrm{MHz}, \mathrm{D}_{2} \mathrm{O}\right.$, $\left.35^{\circ} \mathrm{C}\right): \delta$ [ppm] $=19.69\left(\mathrm{C}_{\mathrm{a}}-4^{\prime \prime \prime \prime \prime \prime}\right), 21.18\left(\mathrm{C}_{\mathrm{b}}-4^{\prime \prime \prime \prime \prime \prime}\right), 23.33\left(\mathrm{C}_{\mathrm{a}}-5^{\prime \prime \prime}\right), 24.72\left(\mathrm{C}-4^{\prime \prime \prime \prime}\right), 24.80\left(\mathrm{C}_{\mathrm{b}}-5^{\prime \prime \prime}\right), 27.08$ $\left(\mathrm{C}-4^{\prime \prime \prime}\right), 27.81\left(\mathrm{C}-2^{\prime \prime}\right), 28.93\left(\mathrm{C}-5^{\prime \prime \prime \prime}\right), 32.69\left(\mathrm{C}-3^{\prime \prime \prime \prime \prime \prime}\right), 33.35\left(\mathrm{C}-3^{\prime \prime \prime \prime}\right), 38.32\left(\mathrm{C}-3^{\prime \prime}\right), 41.92\left(\mathrm{C}-6^{\prime \prime \prime \prime}\right), 42.15$ $\left(\mathrm{C}-3^{\prime \prime \prime}\right), 48.22\left(\mathrm{C}-1^{\prime \prime}\right), 55.23\left(\mathrm{C}-2^{\prime \prime \prime}\right), 56.87\left(\mathrm{C}-2^{\prime \prime \prime \prime}\right), 61.51\left(\mathrm{C}-2^{\prime \prime \prime \prime \prime \prime}\right), 68.51\left(\mathrm{C}-6^{\prime}\right), 69.43\left(\mathrm{C}-5^{\prime}\right), 72.48\left(\mathrm{C}-3^{\prime}\right)$, $75.64\left(\mathrm{C}-2^{\prime}\right), 85.67\left(\mathrm{C}-4^{\prime}\right), 92.87\left(\mathrm{C}-1^{\prime}\right), 104.74(\mathrm{C}-5), 118.93\left(\mathrm{q},{ }^{1} \mathrm{~J}_{\mathrm{CF}}=292.3 \mathrm{~Hz}, \mathrm{TFA}-\mathrm{CF}_{3}\right), 145.06(\mathrm{C}-6)$, $154.07(\mathrm{C}-2), 161.96(\mathrm{NC}(=\mathrm{O}) \mathrm{N}), 165.37\left(\mathrm{q},{ }^{2} \mathrm{~J}_{\mathrm{CF}}=35.3 \mathrm{~Hz}, \mathrm{TFA}-\mathrm{COO}\right), 168.55(\mathrm{C}-4), 172.02\left(\mathrm{C}-7^{\prime}\right), 177.43$ $\left(\mathrm{C}-1^{\prime \prime \prime}\right), 177.93\left(\mathrm{C}-1^{\prime \prime \prime \prime}\right), 179.06\left(\mathrm{C}-1^{\prime \prime \prime \prime \prime \prime}\right) .{ }^{19} \mathrm{~F}$ NMR $\left(282 \mathrm{MHz}, \mathrm{D}_{2} \mathrm{O}, 35^{\circ} \mathrm{C}\right): \delta[\mathrm{ppm}]=-72.86\left(\mathrm{TFA}-\mathrm{CF}_{3}\right)$. MS $\left(\mathrm{ESI}^{+}\right): m / z=759.5[\mathrm{M}+\mathrm{H}]^{+}$. HRMS $\left(\mathrm{ESI}^{+}\right)$: calcd.: $759.3883[\mathrm{M}+\mathrm{H}]^{+}$, found: 759.3886 . IR (ATR): $v\left[\mathrm{~cm}^{-1}\right]=1632,1549,1198,1182,1128,1049,720,560,520 . \mathrm{UV}\left(\mathrm{H}_{2} \mathrm{O}\right): \lambda_{\max }(\log \varepsilon)=262$ (3.94). Optical rotation: $[\alpha]_{\mathrm{D}}{ }^{25}=+5.4\left(\mathrm{c}=0.54, \mathrm{H}_{2} \mathrm{O}\right) . \mathrm{m} . \mathrm{p} .=215^{\circ} \mathrm{C} .15:{ }^{1} \mathrm{H} \mathrm{NMR}\left(600 \mathrm{MHz}, \mathrm{D}_{2} \mathrm{O}, 35^{\circ} \mathrm{C}\right): \delta[\mathrm{ppm}]$ $=0.98\left(\mathrm{~d}, J=5.3 \mathrm{~Hz}, 3 \mathrm{H}, 5^{\prime \prime \prime}-\mathrm{H}_{\mathrm{a}}\right), 1.04\left(\mathrm{~d}, J=5.3 \mathrm{~Hz}, 3 \mathrm{H}, 5^{\prime \prime \prime}-\mathrm{H}_{\mathrm{b}}\right), 1.04\left(\mathrm{~d}, J=6.5 \mathrm{~Hz}, 3 \mathrm{H}, 4^{\prime \prime \prime \prime \prime}-\mathrm{H}_{\mathrm{a}}\right)$, $1.08\left(\mathrm{~d}, J=6.8 \mathrm{~Hz}, 3 \mathrm{H}, 4^{\prime \prime \prime \prime \prime \prime}-\mathrm{H}_{\mathrm{b}}\right), 1.49-1.54\left(\mathrm{~m}, 1 \mathrm{H}, 4^{\prime \prime \prime \prime}-\mathrm{H}_{\mathrm{a}}\right), 1.56-1.62\left(\mathrm{~m}, 1 \mathrm{H}, 4^{\prime \prime \prime \prime}-\mathrm{H}_{\mathrm{b}}\right), 1.66-1.92(\mathrm{~m}$, $\left.7 \mathrm{H}, 3^{\prime \prime \prime}-\mathrm{H}, 4^{\prime \prime \prime}-\mathrm{H}, 3^{\prime \prime \prime \prime \prime}-\mathrm{H}, 5^{\prime \prime \prime \prime}-\mathrm{H}\right), 1.98-2.07\left(\mathrm{~m}, 2 \mathrm{H}, 2^{\prime \prime}-\mathrm{H}\right), 2.27\left(\mathrm{dqq}, J=6.8,6.5,4.8 \mathrm{~Hz}, 1 \mathrm{H}, 3^{\prime \prime \prime \prime \prime \prime}-\mathrm{H}\right)$, $3.11\left(\mathrm{dd}, J=7.6,7.6 \mathrm{~Hz}, 2 \mathrm{H}, 6^{\prime \prime \prime \prime}-\mathrm{H}\right), 3.18\left(\mathrm{ddd}, J=13.7,7.1,6.0 \mathrm{~Hz}, 1 \mathrm{H}, 1^{\prime \prime}-\mathrm{H}_{\mathrm{a}}\right), 3.24(\mathrm{ddd}, J=13.7$, $\left.7.3,7.2 \mathrm{~Hz}, 1 \mathrm{H}, 1^{\prime \prime}-\mathrm{H}_{\mathrm{b}}\right), 3.37-3.43\left(\mathrm{~m}, 2 \mathrm{H}, 3^{\prime \prime}-\mathrm{H}\right), 4.14\left(\mathrm{~d}, J=5.4 \mathrm{~Hz}, 1 \mathrm{H}, 6^{\prime}-\mathrm{H}\right), 4.19(\mathrm{~d}, J=4.8 \mathrm{~Hz}, 1 \mathrm{H}$, $\left.2^{\prime \prime \prime \prime \prime \prime}-\mathrm{H}\right), 4.22\left(\mathrm{dd}, J=6.1,4.9 \mathrm{~Hz}, 1 \mathrm{H}, 2^{\prime \prime \prime \prime}-\mathrm{H}\right), 4.23\left(\mathrm{dd}, J=5.8,1.8 \mathrm{~Hz}, 1 \mathrm{H}, 4^{\prime}-\mathrm{H}\right), 4.35(\mathrm{dd}, J=10.3$, $\left.4.1 \mathrm{~Hz}, 1 \mathrm{H}, 2^{\prime \prime \prime}-\mathrm{H}\right), 4.45\left(\mathrm{dd}, J=5.8,5.3 \mathrm{~Hz}, 1 \mathrm{H}, 3^{\prime}-\mathrm{H}\right), 4.48\left(\mathrm{dd}, J=5.3,4.1 \mathrm{~Hz}, 1 \mathrm{H}, 2^{\prime}-\mathrm{H}\right), 4.58(\mathrm{dd}, J=$ $\left.5.4,1.8 \mathrm{~Hz}, 1 \mathrm{H}, 5^{\prime}-\mathrm{H}\right), 5.98(\mathrm{~d}, J=8.1 \mathrm{~Hz}, 1 \mathrm{H}, 5-\mathrm{H}), 5.99\left(\mathrm{~d}, J=4.1 \mathrm{~Hz}, 1 \mathrm{H}, 1^{\prime}-\mathrm{H}\right), 8.12(\mathrm{~d}, J=8.1 \mathrm{~Hz}$, 
1H, 6-H). ${ }^{13} \mathrm{C}$ NMR $\left(126 \mathrm{MHz}, \mathrm{D}_{2} \mathrm{O}, 35^{\circ} \mathrm{C}\right): \delta[\mathrm{ppm}]=19.69\left(\mathrm{C}_{\mathrm{a}}-4^{\prime \prime \prime \prime \prime \prime}\right), 21.18\left(\mathrm{C}_{\mathrm{b}}-4^{\prime \prime \prime \prime \prime \prime}\right), 23.00\left(\mathrm{C}_{\mathrm{a}}-5^{\prime \prime \prime}\right)$, $24.79\left(\mathrm{C}-4^{\prime \prime \prime \prime}\right), 24.93\left(\mathrm{C}_{\mathrm{b}}-5^{\prime \prime \prime}\right), 27.13\left(\mathrm{C}-4^{\prime \prime \prime}\right), 27.87\left(\mathrm{C}-2^{\prime \prime}\right), 28.94\left(\mathrm{C}-5^{\prime \prime \prime \prime}\right), 32.61\left(\mathrm{C}-3^{\prime \prime \prime \prime \prime \prime}\right), 33.47\left(\mathrm{C}-3^{\prime \prime \prime \prime}\right)$, $38.23\left(\mathrm{C}-3^{\prime \prime}\right), 41.90\left(\mathrm{C}-6^{\prime \prime \prime \prime}\right), 42.14\left(\mathrm{C}-3^{\prime \prime \prime}\right), 48.20\left(\mathrm{C}-1^{\prime \prime}\right), 55.22\left(\mathrm{C}-2^{\prime \prime \prime}\right), 56.88\left(\mathrm{C}-2^{\prime \prime \prime \prime}\right), 61.53\left(\mathrm{C}-2^{\prime \prime \prime \prime \prime \prime}\right), 68.51$ $\left(\mathrm{C}-6^{\prime}\right), 69.43\left(\mathrm{C}-5^{\prime}\right), 72.51\left(\mathrm{C}-3^{\prime}\right), 75.58\left(\mathrm{C}-2^{\prime}\right), 85.77\left(\mathrm{C}-4^{\prime}\right), 92.84\left(\mathrm{C}-1^{\prime}\right), 104.79(\mathrm{C}-5), 118.93\left(\mathrm{q}^{1},{ }^{1} \mathrm{~J}_{\mathrm{CF}}=\right.$ $\left.292.3 \mathrm{~Hz}, \mathrm{TFA}-\mathrm{CF}_{3}\right), 145.10(\mathrm{C}-6), 154.12(\mathrm{C}-2), 161.80(\mathrm{NC}(=\mathrm{O}) \mathrm{N}), 165.39\left(\mathrm{q}^{2}{ }^{2} \mathrm{~J}_{\mathrm{CF}}=36.5 \mathrm{~Hz}, \mathrm{TFA}-\mathrm{COO}\right)$, $168.57(\mathrm{C}-4), 171.97\left(\mathrm{C}-7^{\prime}\right), 177.63\left(\mathrm{C}-1^{\prime \prime \prime}\right), 178.09\left(\mathrm{C}-1^{\prime \prime \prime \prime}\right), 179.16\left(\mathrm{C}-1^{\prime \prime \prime \prime \prime \prime}\right) .{ }^{19} \mathrm{~F}$ NMR $\left(282 \mathrm{MHz}, \mathrm{D}_{2} \mathrm{O}\right.$,

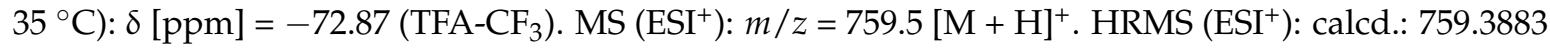
$[\mathrm{M}+\mathrm{H}]^{+}$, found: 759.3884. IR (ATR): $v\left[\mathrm{~cm}^{-1}\right]=1686,1637,1552,1200,1131,721,636,568,554$. UV $\left(\mathrm{H}_{2} \mathrm{O}\right): \lambda_{\max }(\log \varepsilon)=261$ (4.08). Optical rotation: $[\alpha]_{\mathrm{D}}{ }^{25}=+84.5\left(\mathrm{c}=0.22, \mathrm{H}_{2} \mathrm{O}\right)$. m.p. $=210^{\circ} \mathrm{C}$.

$5^{\prime}$-epi-L-Leu muraymycin analogue (16) and 5'-epi-D-Leu muraymycin analogue (17): To a solution of the urea tripeptide $18(6.7 \mathrm{mg}, 0.012 \mathrm{mmol})$ in THF $(1.5 \mathrm{~mL})$, HOBt $(1.6 \mathrm{mg}, 0.012 \mathrm{mmol}), \mathrm{ECD}$ ( $2.3 \mathrm{mg}, 0.012 \mathrm{mmol})$, and DIPEA $(2.1 \mu \mathrm{L}, 0.012 \mathrm{mmol})$ were added and the mixture was stirred at room temperature for $45 \mathrm{~min}$. It was then added to a solution of amine $22(10 \mathrm{mg}, 0.015 \mathrm{mmol})$ in THF $(3 \mathrm{~mL})$ and stirred at room temperature for $18 \mathrm{~h}$. EtOAc $(30 \mathrm{~mL})$ was added and the solution was washed with sat. $\mathrm{NaHCO}_{3}(30 \mathrm{~mL})$. The organic layer was dried over $\mathrm{Na}_{2} \mathrm{SO}_{4}$ and the solvent was removed under reduced pressure. The protected analogues of $\mathbf{1 6}$ and $\mathbf{1 7}$ were obtained after column chromatography (98:2-96:4, $\left.\mathrm{CH}_{2} \mathrm{Cl}_{2}-\mathrm{MeOH}\right)$ as colourless solids. This material was dissolved in TFA $(80 \%$ in water, $1.8 \mathrm{~mL})$ and stirred at room temperature for $24 \mathrm{~h}$. Water $(10 \mathrm{~mL})$ was added and the solvent was removed under reduced pressure. The muraymycin analogues 16 (6.4 mg, 54\%) and 17 $(3.2 \mathrm{mg}, 27 \%)$ were separated by preparative $\operatorname{HPLC}\left(\mathbf{1 6}: t_{\mathrm{R}}=17.9 \mathrm{~min}, 17: t_{\mathrm{R}}=16.3 \mathrm{~min}\right)$ and obtained as colourless solids. 16: ${ }^{1} \mathrm{H}$ NMR $\left(600 \mathrm{MHz}, \mathrm{D}_{2} \mathrm{O}, 35^{\circ} \mathrm{C}\right): \delta[\mathrm{ppm}]=0.98\left(\mathrm{~d}, J=5.7 \mathrm{~Hz}, 3 \mathrm{H}, 5^{\prime \prime \prime}-\mathrm{H}_{\mathrm{a}}\right), 1.03$ $\left(\mathrm{d}, J=5.5 \mathrm{~Hz}, 3 \mathrm{H}, 5^{\prime \prime \prime}-\mathrm{H}_{\mathrm{b}}\right), 1.04\left(\mathrm{~d}, J=6.4 \mathrm{~Hz}, 3 \mathrm{H}, 4^{\prime \prime \prime \prime \prime \prime}-\mathrm{H}_{\mathrm{a}}\right), 1.08\left(\mathrm{~d}, J=7.0 \mathrm{~Hz}, 3 \mathrm{H}, 4^{\prime \prime \prime \prime \prime \prime}-\mathrm{H}_{\mathrm{b}}\right), 1.50-1.60$ (m, 2H, $\left.4^{\prime \prime \prime \prime}-\mathrm{H}\right), 1.66-1.83\left(\mathrm{~m}, 6 \mathrm{H}, 3^{\prime \prime \prime}-\mathrm{H}, 4^{\prime \prime \prime}-\mathrm{H}, 3^{\prime \prime \prime \prime}-\mathrm{H}_{\mathrm{a}}, 5^{\prime \prime \prime \prime}-\mathrm{H}\right), 1.87-1.93\left(\mathrm{~m}, 1 \mathrm{H}, 3^{\prime \prime \prime \prime}-\mathrm{H}_{\mathrm{b}}\right), 2.07$ (dddd, $\left.J=7.7,7.6,6.6,6.5 \mathrm{~Hz}, 2 \mathrm{H}, 2^{\prime \prime}-\mathrm{H}\right), 2.28\left(\mathrm{dqq}, J=7.0,6.4,5.7 \mathrm{~Hz}, 1 \mathrm{H}, 3^{\prime \prime \prime \prime \prime}-\mathrm{H}\right), 3.11(\mathrm{dd}, J=7.7,7.7 \mathrm{~Hz}, 2 \mathrm{H}$, $\left.6^{\prime \prime \prime \prime}-\mathrm{H}\right), 3.25\left(\mathrm{dd}, J=7.7,7.6 \mathrm{~Hz}, 2 \mathrm{H}, 1^{\prime \prime}-\mathrm{H}\right), 3.39\left(\mathrm{ddd}, J=14.2,6.6,6.5 \mathrm{~Hz}, 1 \mathrm{H}, 3^{\prime \prime}-\mathrm{H}_{\mathrm{a}}\right), 3.48(\mathrm{ddd}, J=$ $\left.14.2,6.6,6.5 \mathrm{~Hz}, 1 \mathrm{H}, 3^{\prime \prime}-\mathrm{H}_{\mathrm{b}}\right), 4.14\left(\mathrm{~d}, J=2.9 \mathrm{~Hz}, 1 \mathrm{H}, 6^{\prime}-\mathrm{H}\right), 4.22\left(\mathrm{~d}, J=5.7 \mathrm{~Hz}, 1 \mathrm{H}, 2^{\prime \prime \prime \prime \prime}-\mathrm{H}\right), 4.24(\mathrm{dd}, J=$ 8.7, $\left.5.5 \mathrm{~Hz}, 1 \mathrm{H}, 2^{\prime \prime \prime \prime}-\mathrm{H}\right), 4.30\left(\mathrm{dd}, J=8.4,3.5 \mathrm{~Hz}, 1 \mathrm{H}, 4^{\prime}-\mathrm{H}\right), 4.39$ (dd, J = 9.5, $\left.4.7 \mathrm{~Hz}, 1 \mathrm{H}, 2^{\prime \prime \prime}-\mathrm{H}\right), 4.46(\mathrm{dd}$, $\left.J=8.4,2.9 \mathrm{~Hz}, 1 \mathrm{H}, 5^{\prime}-\mathrm{H}\right), 4.49\left(\mathrm{dd}, J=5.5,3.5 \mathrm{~Hz}, 1 \mathrm{H}, 3^{\prime}-\mathrm{H}\right), 4.74\left(\mathrm{dd}, J=5.9,5.5 \mathrm{~Hz}, 1 \mathrm{H}, 2^{\prime}-\mathrm{H}\right), 5.84(\mathrm{~d}, J$ $\left.=5.9 \mathrm{~Hz}, 1 \mathrm{H}, 1^{\prime}-\mathrm{H}\right), 6.00(\mathrm{~d}, J=8.0 \mathrm{~Hz}, 1 \mathrm{H}, 5-\mathrm{H}), 7.78(\mathrm{~d}, J=8.0 \mathrm{~Hz}, 1 \mathrm{H}, 6-\mathrm{H}) .{ }^{13} \mathrm{C}$ NMR $\left(126 \mathrm{MHz}, \mathrm{D}_{2} \mathrm{O}\right.$, $\left.35^{\circ} \mathrm{C}\right): \delta[\mathrm{ppm}]=19.68\left(\mathrm{C}_{\mathrm{a}}-4^{\prime \prime \prime \prime \prime \prime}\right), 21.18\left(\mathrm{C}_{\mathrm{b}}-4^{\prime \prime \prime \prime \prime \prime}\right), 23.39\left(\mathrm{C}_{\mathrm{a}}-5^{\prime \prime \prime}\right), 24.69\left(\mathrm{C}-4^{\prime \prime \prime \prime}\right), 24.76\left(\mathrm{C}_{\mathrm{b}}-5^{\prime \prime \prime}\right), 27.09$ $\left(\mathrm{C}-4^{\prime \prime \prime}\right), 28.12\left(\mathrm{C}-2^{\prime \prime}\right), 28.93\left(\mathrm{C}-5^{\prime \prime \prime \prime}\right), 32.66\left(\mathrm{C}-3^{\prime \prime \prime \prime \prime \prime}\right), 33.45\left(\mathrm{C}-3^{\prime \prime \prime \prime}\right), 38.74\left(\mathrm{C}-3^{\prime \prime}\right), 41.92\left(\mathrm{C}-6^{\prime \prime \prime \prime}\right), 42.23$ $\left(\mathrm{C}-3^{\prime \prime \prime}\right), 47.50\left(\mathrm{C}-1^{\prime \prime}\right), 55.25\left(\mathrm{C}-2^{\prime \prime \prime}\right), 56.73\left(\mathrm{C}-2^{\prime \prime \prime \prime}\right), 61.48\left(\mathrm{C}-2^{\prime \prime \prime \prime \prime \prime}\right), 65.70\left(\mathrm{C}-6^{\prime}\right), 71.73\left(\mathrm{C}-5^{\prime}\right), 73.67\left(\mathrm{C}-3^{\prime}\right)$, 74.33 (C-2'), $86.08\left(\mathrm{C}-4^{\prime}\right), 94.17\left(\mathrm{C}-1^{\prime}\right), 104.86(\mathrm{C}-5), 118.93$ (q, $\left.{ }^{1} \mathrm{~J}_{\mathrm{CF}}=291.1 \mathrm{~Hz}, \mathrm{TFA}-\mathrm{CF}_{3}\right), 146.11(\mathrm{C}-6)$, $153.90(\mathrm{C}-2), 161.92(\mathrm{NC}(=\mathrm{O}) \mathrm{N}), 165.38\left(\mathrm{q},{ }^{2} \mathrm{~J}_{\mathrm{CF}}=35.3 \mathrm{~Hz}\right.$, TFA-COO), $168.59(\mathrm{C}-4), 171.19\left(\mathrm{C}-7^{\prime}\right), 177.37$ $\left(\mathrm{C}-1^{\prime \prime \prime}\right), 177.76\left(\mathrm{C}-1^{\prime \prime \prime \prime}\right), 179.05\left(\mathrm{C}-1^{\prime \prime \prime \prime \prime \prime}\right) .{ }^{19} \mathrm{~F}$ NMR $\left(282 \mathrm{MHz}, \mathrm{D}_{2} \mathrm{O}, 35^{\circ} \mathrm{C}\right): \delta[\mathrm{ppm}]=-72.88\left(\mathrm{TFA}-\mathrm{CF}_{3}\right)$. MS (ESI $\left.{ }^{+}\right): m / z=759.5[\mathrm{M}+\mathrm{H}]^{+}$. HRMS $\left(\mathrm{ESI}^{+}\right)$: calcd.: $759.3883[\mathrm{M}+\mathrm{H}]^{+}$, found: 759.3884 . IR (ATR): $v\left[\mathrm{~cm}^{-1}\right]=1660,1633,1551,1197,1184,1132,720,547,511 . \mathrm{UV}\left(\mathrm{H}_{2} \mathrm{O}\right): \lambda_{\max }(\log \varepsilon)=260$ (3.98). Optical rotation: $[\alpha]_{\mathrm{D}}{ }^{25}=-10.6\left(\mathrm{c}=0.16, \mathrm{H}_{2} \mathrm{O}\right)$. m.p. $=214{ }^{\circ} \mathrm{C} .17:{ }^{1} \mathrm{H} \mathrm{NMR}\left(600 \mathrm{MHz}, \mathrm{D}_{2} \mathrm{O}, 35^{\circ} \mathrm{C}\right): \delta[\mathrm{ppm}]=$ $0.98\left(\mathrm{~d}, J=5.3 \mathrm{~Hz}, 3 \mathrm{H}, 5^{\prime \prime \prime}-\mathrm{H}_{\mathrm{a}}\right), 1.00\left(\mathrm{~d}, J=6.8 \mathrm{~Hz}, 3 \mathrm{H}, 5^{\prime \prime \prime}-\mathrm{H}_{\mathrm{b}}\right), 1.04\left(\mathrm{~d}, J=6.0 \mathrm{~Hz}, 3 \mathrm{H}, 4^{\prime \prime \prime \prime \prime \prime}-\mathrm{H}_{\mathrm{a}}\right), 1.05(\mathrm{~d}$, $\left.J=6.8 \mathrm{~Hz}, 3 \mathrm{H}, 4^{\prime \prime \prime \prime \prime \prime}-\mathrm{H}_{\mathrm{b}}\right), 1.51-1.63\left(\mathrm{~m}, 2 \mathrm{H}, 4^{\prime \prime \prime \prime}-\mathrm{H}\right), 1.69-1.87\left(\mathrm{~m}, 6 \mathrm{H}, 3^{\prime \prime \prime}-\mathrm{H}, 4^{\prime \prime \prime}-\mathrm{H}, 3^{\prime \prime \prime \prime}-\mathrm{H}_{\mathrm{a}}, 5^{\prime \prime \prime \prime}-\mathrm{H}\right)$, $1.88-1.94\left(\mathrm{~m}, 1 \mathrm{H}, 3^{\prime \prime \prime \prime}-\mathrm{H}_{\mathrm{b}}\right), 2.07$ (dddd, $\left.J=7.3,7.2,6.6,6.3 \mathrm{~Hz}, 2 \mathrm{H}, 2^{\prime \prime}-\mathrm{H}\right), 2.21(\mathrm{dqq}, J=6.8,6.0,5.9 \mathrm{~Hz}$, $\left.1 \mathrm{H}, 3^{\prime \prime \prime \prime \prime \prime}-\mathrm{H}\right), 3.12\left(\mathrm{dd}, J=7.6,7.4 \mathrm{~Hz}, 2 \mathrm{H}, 6^{\prime \prime \prime \prime}-\mathrm{H}\right), 3.20-3.26\left(\mathrm{~m}, 2 \mathrm{H}, 1^{\prime \prime}-\mathrm{H}\right), 3.39$ (ddd, $J=14.3,6.6$, $\left.6.3 \mathrm{~Hz}, 1 \mathrm{H}, 3^{\prime \prime}-\mathrm{H}_{\mathrm{a}}\right), 3.47\left(\mathrm{ddd}, J=14.3,6.6,6.3 \mathrm{~Hz}, 1 \mathrm{H}, 3^{\prime \prime}-\mathrm{H}_{\mathrm{b}}\right), 3.95\left(\mathrm{~d}, J=3.0 \mathrm{~Hz}, 1 \mathrm{H}, 6^{\prime}-\mathrm{H}\right), 4.06(\mathrm{~d}, J=$ $\left.5.9 \mathrm{~Hz}, 1 \mathrm{H}, 2^{\prime \prime \prime \prime \prime \prime}-\mathrm{H}\right), 4.23\left(\mathrm{dd}, J=7.3,7.1 \mathrm{~Hz}, 1 \mathrm{H}, 2^{\prime \prime \prime \prime}-\mathrm{H}\right), 4.29\left(\mathrm{dd}, J=7.6,4.4 \mathrm{~Hz}, 1 \mathrm{H}, 4^{\prime}-\mathrm{H}\right), 4.38(\mathrm{dd}, J$ $\left.=9.5,4.1 \mathrm{~Hz}, 1 \mathrm{H}, 2^{\prime \prime \prime}-\mathrm{H}\right), 4.44\left(\mathrm{dd}, J=7.6,3.0 \mathrm{~Hz}, 1 \mathrm{H}, 5^{\prime}-\mathrm{H}\right), 4.49\left(\mathrm{dd}, J=5.3,4.4 \mathrm{~Hz}, 1 \mathrm{H}, 3^{\prime}-\mathrm{H}\right), 4.65(\mathrm{dd}$, $\left.J=5.6,5.3 \mathrm{~Hz}, 1 \mathrm{H}, 2^{\prime}-\mathrm{H}\right), 5.89\left(\mathrm{~d}, J=5.6 \mathrm{~Hz}, 1 \mathrm{H}, 1^{\prime}-\mathrm{H}\right), 6.01(\mathrm{~d}, J=8.1 \mathrm{~Hz}, 1 \mathrm{H}, 5-\mathrm{H}), 7.83(\mathrm{~d}, J=8.1 \mathrm{~Hz}$, 1H, 6-H). ${ }^{13} \mathrm{C}$ NMR $\left(126 \mathrm{MHz}, \mathrm{D}_{2} \mathrm{O}, 35^{\circ} \mathrm{C}\right): \delta[\mathrm{ppm}]=19.77\left(\mathrm{C}_{\mathrm{a}}-4^{\prime \prime \prime \prime \prime \prime}\right), 21.56\left(\mathrm{C}_{\mathrm{b}}-4^{\prime \prime \prime \prime \prime \prime}\right), 22.98\left(\mathrm{C}_{\mathrm{a}}-5^{\prime \prime \prime}\right)$, $24.79\left(\mathrm{C}-4^{\prime \prime \prime \prime}\right), 24.95\left(\mathrm{C}_{\mathrm{b}}-5^{\prime \prime \prime}\right), 27.12\left(\mathrm{C}-4^{\prime \prime \prime}\right), 28.13\left(\mathrm{C}-2^{\prime \prime}\right), 28.98\left(\mathrm{C}-5^{\prime \prime \prime \prime}\right), 33.04\left(\mathrm{C}-3^{\prime \prime \prime \prime \prime \prime}\right), 33.38\left(\mathrm{C}-3^{\prime \prime \prime \prime}\right)$, $38.77\left(\mathrm{C}-3^{\prime \prime}\right), 41.92\left(\mathrm{C}-6^{\prime \prime \prime \prime}\right), 42.17\left(\mathrm{C}-3^{\prime \prime \prime}\right), 47.46\left(\mathrm{C}-1^{\prime \prime}\right), 55.19\left(\mathrm{C}-2^{\prime \prime \prime}\right), 56.84\left(\mathrm{C}-2^{\prime \prime \prime \prime}\right), 63.09\left(\mathrm{C}-2^{\prime \prime \prime \prime \prime \prime}\right), 66.68$ $\left(\mathrm{C}-6^{\prime}\right), 71.79\left(\mathrm{C}-5^{\prime}\right), 73.11\left(\mathrm{C}-3^{\prime}\right), 74.83\left(\mathrm{C}-2^{\prime}\right), 86.09\left(\mathrm{C}-4^{\prime}\right), 94.45\left(\mathrm{C}-1^{\prime}\right), 104.88(\mathrm{C}-5), 118.89\left(\mathrm{q},{ }^{1} \mathrm{~J}_{\mathrm{CF}}=\right.$ 
291.1 Hz, TFA-CF 3 ), $145.66(\mathrm{C}-6), 154.01(\mathrm{C}-2), 161.81(\mathrm{NC}(=\mathrm{O}) \mathrm{N}), 165.39\left(\mathrm{q},{ }^{2} \mathrm{~J}_{\mathrm{CF}}=37.8 \mathrm{~Hz}, \mathrm{TFA}-\mathrm{COO}\right)$, $168.63(\mathrm{C}-4), 171.91\left(\mathrm{C}-7^{\prime}\right), 177.01\left(\mathrm{C}-1^{\prime \prime \prime}\right), 177.54\left(\mathrm{C}-1^{\prime \prime \prime \prime}\right), 178.33\left(\mathrm{C}-1^{\prime \prime \prime \prime \prime \prime}\right) .{ }^{19} \mathrm{~F}$ NMR $\left(282 \mathrm{MHz}, \mathrm{D}_{2} \mathrm{O}\right.$, $\left.35^{\circ} \mathrm{C}\right): \delta[\mathrm{ppm}]=-72.88\left(\mathrm{TFA}^{-C_{3}}\right) . \mathrm{MS}\left(\mathrm{ESI}^{+}\right): m / z=759.5[\mathrm{M}+\mathrm{H}]^{+}$. HRMS $\left(\mathrm{ESI}^{+}\right)$: calcd.: 759.3883 $[\mathrm{M}+\mathrm{H}]^{+}$, found: 759.3888. IR (ATR): $v\left[\mathrm{~cm}^{-1}\right]=1667,1634,1552,1201,1132,1056,800,721,547$. UV $\left(\mathrm{H}_{2} \mathrm{O}\right): \lambda_{\max }(\log \varepsilon)=260$ (3.95). optical rotation: $[\alpha]_{\mathrm{D}}{ }^{25}=+13.1\left(\mathrm{c}=0.13, \mathrm{H}_{2} \mathrm{O}\right)$. m.p. $=218^{\circ} \mathrm{C}$.

Protected urea tripeptide (18): To a solution of $29(50 \mathrm{mg}, 0.076 \mathrm{mmol})$ in THF $(4 \mathrm{~mL})$, tetrabutylammonium fluoride (TBAF, $1 \mathrm{M}$ in THF, $91 \mu \mathrm{L}, 0.091 \mathrm{mmol}$ ) was added at $0{ }^{\circ} \mathrm{C}$ and the mixture was stirred at $0{ }^{\circ} \mathrm{C}$ for $1 \mathrm{~h}$. More TBAF ( $1 \mathrm{M}$ in THF, $30 \mu \mathrm{L}, 0.030 \mathrm{mmol}$ ) was added and the mixture was stirred at room temperature for $3 \mathrm{~h}$. The solvent was removed under reduced pressure. The urea tripeptide 18 was obtained after column chromatography (95:4:1, $\mathrm{CH}_{2} \mathrm{Cl}_{2}-\mathrm{MeOH}-\mathrm{HOAc}$ ) as colourless solid (39 mg, 92\%). ${ }^{1} \mathrm{H}$ NMR $\left(600 \mathrm{MHz}, \mathrm{DMSO}-\mathrm{d}_{6}, 35^{\circ} \mathrm{C}\right): \delta[\mathrm{ppm}]=0.83(\mathrm{~d}, J=6.9 \mathrm{~Hz}, 3 \mathrm{H}$, $\left.4-\mathrm{H}_{\mathrm{a}}\right), 0.83\left(\mathrm{~d}, J=6.5 \mathrm{~Hz}, 3 \mathrm{H}, 5^{\prime \prime}-\mathrm{H}_{\mathrm{a}}\right), 0.85\left(\mathrm{~d}, J=6.8 \mathrm{~Hz}, 3 \mathrm{H}, 4-\mathrm{H}_{\mathrm{b}}\right), 0.88\left(\mathrm{~d}, J=6.6 \mathrm{~Hz}, 3 \mathrm{H}, 5^{\prime \prime}-\mathrm{H}_{\mathrm{b}}\right)$, $1.22-1.28\left(\mathrm{~m}, 2 \mathrm{H}, 4^{\prime}-\mathrm{H}\right), 1.35-1.44\left(\mathrm{~m}, 3 \mathrm{H}, 3^{\prime}-\mathrm{H}_{\mathrm{a}}, 5^{\prime \prime}-\mathrm{H}\right), 1.38\left(\mathrm{~s}, 9 \mathrm{H}, \mathrm{OC}\left(\mathrm{CH}_{3}\right)_{3}\right), 1.40\left(\mathrm{~s}, 9 \mathrm{H}, \mathrm{OC}\left(\mathrm{CH}_{3}\right)_{3}\right)$, $1.52\left(\mathrm{ddd}, J=9.1,5.3,5.0 \mathrm{~Hz}, 2 \mathrm{H}, 3^{\prime \prime}-\mathrm{H}\right), 1.53-1.58\left(\mathrm{~m}, 1 \mathrm{H}, 3^{\prime}-\mathrm{H}_{\mathrm{b}}\right), 1.57 .1 .65\left(\mathrm{~m}, 1 \mathrm{H}, 4^{\prime \prime}-\mathrm{H}\right), 1.96(\mathrm{dqq}, J$ $=6.9,6.8,5.1 \mathrm{~Hz}, 1 \mathrm{H}, 3-\mathrm{H}), 2.84-2.88\left(\mathrm{~m}, 2 \mathrm{H}, 6^{\prime}-\mathrm{NH}\right), 3.92(\mathrm{dd}, J=8.6,5.1 \mathrm{~Hz}, 1 \mathrm{H}, 2-\mathrm{H}), 4.14$ (ddd, $J$ $\left.=8.2,7.7,5.3 \mathrm{~Hz}, 1 \mathrm{H}, 2^{\prime}-\mathrm{H}\right), 4.20\left(\mathrm{ddd}, J=9.1,8.0,5.6 \mathrm{~Hz}, 1 \mathrm{H}, 2^{\prime \prime}-\mathrm{H}\right), 6.25(\mathrm{~d}, J=8.6 \mathrm{~Hz}, 1 \mathrm{H}, 2-\mathrm{NH})$, $6.27\left(\mathrm{~d}, J=7.7 \mathrm{~Hz}, 1 \mathrm{H}, 2^{\prime}-\mathrm{NH}\right), 6.66\left(\mathrm{dd}, J=6.0,5.8 \mathrm{~Hz}, 1 \mathrm{H}, 6^{\prime}-\mathrm{NH}\right), 8.01\left(\mathrm{~d}, J=8.0 \mathrm{~Hz}, 1 \mathrm{H}, 2^{\prime \prime}-\mathrm{NH}\right)$. ${ }^{13} \mathrm{C}$ NMR $\left(126 \mathrm{MHz}\right.$, DMSO-d $\left.6,35^{\circ} \mathrm{C}\right): \delta[\mathrm{ppm}]=17.59\left(\mathrm{C}_{\mathrm{a}}-4\right), 18.92\left(\mathrm{C}_{\mathrm{b}}-4\right), 21.33\left(\mathrm{C}_{\mathrm{a}}-5^{\prime \prime}\right), 22.24\left(\mathrm{C}-4^{\prime}\right)$, $24.79\left(\mathrm{C}_{\mathrm{b}}-5^{\prime \prime}\right), 24.17\left(\mathrm{C}-4^{\prime \prime}\right), 27.64\left(\mathrm{OC}\left(\mathrm{CH}_{3}\right)_{3}\right), 28.20\left(\mathrm{OC}\left(\mathrm{CH}_{3}\right)_{3}\right), 29.30\left(\mathrm{C}-5^{\prime}\right), 30.43(\mathrm{C}-3), 32.97\left(\mathrm{C}-3^{\prime}\right)$, $39.76\left(\mathrm{C}-6^{\prime}\right), 39.92\left(\mathrm{C}-3^{\prime \prime}\right), 50.09\left(\mathrm{C}-2^{\prime \prime}\right), 52.41\left(\mathrm{C}-2^{\prime}\right), 58.10(\mathrm{C}-2), 77.13\left(\mathrm{OC}\left(\mathrm{CH}_{3}\right)_{3}\right), 80.04\left(\mathrm{OC}^{-}\left(\mathrm{CH}_{3}\right)_{3}\right)$, $155.25(\mathrm{NC}(=\mathrm{O}) \mathrm{O}), 157.09(\mathrm{NC}(=\mathrm{O}) \mathrm{N}), 171.36(\mathrm{C}-1), 172.09\left(\mathrm{C}-1^{\prime}\right), 173.64\left(\mathrm{C}-1^{\prime \prime}\right)$. MS $\left(\mathrm{ESI}^{+}\right): \mathrm{m} / z=581.3$ $[\mathrm{M}+\mathrm{Na}]^{+}$. HRMS $\left(\mathrm{ESI}^{+}\right)$: calcd.: $581.3521[\mathrm{M}+\mathrm{Na}]^{+}$, found: 581.3522. IR (ATR): $v\left[\mathrm{~cm}^{-1}\right]=1719,1688$, $1633,1546,1391,1366,1250,1156,665$. Optical rotation: $[\alpha]_{\mathrm{D}}{ }^{25}=-3.3\left(\mathrm{c}=0.24, \mathrm{CHCl}_{3}\right) . \mathrm{m} . \mathrm{p} .=73^{\circ} \mathrm{C}$. TLC: $\mathrm{R}_{f}=0.25$ (94:5:1, $\left.\mathrm{CH}_{2} \mathrm{Cl}_{2}-\mathrm{MeOH}-\mathrm{AcOH}\right)$.

$6^{\prime}$-epi nucleoside building block (21): To a solution of 33 (45 mg, $\left.0.057 \mathrm{mmol}\right)$ in $\mathrm{MeOH}(4 \mathrm{~mL})$, $\mathrm{Pd} / \mathrm{C}(10 \%, 10 \mathrm{mg}, 9.4 \mu \mathrm{mol})$ and 1,4-cyclohexadiene $(54 \mu \mathrm{L}, 0.57 \mathrm{mmol})$ were added and the mixture was stirred at room temperature for $2 \mathrm{~h}$. More $\mathrm{Pd} / \mathrm{C}(10 \%, 5 \mathrm{mg}, 5 \mu \mathrm{mol})$ and 1,4-cyclohexadiene $(54 \mu \mathrm{L}, 0.57 \mathrm{mmol}$ ) were added and the mixture was stirred at room temperature for $1 \mathrm{~h}$. The mixture was filtered and the residue was washed with $\mathrm{MeOH}(3 \times 4 \mathrm{~mL})$. The solvent of the combined filtrates was removed under reduced pressure to give 21 as a colourless solid $(37 \mathrm{mg}, 99 \%) .{ }^{1} \mathrm{H} \mathrm{NMR}(600 \mathrm{MHz}$, $\left.\mathrm{CD}_{3} \mathrm{OD}\right): \delta[\mathrm{ppm}]=0.05\left(\mathrm{~s}, 3 \mathrm{H}, \mathrm{SiCH}_{3}\right), 0.07\left(\mathrm{~s}, 3 \mathrm{H}, \mathrm{SiCH}_{3}\right), 0.12\left(\mathrm{~s}, 3 \mathrm{H}, \mathrm{SiCH}_{3}\right), 0.14\left(\mathrm{~s}, 3 \mathrm{H}, \mathrm{SiCH}_{3}\right), 0.88$ $\left(\mathrm{s}, 9 \mathrm{H}, \mathrm{SiC}\left(\mathrm{CH}_{3}\right)_{3}\right), 0.94\left(\mathrm{~s}, 9 \mathrm{H}, \mathrm{SiC}\left(\mathrm{CH}_{3}\right)_{3}\right), 1.49\left(\mathrm{~s}, 9 \mathrm{H}, \mathrm{OC}\left(\mathrm{CH}_{3}\right)_{3}\right), 1.66-1.75\left(\mathrm{~m}, 2 \mathrm{H}, 2^{\prime \prime}-\mathrm{H}\right), 2.63$ (ddd, J $\left.=12.3,6.2,5.9 \mathrm{~Hz}, 1 \mathrm{H}, 1^{\prime \prime}-\mathrm{H}_{\mathrm{a}}\right), 2.76\left(\mathrm{ddd}, J=12.3,7.2,5.6 \mathrm{~Hz}, 1 \mathrm{H}, 1^{\prime \prime}-\mathrm{H}_{\mathrm{b}}\right), 2.94-2.96\left(\mathrm{~m}, 2 \mathrm{H}, 3^{\prime \prime}-\mathrm{H}\right), 3.38$ $\left(\mathrm{d}, J=7.4 \mathrm{~Hz}, 1 \mathrm{H}, 6^{\prime}-\mathrm{H}\right), 3.87\left(\mathrm{dd}, J=7.4,1.2 \mathrm{~Hz}, 1 \mathrm{H}, 5^{\prime}-\mathrm{H}\right), 4.17\left(\mathrm{dd}, J=4.2,3.7 \mathrm{~Hz}, 1 \mathrm{H}, 3^{\prime}-\mathrm{H}\right), 4.20(\mathrm{dd}$, $\left.J=3.7,1.2 \mathrm{~Hz}, 1 \mathrm{H}, 4^{\prime}-\mathrm{H}\right), 4.36\left(\mathrm{dd}, J=5.3,4.2 \mathrm{~Hz}, 1 \mathrm{H}, 2^{\prime}-\mathrm{H}\right), 5.72(\mathrm{~d}, J=8.1 \mathrm{~Hz}, 1 \mathrm{H}, 5-\mathrm{H}), 5.88(\mathrm{~d}, J=$ $\left.5.3 \mathrm{~Hz}, 1 \mathrm{H}, \mathrm{1}^{\prime}-\mathrm{H}\right), 8.18(\mathrm{~d}, J=8.1 \mathrm{~Hz}, 1 \mathrm{H}, 6-\mathrm{H}) .{ }^{13} \mathrm{C} \mathrm{NMR}\left(126 \mathrm{MHz}, \mathrm{CD}_{3} \mathrm{OD}\right): \delta[\mathrm{ppm}]=-4.58\left(\mathrm{SiCH}_{3}\right)$, $-4.49\left(\mathrm{SiCH}_{3}\right),-4.49\left(\mathrm{SiCH}_{3}\right),-4.22\left(\mathrm{SiCH}_{3}\right), 18.76\left(\mathrm{SiC}\left(\mathrm{CH}_{3}\right)_{3}\right), 18.85\left(\mathrm{SiC}\left(\mathrm{CH}_{3}\right)_{3}\right), 26.24\left(\mathrm{SiC}\left(\mathrm{CH}_{3}\right)_{3}\right)$, $26.31\left(\mathrm{SiC}\left(\mathrm{CH}_{3}\right)_{3}\right), 28.29\left(\mathrm{OC}\left(\mathrm{CH}_{3}\right)_{3}\right), 29.82\left(\mathrm{C}-2^{\prime \prime}\right), 40.38\left(\mathrm{C}-3^{\prime \prime}\right), 46.92\left(\mathrm{C}-1^{\prime \prime}\right), 65.99\left(\mathrm{C}-6^{\prime}\right), 71.28\left(\mathrm{C}-5^{\prime}\right)$, $74.41\left(\mathrm{C}-3^{\prime}\right), 76.01\left(\mathrm{C}-2^{\prime}\right), 82.79\left(\mathrm{O} \underline{C}\left(\mathrm{CH}_{3}\right)_{3}\right), 86.15\left(\mathrm{C}-4^{\prime}\right), 90.00\left(\mathrm{C}-1^{\prime}\right), 102.72(\mathrm{C}-5), 142.68(\mathrm{C}-6), 152.45$ (C-2), $166.11(\mathrm{C}-4), 174.08\left(\mathrm{C}-7^{\prime}\right)$. MS $\left(\mathrm{ESI}^{+}\right): m / z=659.4[\mathrm{M}+\mathrm{H}]^{+}$. HRMS (ESI $\left.{ }^{+}\right)$: calcd.: $659.3866[\mathrm{M}+$ $\mathrm{H}]^{+}$, found: 659.3867. IR (ATR): $v\left[\mathrm{~cm}^{-1}\right]=1686,1253,1153,1113,1051,869,834,812,773$. UV (MeOH): $\lambda_{\max }(\log \varepsilon)=207$ (3.98), 262 (3.98). Optical rotation: $[\alpha]_{\mathrm{D}}{ }^{25}=+24.0(\mathrm{c}=0.30, \mathrm{MeOH}) . \mathrm{m} . \mathrm{p} .=115^{\circ} \mathrm{C}$.

$5^{\prime}$-epi nucleoside building block (22): To a solution of 34 (5.0 mg, $\left.6.3 \mu \mathrm{mol}\right)$ in $\mathrm{MeOH}(4 \mathrm{~mL}), \mathrm{Pd} / \mathrm{C}$ $(10 \%, 5 \mathrm{mg}, 5 \mu \mathrm{mol})$, and 1,4-cyclohexadiene $(6.3 \mu \mathrm{L}, 0.063 \mathrm{mmol})$ were added and the mixture was stirred at room temperature for $30 \mathrm{~min}$. More $\mathrm{Pd} / \mathrm{C}(10 \%, 5 \mathrm{mg}, 5 \mu \mathrm{mol})$ was added and the mixture was stirred at room temperature for $30 \mathrm{~min}$. The mixture was filtered and the residue was washed with $\mathrm{MeOH}(3 \times 4 \mathrm{~mL})$. The solvent of the combined filtrates was removed under reduced pressure to give 22 as a colourless solid $(4.1 \mathrm{mg}, 99 \%) .{ }^{1} \mathrm{H}$ NMR $\left(600 \mathrm{MHz}\right.$, pyridine- $\left.\mathrm{d}_{5}, 35^{\circ} \mathrm{C}\right): \delta[\mathrm{ppm}]=0.14(\mathrm{~s}$, $\left.3 \mathrm{H}, \mathrm{SiCH}_{3}\right), 0.16\left(\mathrm{~s}, 3 \mathrm{H}, \mathrm{SiCH}_{3}\right), 0.26\left(\mathrm{~s}, 3 \mathrm{H}, \mathrm{SiCH}_{3}\right), 0.35\left(\mathrm{~s}, 3 \mathrm{H}, \mathrm{SiCH}_{3}\right), 0.94\left(\mathrm{~s}, 9 \mathrm{H}, \mathrm{SiC}\left(\mathrm{CH}_{3}\right)_{3}\right), 1.06$ $\left(\mathrm{s}, 9 \mathrm{H}, \mathrm{SiC}\left(\mathrm{CH}_{3}\right)_{3}\right), 1.59\left(\mathrm{~s}, 9 \mathrm{H}, \mathrm{OC}\left(\mathrm{CH}_{3}\right)_{3}\right), 2.11-2.16\left(\mathrm{~m}, 1 \mathrm{H}, 2^{\prime \prime}-\mathrm{H}_{\mathrm{a}}\right), 2.21-2.26\left(\mathrm{~m}, 1 \mathrm{H}, 2^{\prime \prime}-\mathrm{H}_{\mathrm{b}}\right), 3.09$ 
$\left(\mathrm{ddd}, J=12.3,7.2,5.6 \mathrm{~Hz}, 1 \mathrm{H}, 1^{\prime \prime}-\mathrm{H}_{\mathrm{a}}\right), 3.22\left(\mathrm{ddd}, J=12.3,6.1,6.1 \mathrm{~Hz}, 1 \mathrm{H}, 1^{\prime \prime}-\mathrm{H}_{\mathrm{b}}\right), 3.45(\mathrm{ddd}, J=12.5,6.8$, $\left.6.7 \mathrm{~Hz}, 1 \mathrm{H}, 3^{\prime \prime}-\mathrm{H}_{\mathrm{a}}\right), 3.50\left(\mathrm{ddd}, J=12.5,6.6 \mathrm{~Hz}, 6.5 \mathrm{~Hz}, 1 \mathrm{H}, 3^{\prime \prime}-\mathrm{H}_{\mathrm{b}}\right), 4.06\left(\mathrm{~d}, J=3.8 \mathrm{~Hz}, 1 \mathrm{H}, 6^{\prime}-\mathrm{H}\right), 4.68(\mathrm{~d}$, $\left.J=7.9 \mathrm{~Hz}, 1 \mathrm{H}, 4^{\prime}-\mathrm{H}\right), 4.79\left(\mathrm{~d}, J=4.3 \mathrm{~Hz}, 1 \mathrm{H}, 3^{\prime}-\mathrm{H}\right), 4.88\left(\mathrm{dd}, J=7.9,3.8 \mathrm{~Hz}, 1 \mathrm{H}, 5^{\prime}-\mathrm{H}\right), 5.12(\mathrm{dd}, J=7.9$, $\left.4.3 \mathrm{~Hz}, 1 \mathrm{H}, 2^{\prime}-\mathrm{H}\right), 6.03(\mathrm{~d}, J=8.1 \mathrm{~Hz}, 1 \mathrm{H}, 5-\mathrm{H}), 6.88\left(\mathrm{~d}, J=7.9 \mathrm{~Hz}, 1 \mathrm{H}, 1^{\prime}-\mathrm{H}\right), 8.41(\mathrm{~d}, J=8.1 \mathrm{~Hz}, 1 \mathrm{H}$, 6-H). ${ }^{13} \mathrm{C}$ NMR $\left(126 \mathrm{MHz}\right.$, pyridine- $\left.\mathrm{d}_{5}, 35^{\circ} \mathrm{C}\right): \delta[\mathrm{ppm}]=-4.46\left(\mathrm{SiCH}_{3}\right),-4.05\left(\mathrm{SiCH}_{3}\right),-4.00\left(\mathrm{SiCH}_{3}\right)$, -3.95 $\left(\mathrm{SiCH}_{3}\right), 18.32\left(\mathrm{SiC}\left(\mathrm{CH}_{3}\right)_{3}\right), 18.51\left(\mathrm{SiC}\left(\mathrm{CH}_{3}\right)_{3}\right), 26.16\left(\mathrm{SiC}\left(\mathrm{CH}_{3}\right)_{3}\right), 26.26\left(\mathrm{SiC}\left(\mathrm{CH}_{3}\right)_{3}\right), 27.75\left(\mathrm{C}-2^{\prime \prime}\right)$, $28.41\left(\mathrm{OC}\left(\mathrm{CH}_{3}\right)_{3}\right), 39.51\left(\mathrm{C}-3^{\prime \prime}\right), 46.86\left(\mathrm{C}-1^{\prime \prime}\right), 64.60\left(\mathrm{C}-6^{\prime}\right), 73.58\left(\mathrm{C}-5^{\prime}\right), 73.85\left(\mathrm{C}-2^{\prime}\right), 74.03\left(\mathrm{C}-3^{\prime}\right), 81.72$ $\left(\mathrm{OC}\left(\mathrm{CH}_{3}\right)_{3}\right), 87.19\left(\mathrm{C}-4^{\prime}\right), 87.19\left(\mathrm{C}-1^{\prime}\right), 103.29$ (C-5), 142.71 (C-6), 152.37 (C-2), $164.15(\mathrm{C}-4), 171.56$ (C-7'). MS $\left(\mathrm{ESI}^{+}\right): m / z=659.4[\mathrm{M}+\mathrm{H}]^{+}$. HRMS $\left(\mathrm{ESI}^{+}\right)$: calcd.: $659.3866[\mathrm{M}+\mathrm{H}]^{+}$, found: 659.3871. IR (ATR): $v\left[\mathrm{~cm}^{-1}\right]=1678,1252,1155,1057,865,833,813,776,542 . \mathrm{UV}(\mathrm{MeOH}): \lambda_{\max }(\log \varepsilon)=205(3.98), 260$ (3.84). Optical rotation: $[\alpha]_{\mathrm{D}}{ }^{25}=-32.1(\mathrm{c}=0.42, \mathrm{MeOH})$. m.p. $=184{ }^{\circ} \mathrm{C}$.

$N^{\varepsilon}$-tert-butyloxycarbonyl-L-lysine trimethylsilylethyl ester (24): To a solution of $N^{\alpha}$ benzyloxycarbonyl- $N^{\varepsilon}$-tert-butyloxycarbonyl-L-lysine $23(667 \mathrm{mg}, 1.75 \mathrm{mmol})$, ECD $(673 \mathrm{mg}$, $3.51 \mathrm{mmol}$ ), and 4-(dimethylamino)pyridine (DMAP, $175 \mathrm{mg}, 1.43 \mathrm{mmol}$ ) in $\mathrm{CH}_{2} \mathrm{Cl}_{2}(8.9 \mathrm{~mL}$ ), 2-(trimethylsilyl)ethanol $(380 \mu \mathrm{L}, 310 \mathrm{mg}, 2.62 \mathrm{mmol})$ was added and the mixture was stirred at room temperature for $25 \mathrm{~h}$. It was then washed with sat. $\mathrm{NaHCO}_{3}(3 \times 30 \mathrm{~mL})$, brine $(3 \times 30 \mathrm{~mL})$, and water $(60 \mathrm{~mL})$. The organic layer was dried over $\mathrm{Na}_{2} \mathrm{SO}_{4}$ and the solvent was removed under reduced pressure. The resultant crude product was purified by column chromatography $(6: 4$, petroleum ether- $\left.\mathrm{CH}_{2} \mathrm{Cl}_{2}\right)$ to give the $\mathrm{N}^{\alpha}$-protected lysine ester as a colourless oil $(653 \mathrm{mg}, 77 \%)$. This material (600 mg, $1.25 \mathrm{mmol}$ ) was dissolved in $\mathrm{MeOH}(2 \mathrm{~mL}), \mathrm{Pd} / \mathrm{C}(10 \%, 190 \mathrm{mg}, 0.179 \mathrm{mmol})$ was added and the mixture was stirred under a hydrogen atmosphere ( $1 \mathrm{bar}$ ) at room temperature for $3 \mathrm{~h}$. It was then filtered over celiter ${ }^{\mathrm{TM}}$, the residue was washed with $\mathrm{MeOH}$ and the solvent of the combined filtrates was removed under reduced pressure to give 24 as a colourless oil ( $422 \mathrm{mg}, 99 \%, 77 \%$ over 2 steps from 23). ${ }^{1} \mathrm{H}$ NMR $\left(300 \mathrm{MHz}, \mathrm{CD}_{2} \mathrm{Cl}_{4}, 100{ }^{\circ} \mathrm{C}\right): \delta[\mathrm{ppm}]=4.53-4.44\left(\mathrm{~m}, 1 \mathrm{H}, \mathrm{N}^{\varepsilon} \mathrm{H}\right), 4.26-4.20(\mathrm{~m}, 2 \mathrm{H}$, H-1'), 3.39-3.35 (m, 1H, H-2), 3.14-3.07 (m, 2H, H-6), 1.80-1.68 (m, 1H, H-3 $\mathrm{a}^{\mathrm{a}}, 1.59-1.39$ (m, 5H, H-3 $\mathrm{H}-4, \mathrm{H}-5), 1.45$ (s, 9H, Boc- $\left.\mathrm{CH}_{3}\right), 1.05-1.00\left(\mathrm{~m}, 2 \mathrm{H}, \mathrm{H}-2^{\prime}\right), 0.08$ (s, 9H, Si( $\left.\left(\mathrm{CH}_{3}\right)_{3}\right) .{ }^{13} \mathrm{C}-\mathrm{NMR}(75 \mathrm{MHz}$, $\left.\mathrm{CD}_{2} \mathrm{Cl}_{4}, 100{ }^{\circ} \mathrm{C}\right): \delta[\mathrm{ppm}]=175.38(\mathrm{C}-1), 155.57\left(\right.$ Boc-C=O), 78.67 (Boc-C), $62.70\left(\mathrm{C}-1^{\prime}\right), 54.33(\mathrm{C}-2), 40.48$ (C-6), 34.25 (C-3), $29.64(\mathrm{C}-5), 28.23\left(\mathrm{Boc}^{\left.-\mathrm{CH}_{3}\right)}, 22.71(\mathrm{C}-4), 17.34\left(\mathrm{C}-2^{\prime}\right),-1.77\left(\mathrm{Si}^{(} \mathrm{CH}_{3}\right)_{3}\right) . \mathrm{MS}\left(\mathrm{ESI}^{+}\right)$: $m / z=347.2[\mathrm{M}+\mathrm{H}]^{+}$. HRMS (ESI ${ }^{+}$): calcd.: $347.2361[\mathrm{M}+\mathrm{H}]^{+}$, found: 347.2364. IR (ATR): $v\left[\mathrm{~cm}^{-1}\right]=$ $3372,2952,2364,1713,1520,1365,1250,1171,838$. Optical rotation: $[\alpha]_{\mathrm{D}}{ }^{25}=+5.5\left(\mathrm{c}=0.58, \mathrm{CHCl}_{3}\right)$. TLC: $\mathrm{R}_{f}\left(95: 5, \mathrm{CH}_{2} \mathrm{Cl}_{2}-\mathrm{MeOH}\right)=0.80$.

Protected urea dipeptide trimethylsilylethyl ester (26): To a solution of 24 (10 mg, $29 \mu \mathrm{mol})$ and $N$-(S-methylthiocarbonyl)-L-valine tert-butyl ester $25(7.9 \mathrm{mg}, 32 \mu \mathrm{mol})$ in EtOAc $(1 \mathrm{~mL})$, $\mathrm{N}$-methylmorpholine (NMM, $9.5 \mu \mathrm{L}, 8.7 \mathrm{mg}, 86 \mu \mathrm{mol}$ ) and silver(I)-trifluoromethanesulfonate (AgOTf, $11 \mathrm{mg}, 43 \mu \mathrm{mol}$ ) were added and the mixture was stirred at room temperature for $17 \mathrm{~h}$. The solvent was removed under reduced pressure, and the resultant crude product was purified by column chromatography (3:1, petroleum ether-EtOAc) to give 26 as colourless oil $(12 \mathrm{mg}, 76 \%) .{ }^{1} \mathrm{H} \mathrm{NMR}$ $\left(300 \mathrm{MHz}, \mathrm{CD}_{2} \mathrm{Cl}_{4}, 100^{\circ} \mathrm{C}\right): \delta[\mathrm{ppm}]=4.98\left(\mathrm{~d}, J=8.0 \mathrm{~Hz}, 1 \mathrm{H}, \mathrm{Lys}-\mathrm{N}^{\alpha} \mathrm{H}\right), 4.95(\mathrm{~d}, J=8.8 \mathrm{~Hz}, 1 \mathrm{H}, \mathrm{Val}-\mathrm{NH})$, 4.63-4.48 (m, 1H, Lys- $\left.{ }^{\varepsilon} \mathrm{H}\right), 4.38$ (ddd, $\left.J=8.0,7.6,5.5 \mathrm{~Hz}, 1 \mathrm{H}, \mathrm{Lys}-\mathrm{H}-2\right), 4.31-4.14$ (m, 3H, Val-H-2, H-1), 3.10 (dd, J = 13.0, 6.7 Hz, 2H, Lys-H-6), 2.18-2.03 (m, 1H, Val-H-3), 1.89-1.75 (m, 1H, Lys-H-3a), 1.75-1.59 (m, 1H, Lys-H-3b), 1.59-1.32 (m, 4H, Lys-H-4, Lys-H-5), 1.49 (s, 9H, $\left.t-\mathrm{Bu}^{-} \mathrm{CH}_{3}\right) 1.46(\mathrm{~s}, 9 \mathrm{H}$, Boc- $\left.\mathrm{CH}_{3}\right), 1.08-0.99(\mathrm{~m}, 2 \mathrm{H}, \mathrm{H}-2), 0.97(\mathrm{~d}, J=9.5 \mathrm{~Hz}, 3 \mathrm{H}, \mathrm{Val}-\mathrm{H}-4), 0.94(\mathrm{~d}, J=9.5 \mathrm{~Hz}, 3 \mathrm{H}, \mathrm{Val}-\mathrm{H}-4), 0.08$ $\left(\mathrm{s}, 9 \mathrm{H}, \mathrm{Si}\left(\mathrm{CH}_{3}\right)_{3}\right) .{ }^{13} \mathrm{C} \mathrm{NMR}\left(75 \mathrm{MHz}, \mathrm{CD}_{2} \mathrm{Cl}_{4}, 100{ }^{\circ} \mathrm{C}\right): \delta$ [ppm] = 172.89 (Lys-C-1), 171.56 (Val-C-1), 156.78 (Boc-C=O), 155.69 (urea-C=O), 81.42 ( $t$-Bu-C), 78.71 (Boc-C), 63.24 (C-1), 58.68 (Val-C-2), 53.13

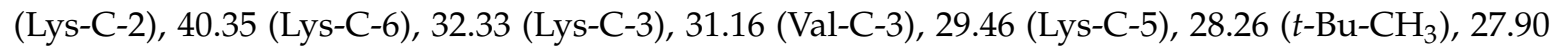

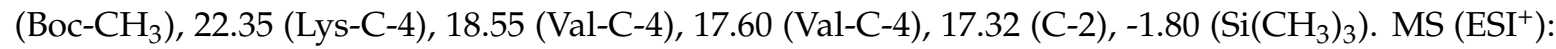
$m / z=568.3[\mathrm{M}+\mathrm{Na}]^{+}$. HRMS (ESI) ${ }^{+}$: calcd.: $568.3388[\mathrm{M}+\mathrm{Na}]^{+}$, found: 568.3391 . IR (ATR): $v\left[\mathrm{~cm}^{-1}\right]$ $=3355,2961,1715,1644,1550,1365,1249,1164,836$. Optical rotation: $[\alpha]_{\mathrm{D}}{ }^{25}=7.7\left(\mathrm{c}=0.38, \mathrm{CHCl}_{3}\right)$. TLC: $\mathrm{R}_{f}(3: 2$, petroleum ether-EtOAc $)=0.47$. 
Protected urea dipeptide (27): To a solution of $26(380 \mathrm{mg}, 0.696 \mathrm{mmol})$ in THF $(8.7 \mathrm{~mL})$, tetrabutylammoniumfluoride solution (TBAF, $1 \mathrm{M}$ in THF, $840 \mu \mathrm{L}, 0.840 \mathrm{mmol}$ ) was added at $0{ }^{\circ} \mathrm{C}$ and the mixture was stirred at room temperature for $5 \mathrm{~h}$. The solvent was removed under reduced pressure, and the resultant crude product was purified by column chromatography (95:5:1, $\mathrm{CH}_{2} \mathrm{Cl}_{2}$-MeOH-HOAc) to give 27 as colourless oil (287 mg, 93\%). ${ }^{1} \mathrm{H} \mathrm{NMR}\left(300 \mathrm{MHz}, \mathrm{CD}_{2} \mathrm{Cl}_{4}, 100{ }^{\circ} \mathrm{C}\right)$ : $\delta[\mathrm{ppm}]=5.69-5.37\left(\mathrm{~m}, 2 \mathrm{H}\right.$, Lys-N $^{\alpha} \mathrm{H}$, Val-N $\left.{ }^{\alpha} \mathrm{H}\right) .4 .95-4.83\left(\mathrm{~m}, 1 \mathrm{H}\right.$, Lys-N $\left.^{\varepsilon} \mathrm{H}\right), 4.36-4.28(\mathrm{~m}, 1 \mathrm{H}$, Lys-H-2), 4.25-4.18 (m, 1H, Val-H-2), 3.16-3.06 (m, 2H, Lys-H-6), 2.23-2.02 (m, 1H, Val-H-3), 1.95-1.80 $(\mathrm{m}, 1 \mathrm{H}$, Lys-H-3a $), 1.80-1.66$ (m, 1H, Lys-H-3 $\mathrm{b}), 1.51-1.48$ (m, 4H, Lys-H-4, Lys-H-5), 1.48 (s, 9H, t-Bu-CH$\left.{ }_{3}\right) 1.47\left(\mathrm{~s}, 9 \mathrm{H}\right.$, Boc-CH $\left.\mathrm{CH}_{3}\right), 0.97$ (d, $\left.J=10.5 \mathrm{~Hz}, 3 \mathrm{H}, \mathrm{Val}-\mathrm{H}-4\right), 0.94$ (d, J = $\left.10.5 \mathrm{~Hz}, 3 \mathrm{H}, \mathrm{Val}-\mathrm{H}-4\right)$. ${ }^{13} \mathrm{C}$ NMR $\left(75 \mathrm{MHz}, \mathrm{CD}_{2} \mathrm{Cl}_{4}, 100{ }^{\circ} \mathrm{C}\right): \delta$ [ppm] = 175.12 (Lys-C-1) 171.99 (Val-C-1), 158.34 (Boc-C=O), 156.21 (urea-C=O), 81.98 ( $t$-Bu-C), 81.74 (Boc-C), 58.46 (Val-C-2), 53.38 (Lys-C-2), 40.04 (Lys-C-6), 31.16 (Lys-C-3), 31.11 (Val-C-3), 29.29 (Lys-C-5), 28.26 (t-Bu-CH 3$), 27.85\left(\right.$ Boc-CH $\left._{3}\right), 22.25$ (Lys-C-4), 18.69 (Val-C-4), 17.43 (Val-C-4). MS (ESI $\left.{ }^{+}\right): m / z=468.3[\mathrm{M}+\mathrm{Na}]^{+}$. HRMS (ESI ${ }^{+}$): calcd.: $468.2680[\mathrm{M}+\mathrm{Na}]^{+}$, found: 468.2681. IR (ATR): $v\left[\mathrm{~cm}^{-1}\right]=3359,2967,1715,1640,1552,1366,1159$, 847. Optical rotation: $[\alpha]_{\mathrm{D}}^{25}=19.9\left(\mathrm{c}=0.80, \mathrm{CHCl}_{3}\right)$. TLC: $\mathrm{R}_{f}\left(7: 3: 1, \mathrm{CH}_{2} \mathrm{Cl}_{2}: \mathrm{MeOH}: \mathrm{HOAc}\right)=0.41$.

L-leucine trimethylsilylethyl ester trifluoroacetate (28): To a solution of $N$-benzyloxycarbonyl-L-leucine 30 (10.0 g, $37.8 \mathrm{mmol})$ in $\mathrm{CH}_{2} \mathrm{Cl}_{2}$ (385 mL), EDC (9.21 g, $\left.48 \mathrm{mmol}\right)$, DMAP (922 mg, $7.55 \mathrm{mmol})$, and 2-(trimethylsilyl)ethanol $(6.87 \mathrm{~mL}, 5.67 \mathrm{~g}, 48.0 \mathrm{mmol})$ were added and the mixture was stirred at room temperature for $14 \mathrm{~h}$. It was then washed with $\mathrm{HCl}(1 \mathrm{M}, 3 \times 600 \mathrm{~mL})$, sat. $\mathrm{NaHCO}_{3}(3 \times 600 \mathrm{~mL})$, and brine $(3 \times 600 \mathrm{~mL})$. The organic layer was dried over $\mathrm{NaSO}_{4}$ and the solvent was removed under reduced pressure. $N$-benzyloxycarbonyl-L-leucine trimethylsilylethyl ester was isolated after column chromatography as a colourless oil (11.8 $\mathrm{g}, 86 \%)$. To a solution of this material $(366 \mathrm{mg}, 1.00 \mathrm{mmol})$ in $\mathrm{MeOH}(40 \mathrm{~mL})$, TFA $(80 \mu \mathrm{L}, 0.12 \mathrm{~g}, 1.0 \mathrm{mmol})$ and Pd/C (10\%, $146 \mathrm{mg}, 0.130 \mathrm{mmol})$ were added and the mixture was stirred under hydrogen atmosphere (1 bar) at room temperature for $4 \mathrm{~h}$. It was then filtered over celite ${ }^{\mathrm{TM}}$ and the residue was washed with $\mathrm{MeOH}$. The solvent of the combined filtrates was removed under reduced pressure to give $\mathbf{2 8}$ as a colourless solid (345 mg, quant., 86\% over 2 steps from 30$) .{ }^{1} \mathrm{H} \mathrm{NMR}\left(300 \mathrm{MHz}, \mathrm{CDCl}_{3}\right): \delta[\mathrm{ppm}]=4.29-4.23$ $\left(\mathrm{m}, 2 \mathrm{H}, \mathrm{H}-1^{\prime}\right), 3.90(\mathrm{dd}, J=7.0,7.0 \mathrm{~Hz}, 1 \mathrm{H}, \mathrm{H}-2), 1.87-1.73(\mathrm{~m}, 3 \mathrm{H}, \mathrm{H}-3, \mathrm{H}-4), 1.05-0.99\left(\mathrm{~m}, 2 \mathrm{H}, \mathrm{H}-2^{\prime}\right)$, $0.97(\mathrm{~d}, J=6.1 \mathrm{~Hz}, 3 \mathrm{H}, \mathrm{H}-5), 0.95(\mathrm{~d}, J=6.1 \mathrm{~Hz}, 3 \mathrm{H}, \mathrm{H}-5), 0.04\left(\mathrm{~s}, 9 \mathrm{H}, \mathrm{Si}\left(\mathrm{CH}_{3}\right)_{3}\right) .{ }^{13} \mathrm{C} \mathrm{NMR}(75 \mathrm{MHz}$, $\left.\mathrm{CDCl}_{3}\right): \delta[\mathrm{ppm}]=170.12(\mathrm{C}-1), 162.73-161.77(\mathrm{~m}, \mathrm{TFA}-\mathrm{COO}), 116.32-114.45\left(\mathrm{~m}, \mathrm{TFA}-\mathrm{CF}_{3}\right), 65.12\left(\mathrm{C}-1^{\prime}\right)$, 51.54 (C-2), 39.61 (C-3), 24.29 (C-4), 22.09 (C-5), 21.74 (C-5), $17.19\left(\mathrm{C}-2^{\prime}\right),-1.68\left(\mathrm{Si}\left(\mathrm{CH}_{3}\right)_{3}\right) .{ }^{19} \mathrm{~F} \mathrm{NMR}$ $\left.\left.\left(282 \mathrm{MHz}, \mathrm{CDCl}_{3}\right): \delta[\mathrm{ppm}]=-75.98\left(\mathrm{TFA}_{-} \mathrm{CF}_{3}\right) . \mathrm{MS}\left(\mathrm{ESI}^{+}\right): m / z=232.2[\mathrm{M}-\mathrm{TFA}]^{+} . \mathrm{HRMS}_{(\mathrm{ESI}}\right)^{\prime}\right)$ calcd.: 232.1727 [M - TFA $]^{+}$, found: 232.1724. IR (ATR): $v\left[\mathrm{~cm}^{-1}\right]=1733,1665,1250,1201,1174,1137$, $1042,930,834$. Optical rotation: $[\alpha]_{\mathrm{D}}{ }^{25}=3.6\left(\mathrm{c}=1.0, \mathrm{CHCl}_{3}\right)$. m.p. $=85^{\circ} \mathrm{C}$. TLC: $\mathrm{R}_{f}(9: 1$, petroleum ether:EtOAc) $=0.76$.

Protected urea tripeptide trimethylsilylethyl ester (29): To a solution of 27 (15 mg, $35 \mu \mathrm{mol})$ in THF $(1 \mathrm{~mL}), \mathrm{HOBt}(4.7 \mathrm{mg}, 35 \mu \mathrm{mol})$, and EDC $(6.7 \mathrm{mg}, 35 \mu \mathrm{mol})$ were added and the mixture was stirred at room temperature for $30 \mathrm{~min}$. A solution of $28(12 \mathrm{mg}, 35 \mu \mathrm{mol})$ and DIPEA $(12 \mu \mathrm{L}, 9.0 \mathrm{mg}$, $70 \mu \mathrm{mol})$ in $\mathrm{CH}_{2} \mathrm{Cl}_{2}(1 \mathrm{~mL})$ was added and the mixture was stirred at room temperature for $18 \mathrm{~h}$. The solvent was removed under reduced pressure, and the resultant crude product was purified by column chromatography $\left(99: 1, \mathrm{CH}_{2} \mathrm{Cl}_{2}-\mathrm{MeOH}\right)$ to give 29 as a colourless solid $(18 \mathrm{mg}, 80 \%)$. ${ }^{1} \mathrm{H}$ $\operatorname{NMR}\left(300 \mathrm{MHz}, \mathrm{CD}_{2} \mathrm{Cl}_{4}, 100{ }^{\circ} \mathrm{C}\right): \delta[\mathrm{ppm}]=6.59\left(\mathrm{~d}, J=8.1 \mathrm{~Hz}, 1 \mathrm{H}, \mathrm{Lys}-\mathrm{N}^{\alpha} \mathrm{H}\right), 5.21(\mathrm{~d}, J=7.8 \mathrm{~Hz}$, 1H, Leu-NH), 5.14 (d, $J=8.7 \mathrm{~Hz}, 1 \mathrm{H}$, Val-NH), 4.76-4.64 (m, 1H, Lys-N $\left.{ }^{\varepsilon} \mathrm{H}\right), 4.53$ (ddd, $J=8.2,8.1$, 5.2 Hz, 1H, Lys-H-2), 4.31-4.12 (m, 4H, Val-H-2, Leu-H-2, H-1), 3.10 (dd, J = 13.1, 6.3 Hz, 2H, Lys-H-6), 2.20-2.02 (m, 1H, Val-H-3), 1.93-1.76 (m, 1H, Lys-H-3a), 1.77-1.34 (m, 8H, Lys-H-3 Leu-H-3, Leu-H-4), 1.46 (s, 9H, Boc-CH $), 1.49$ (s, 9H, t-Bu-CH $), 1.10-1.00$ (m, 2H, H-2), 1.01-0.87 (m, $12 \mathrm{H}, 2 \times$ Val-H-4, $2 \times$ Leu-H-5), $0.07\left(\mathrm{~s}, 9 \mathrm{H}, \mathrm{Si}\left(\mathrm{CH}_{3}\right)_{3}\right) .{ }^{13} \mathrm{C} \mathrm{NMR}\left(75 \mathrm{MHz}, \mathrm{CD}_{2} \mathrm{Cl}_{4}, 100{ }^{\circ} \mathrm{C}\right): \delta$ [ppm] = 172.41 (Lys-C-1), 172.36 (Val-C-1), 172.06 (Leu-C-1), 157.52 (Boc-C=O), 155.97 (urea-C=O), 81.55 ( $t$-Bu-C), 78.78 (Boc-C), 63.24 (C-1), 58.34 (Val-C-2), 53.51 (Lys-C-2), 50.77 (Leu-C-2), 41.06 (Lys-C-6), 39.90 (Leu-C-3), 31.51 (Lys-C-3), 31.03 (Val-C-3), 29.47 (Lys-C-5), 28.29 (t-Bu-CH $\left.)_{3}\right), 27.88\left(\mathrm{Boc}^{-C} \mathrm{H}_{3}\right)$, 
24.52 (Leu-C-4), 22.57 (Lys-C-4), 22.39 (Val-C-4), 21.79 (Val-C-4), 18.80 (Leu-C-5), 17.43 (Leu-C-5), 17.15 $(\mathrm{C}-2),-1.73\left(\mathrm{Si}\left(\mathrm{CH}_{3}\right)_{3}\right) . \mathrm{MS}\left(\mathrm{ESI}^{+}\right): m / z=681.50[\mathrm{M}+\mathrm{Na}]^{+}$. HRMS $\left(\mathrm{ESI}^{+}\right)$: calcd.: $681.4229[\mathrm{M}+\mathrm{Na}]^{+}$, found: 681.4233. IR (ATR): $v\left[\mathrm{~cm}^{-1}\right]=3339,2958,1731,1688,1633,1546,1249,1153,837$. Optical rotation: $[\alpha]_{\mathrm{D}}{ }^{25}=-14.1\left(\mathrm{c}=0.91, \mathrm{CHCl}_{3}\right)$. m.p. $=108{ }^{\circ} \mathrm{C} . \mathrm{TLC}: \mathrm{R}_{f}\left(98: 2, \mathrm{CH}_{2} \mathrm{Cl}_{2}: \mathrm{MeOH}\right)=0.48$.

Cbz-protected $6^{\prime}$-epi nucleoside building block (33): To a solution of the uridine-derived epoxy tert-butyl ester 31 (60 mg, $0.10 \mathrm{mmol})$ in $i$-PrOH $(4 \mathrm{~mL}), N$-benzyloxycarbonyl-1,3-diaminopropane 32 (31 mg, $0.15 \mathrm{mmol}$ ) was added and the mixture was stirred under reflux for $4 \mathrm{~d}$. The solvent was removed under reduced pressure, and the resultant crude product was purified by column chromatography (1:1, petroleum ether-EtOAc) to give 33 as a colourless solid (61 $\mathrm{mg}, 77 \%)$. ${ }^{1} \mathrm{H} \mathrm{NMR}$ $\left(600 \mathrm{MHz}_{2} \mathrm{CDCl}_{3}\right): \delta[\mathrm{ppm}]=0.05\left(\mathrm{~s}, 3 \mathrm{H}, \mathrm{SiCH}_{3}\right), 0.05\left(\mathrm{~s}, 3 \mathrm{H}, \mathrm{SiCH}_{3}\right), 0.08\left(\mathrm{~s}, 3 \mathrm{H}, \mathrm{SiCH}_{3}\right), 0.10(\mathrm{~s}, 3 \mathrm{H}$, $\left.\mathrm{SiCH}_{3}\right), 0.86\left(\mathrm{~s}, 9 \mathrm{H}, \mathrm{SiC}\left(\mathrm{CH}_{3}\right)_{3}\right), 0.91\left(\mathrm{~s}, 9 \mathrm{H}, \mathrm{SiC}\left(\mathrm{CH}_{3}\right)_{3}\right), 1.47\left(\mathrm{~s}, 9 \mathrm{H}, \mathrm{OC}\left(\mathrm{CH}_{3}\right)_{3}\right), 1.60-1.65(\mathrm{~m}, 2 \mathrm{H}$, $\left.2^{\prime \prime}-\mathrm{H}\right), 2.39\left(\mathrm{ddd}, J=11.6,7.1,6.9 \mathrm{~Hz}, 1 \mathrm{H}, 1^{\prime \prime}-\mathrm{H}_{\mathrm{a}}\right), 2.84\left(\mathrm{ddd}, J=11.6,5.8,5.8 \mathrm{~Hz}, 1 \mathrm{H}, 1^{\prime \prime}-\mathrm{H}_{\mathrm{b}}\right), 3.26-3.36$ $\left(\mathrm{m}, 3 \mathrm{H}, 6^{\prime}-\mathrm{H}, 3^{\prime \prime}-\mathrm{H}\right), 3.84\left(\mathrm{dd}, J=7.2,1.1 \mathrm{~Hz}, 1 \mathrm{H}, 5^{\prime}-\mathrm{H}\right), 4.07\left(\mathrm{dd}, 4.6,1.1 \mathrm{~Hz}, 1 \mathrm{H}, 4^{\prime}-\mathrm{H}\right), 4.12(\mathrm{dd}, J=4.6$, $\left.4.4 \mathrm{~Hz}, 1 \mathrm{H}, 3^{\prime}-\mathrm{H}\right), 4.36\left(\mathrm{dd}, J=4.5,4.4 \mathrm{~Hz}, 1 \mathrm{H}, 2^{\prime}-\mathrm{H}\right), 5.03\left(\mathrm{dd}, J=6.2,6.1 \mathrm{~Hz}, 1 \mathrm{H}, 3^{\prime \prime}-\mathrm{NH}\right), 5.08(\mathrm{~d}, J=$ $\left.12.2 \mathrm{~Hz}, 1 \mathrm{H}, 1^{\prime \prime \prime}-\mathrm{H}_{\mathrm{a}}\right), 5.10\left(\mathrm{~d}, J=12.2 \mathrm{~Hz}, 1 \mathrm{H}, 1^{\prime \prime \prime}-\mathrm{H}_{\mathrm{b}}\right), 5.52\left(\mathrm{~d}, J=4.5 \mathrm{~Hz}, 1 \mathrm{H}, 1^{\prime}-\mathrm{H}\right), 5.70(\mathrm{~d}, J=8.1 \mathrm{~Hz}$, 1H, 5-H), 7.29-7.35 (m, 5H, aryl-H), 7.59 (d, J = 8.1 Hz, 1H, 6-H), 8.69 (s, 1H, 3-H). ${ }^{13} \mathrm{C} \mathrm{NMR}(126 \mathrm{MHz}$, $\left.\mathrm{CDCl}_{3}\right): \delta[\mathrm{ppm}]=-4.71\left(\mathrm{SiCH}_{3}\right),-4.67\left(\mathrm{SiCH}_{3}\right),-4.62\left(\mathrm{SiCH}_{3}\right),-4.23\left(\mathrm{SiCH}_{3}\right), 17.99\left(\mathrm{SiC}\left(\mathrm{CH}_{3}\right)_{3}\right)$, $18.11\left(\mathrm{SiC}\left(\mathrm{CH}_{3}\right)_{3}\right), 25.82\left(\mathrm{SiC}\left(\underline{\mathrm{CH}}_{3}\right)_{3}\right), 25.90\left(\mathrm{SiC}\left(\underline{\mathrm{CH}}_{3}\right)_{3}\right), 28.13\left(\mathrm{OC}\left(\underline{\mathrm{CH}}_{3}\right)_{3}\right), 30.13\left(\mathrm{C}-2^{\prime \prime}\right), 38.70\left(\mathrm{C}-3^{\prime \prime}\right)$, $45.65\left(\mathrm{C}-1^{\prime \prime}\right), 64.55\left(\mathrm{C}-6^{\prime}\right), 66.67\left(\mathrm{C}-1^{\prime \prime \prime}\right), 68.96\left(\mathrm{C}-5^{\prime}\right), 72.18\left(\mathrm{C}-3^{\prime}\right), 73.77\left(\mathrm{C}-2^{\prime}\right), 82.19\left(\mathrm{OC}\left(\mathrm{CH}_{3}\right)_{3}\right), 84.82$ $\left(\mathrm{C}-4^{\prime}\right), 92.31\left(\mathrm{C}-1^{\prime}\right), 102.03$ (C-5), 128.00, 128.08, 128.43 (aryl-C), $136.54\left(\mathrm{C}-2^{\prime \prime \prime}\right), 141.81(\mathrm{C}-6), 149.94(\mathrm{C}-2)$, $156.38(\mathrm{Cbz}-\mathrm{C}=\mathrm{O}), 162.74(\mathrm{C}-4), 172.04\left(\mathrm{C}-7^{\prime}\right) . \mathrm{MS}\left(\mathrm{ESI}^{+}\right): m / z=793.5[\mathrm{M}+\mathrm{H}]^{+}$. HRMS (ESI $\left.{ }^{+}\right)$: calcd.: 793.4234 [M + H] $]^{+}$, found: 793.4234. IR (ATR): $v\left[\mathrm{~cm}^{-1}\right]=1682,1252,1154,1121,867,834,813,776$, 735. UV (MeCN): $\lambda_{\max }(\log \varepsilon)=204(4.24), 261$ (3.99). Optical rotation: $[\alpha]_{\mathrm{D}}{ }^{25}=+18.0\left(\mathrm{c}=0.55, \mathrm{CHCl}_{3}\right)$. m.p. $=62{ }^{\circ} \mathrm{C} . \mathrm{TLC}: \mathrm{R}_{f}=0.13$ (2:3, petroleum ether:EtOAc).

Cbz-protected 5'-epi nucleoside building block (35): To a solution of uridine-derived epoxy tert-butyl ester 34 (10 mg, $0.017 \mathrm{mmol})$ in $i$-PrOH $(4 \mathrm{~mL}), N$-benzyloxycarbonyl-1,3-diaminopropane 32 (5.4 mg, $0.026 \mathrm{mmol}$ ) was added and the mixture was stirred under reflux for $3 \mathrm{~d}$. The solvent was removed under reduced pressure, and the resultant crude product was purified by column chromatography $\left(97: 3, \mathrm{CH}_{2} \mathrm{Cl}_{2}-\mathrm{MeOH}\right)$ to give 35 as a colourless solid $(12 \mathrm{mg}, 89 \%)$. ${ }^{1} \mathrm{H}$ NMR $\left(600 \mathrm{MHz}, \mathrm{DMSO}_{-} \mathrm{d}_{6}, 35^{\circ} \mathrm{C}\right): \delta[\mathrm{ppm}]=-0.07\left(\mathrm{~s}, 3 \mathrm{H}, \mathrm{SiCH}_{3}\right), 0.01\left(\mathrm{~s}, 3 \mathrm{H}, \mathrm{SiCH}_{3}\right), 0.08\left(\mathrm{~s}, 3 \mathrm{H}, \mathrm{SiCH}_{3}\right)$, $0.11\left(\mathrm{~s}, 3 \mathrm{H}, \mathrm{SiCH}_{3}\right), 0.81$ (s, 9H, SiC $\left.\left(\mathrm{CH}_{3}\right)_{3}\right), 0.89$ (s, 9H, $\left.\mathrm{SiC}\left(\mathrm{CH}_{3}\right)_{3}\right), 1.42\left(\mathrm{~s}, 9 \mathrm{H}, \mathrm{OC}\left(\mathrm{CH}_{3}\right)_{3}\right), 1.49-1.54$ $\left(\mathrm{m}, 2 \mathrm{H}, 2^{\prime \prime}-\mathrm{H}\right), 2.04\left(\mathrm{~s}, 1 \mathrm{H}, 6^{\prime}-\mathrm{NH}\right), 2.34\left(\mathrm{ddd}, J=10.6,8.5,8.2 \mathrm{~Hz}, 1 \mathrm{H}, 1^{\prime \prime}-\mathrm{H}_{\mathrm{a}}\right), 2.54(\mathrm{ddd}, J=10.6,7.1$, $\left.6.8 \mathrm{~Hz}, 1 \mathrm{H}, 1^{\prime \prime}-\mathrm{H}_{\mathrm{b}}\right), 2.99-3.06\left(\mathrm{~m}, 3 \mathrm{H}, 6^{\prime}-\mathrm{H}, 3^{\prime \prime}-\mathrm{H}\right), 3.70\left(\mathrm{ddd}, J=6.3,6.1,5.4 \mathrm{~Hz}, 1 \mathrm{H}, 5^{\prime}-\mathrm{H}\right), 4.10(\mathrm{~d}, J=$ $\left.5.4 \mathrm{~Hz}, 1 \mathrm{H}, 4^{\prime}-\mathrm{H}\right), 4.23\left(\mathrm{~d}, J=4.4 \mathrm{~Hz}, 1 \mathrm{H}, 3^{\prime}-\mathrm{H}\right), 4.32\left(\mathrm{dd}, J=7.7,4.4 \mathrm{~Hz}, 1 \mathrm{H}, 2^{\prime}-\mathrm{H}\right), 5.00\left(\mathrm{~s}, 2 \mathrm{H}, 1^{\prime \prime \prime}-\mathrm{H}\right)$, $5.58(\mathrm{~d}, J=6.3 \mathrm{~Hz}, 1 \mathrm{H}, \mathrm{OH}), 5.67(\mathrm{~d}, J=8.1 \mathrm{~Hz}, 1 \mathrm{H}, 5-\mathrm{H}), 5.87\left(\mathrm{~d}, J=7.7 \mathrm{~Hz}, 1 \mathrm{H}, 1^{\prime}-\mathrm{H}\right), 7.16(\mathrm{dd}, J=$ 5.9, $\left.5.8 \mathrm{~Hz}, 1 \mathrm{H}, 3^{\prime \prime}-\mathrm{NH}\right), 7.33-7.36\left(\mathrm{~m}, 5 \mathrm{H}\right.$, aryl-H), $7.73(\mathrm{~d}, J=8.1 \mathrm{~Hz}, 1 \mathrm{H}, 6-\mathrm{H}), 11.31(\mathrm{~s}, 1 \mathrm{H}, 3-\mathrm{H}) .{ }^{13} \mathrm{C}$ NMR $\left(126 \mathrm{MHz}, \mathrm{DMSO}_{6}, 35{ }^{\circ} \mathrm{C}\right): \delta[\mathrm{ppm}]=-5.15\left(\mathrm{SiCH}_{3}\right),-4.88\left(\mathrm{SiCH}_{3}\right),-4.63\left(\mathrm{SiCH}_{3}\right),-4.53$ $\left(\mathrm{SiCH}_{3}\right), 17.54\left(\mathrm{SiC}\left(\mathrm{CH}_{3}\right)_{3}\right), 17.67\left(\mathrm{SiC}\left(\mathrm{CH}_{3}\right)_{3}\right), 25.54\left(\mathrm{SiC}\left(\underline{C H}_{3}\right)_{3}\right), 25.62\left(\mathrm{SiC}\left(\underline{C H}_{3}\right)_{3}\right), 27.76\left(\mathrm{OC}(\underline{\mathrm{CH}})_{3}\right)_{3}$, $30.07\left(\mathrm{C}-2^{\prime \prime}\right), 38.44\left(\mathrm{C}-3^{\prime \prime}\right), 44.96\left(\mathrm{C}-1^{\prime \prime}\right), 64.21\left(\mathrm{C}-6^{\prime}\right), 64.97\left(\mathrm{C}-1^{\prime \prime \prime}\right), 71.89\left(\mathrm{C}-3^{\prime}\right), 72.22\left(\mathrm{C}-5^{\prime}\right), 73.76\left(\mathrm{C}-2^{\prime}\right)$, $80.11\left(\mathrm{OC}\left(\mathrm{CH}_{3}\right)_{3}\right), 85.66\left(\mathrm{C}-1^{\prime}\right), 86.04\left(\mathrm{C}-4^{\prime}\right), 102.09(\mathrm{C}-5), 127.43,127.47,128.07$ (aryl-C), $137.02\left(\mathrm{C}-2^{\prime \prime \prime}\right)$, $140.51(\mathrm{C}-6), 150.64(\mathrm{C}-2), 155.81(\mathrm{Cbz}-\mathrm{C}=\mathrm{O}), 162.52(\mathrm{C}-4), 171.66\left(\mathrm{C}-7^{\prime}\right) . \mathrm{MS}\left(\mathrm{ESI}^{+}\right): m / z=793.5[\mathrm{M}+$ $\mathrm{H}]^{+}$. HRMS $\left(\mathrm{ESI}^{+}\right)$: calcd.: $793.4234[\mathrm{M}+\mathrm{H}]^{+}$, found: 793.4239. IR (ATR): $v\left[\mathrm{~cm}^{-1}\right]=1689,1252,1153$, $1057,833,813,775,735,697$. UV (MeCN): $\lambda_{\max }(\log \varepsilon)=204(4.13), 259$ (3.77). Optical rotation: $[\alpha]_{\mathrm{D}}{ }^{25}=$ $-30.0\left(\mathrm{c}=0.24, \mathrm{CHCl}_{3}\right)$. m.p. $=78^{\circ} \mathrm{C}$. TLC: $\mathrm{R}_{f}=0.15\left(96: 4, \mathrm{CH}_{2} \mathrm{Cl}_{2}: \mathrm{MeOH}\right)$.

\subsection{Overexpression of MraY from S. aureus}

The overexpression of MraY was performed as described before [48]. A plasmid containing the mraY gene [48] was transformed into E. coli Lemo21 cells, which were plated on lysogeny broth (LB) agar containing kanamycin $(50 \mu \mathrm{g} / \mathrm{mL})$ and chloramphenicol $(30 \mu \mathrm{g} / \mathrm{mL})$. A single colony was picked to induce an overnight culture $(10 \mathrm{~mL})$ of LB media containing kanamycin $(50 \mu \mathrm{g} / \mathrm{mL})$ and 
chloramphenicol $(30 \mu \mathrm{g} / \mathrm{mL})$, which was incubated at $37^{\circ} \mathrm{C}$ and $180 \mathrm{rpm}$ for $16 \mathrm{~h}$. A culture of LB media $(500 \mathrm{~mL})$ containing kanamycin $(50 \mu \mathrm{g} / \mathrm{mL})$, chloramphenicol $(30 \mu \mathrm{g} / \mathrm{mL})$, and L-rhamnose $(1 \mathrm{mM})$ was inoculated with the overnight culture $(500 \mu \mathrm{L})$ and then grown at $37{ }^{\circ} \mathrm{C}$ and $180 \mathrm{rpm}$ to $\mathrm{OD}_{600}$ 0.6. Subsequently, MraY expression was induced with IPTG $(1 \mathrm{mM})$ and the culture was incubated at $37^{\circ} \mathrm{C}$ and $180 \mathrm{rpm}$ for $4 \mathrm{~h}$. Cells were then centrifuged and the pellet was resuspended in buffer A (50 mM Tris- $\mathrm{HCl}$ buffer $\mathrm{pH} 7.5,1 \mathrm{mM} \mathrm{MgCl} 2,2 \mathrm{mM} \beta$-mercaptoethanol, $15 \mathrm{~mL}$ overall). Egg white lysozyme (spatula tip), DNAse I (spatula tip), and cOmplete ${ }^{\mathrm{TM}}$ EDTA-free protease inhibitor cocktail (one tablet) were added. Cells were lysed using sonication and then incubated at $4{ }^{\circ} \mathrm{C}$ for $30 \mathrm{~min}$. The lysate was centrifuged and the supernatant was centrifuged again. The resultant pellet was resuspended in buffer A $(1.7 \mathrm{~mL})$, flash frozen in liquid nitrogen and stored at $-80{ }^{\circ} \mathrm{C}$ (aliquots of $20 \mu \mathrm{L}$ ). This MraY-containing crude membrane preparation (overall protein concentration $\sim 20.5 \mathrm{mg} / \mathrm{mL}$ as determined by $\mathrm{OD}_{280}$ ) was diluted with water (final overall protein concentration $1 \mathrm{mg} / \mathrm{mL}$ ) and then directly used for MraY activity assays without further purification.

\subsection{Fluorescence-Based MraY assay}

The assay was performed as described before [40]. The crude membrane preparation of MraY from S. aureus $(1 \mu \mathrm{L}$, vide supra) was added to a mixture of undecaprenyl phosphate $(50 \mu \mathrm{M})$, dansylated Park's nucleotide $(7.5 \mu \mathrm{M})$ [48], and the tested compound (at varying concentrations) in buffer $(100 \mathrm{mM}$ Tris- $\mathrm{HCl}$ buffer $\mathrm{pH} 7.5,200 \mathrm{mM} \mathrm{KCl}, 10 \mathrm{mM} \mathrm{MgCl}_{2}, 0.1 \%$ Triton X-100, $20 \mu \mathrm{L}$ overall). Fluorescence of the assay mixtures over time was monitored at $\lambda_{\mathrm{ex}}=355 \mathrm{~nm}$ and $\lambda_{\mathrm{em}}=520 \mathrm{~nm}$ (plate reader, 384-well plate format). MraY activity at a certain inhibitor concentration was determined using linear regression from 0 to $2 \mathrm{~min}$. This measure of activity was plotted against logarithmic inhibitor concentrations and fitted using a sigmoidal fit. This procedure furnished $\mathrm{IC}_{50}$ values with standard deviations.

\section{Conclusions}

In summary, we have demonstrated that the synthesis of $5^{\prime}$-epi and $6^{\prime}$-epi muraymycin analogues with retained inhibitory activities against the bacterial target enzyme MraY is feasible. The $5^{\prime}, 6^{\prime}$-anti-configured $5^{\prime}$-hydroxy motif has been newly established as a versatile structural variation in this context. In particular, $\left(5^{\prime} S, 6^{\prime} R\right)$-derivatives (i.e., $5^{\prime}$-hydroxy- $6^{\prime}$-epi analogues) appear to be promising as their synthesis is highly efficient. Therefore, this novel scaffold will allow the introduction of diverse variations of the $5^{\prime}$-O-aminoribose motif for further SAR studies, thus enabling the future optimisation of MraY inhibitor potencies and the development of synthetic muraymycin analogues towards antibacterial drug candidates. Work along this line is on the way in our laboratories.

Supplementary Materials: The following are available online, details on the analysis of peptide units using Marfey's reagent, copies of NMR spectra.

Author Contributions: Conceptualization, C.D.; Formal analysis, A.P.S., S.K., S.S., R.L. and C.D.; Funding acquisition, C.D.; Investigation, A.P.S., S.K., S.S. and R.L.; Project Administration, C.D.; Supervision, C.D.; Writing-Original Draft, A.P.S., S.K. and S.S.; Writing-Review \& Editing, A.P.S., S.K. and C.D.

Funding: This research was funded by the Deutsche Forschungsgemeinschaft, grant number DU 1095/5-1, and the Fonds der Chemischen Industrie, Sachkostenzuschuss.

Conflicts of Interest: The authors declare no conflicts of interest.

\section{References}

1. Taubes, G. The bacteria fight back. Science 2008, 321, 356-361. [CrossRef] [PubMed]

2. Cooper, M.A.; Shlaes, D. Fix the antibiotics pipeline. Nature 2011, 472, 32. [CrossRef] [PubMed]

3. Walsh, C. Where will new antibiotics come from? Nat. Rev. Microbiol. 2003, 1, 65-70. [CrossRef] [PubMed]

4. Dini, C. MraY inhibitors as novel antibacterial agents. Curr. Top. Med. Chem. 2005, 5, 1221-1236. [CrossRef] [PubMed] 
5. Bugg, T.D.H.; Lloyd, A.J.; Roper, D.I. Phospho-murnac-pentapeptide translocase (MraY) as a target for antibacterial agents and antibacterial proteins. Infect. Disord. Drug Targets 2006, 6, 85-106. [CrossRef] [PubMed]

6. Struve, W.G.; Neuhaus, F.C. Evidence for an initial acceptor of UDP-NAc-muramyl-pentapeptide in the synthesis of bacterial mucopeptide. Biochem. Biophys. Res. Commun. 1965, 18, 6-12. [CrossRef]

7. Anderson, J.S.; Matsuhashi, M.; Haskin, M.A.; Strominger, J.L. Lipid-Phosphoacetylmuramyl-pentapeptide and Lipid-Phosphodisaccharide-pentapeptide: Presumed Membrane Transport Intermediates in Cell Wall Synthesis. Proc. Natl. Acad. Sci. USA 1965, 53, 881-889. [CrossRef] [PubMed]

8. Heydanek, M.G., Jr.; Struve, W.G.; Neuhaus, F.C. Initial state in peptidoglycan synthesis. III. Kinetics and uncoupling of phospho-N-acetylmuramyl-pentapeptide translocase (uridine 5'-phosphate). Biochemistry 1969, 8, 1214-1221. [CrossRef]

9. Ikeda, M.; Wachi, M.; Jung, H.K.; Ishino, F.; Matsuhashi, M. The Escherichia coli mraY gene encoding UDP-N-acetylmuramoyl-pentapeptide: undecaprenyl-phosphate phospho-N-acetylmuramoyl-pentapeptide transferase. J. Bacteriol. 1991, 173, 1021-1026. [CrossRef] [PubMed]

10. Boyle, D.S.; Donachie, W.D. MraY is an essential gene for cell growth in Escherichia coli. J. Bacteriol. 1998, 180, 6429-6432. [PubMed]

11. Vollmer, W.; Blanot, D.; Pedro, M.A.D. Peptidoglycan structure and architecture. FEMS Microbiol. Rev. 2008, 32, 149-167. [CrossRef] [PubMed]

12. Wiegmann, D.; Koppermann, S.; Wirth, M.; Niro, G.; Leyerer, K.; Ducho, C. Muraymycin nucleoside-peptide antibiotics: Uridine-derived natural products as lead structures for the development of novel antibacterial agents. Beilstein J. Org. Chem. 2016, 12, 769-795. [CrossRef] [PubMed]

13. Bouhss, A.; Mengin-Lecreulx, D.; Le Beller, D.; Van Heijenoort, J. Topological analysis of the MraY protein catalysing the first membrane step of peptidoglycan synthesis. Mol. Microbiol. 1999, 34, 576-585. [CrossRef] [PubMed]

14. Chung, B.C.; Zhao, J.; Gillespie, R.A.; Kwon, D.-Y.; Guan, Z.; Hong, J.; Zhou, P.; Lee, S.-Y. Crystal structure of MraY, an essential membrane enzyme for bacterial cell wall synthesis. Science 2013, 341, 1012-1016. [CrossRef] [PubMed]

15. Bouhss, A.; Crouvoisier, M.; Blanot, D.; Mengin-Lecreulx, D. Purification and characterization of the bacterial MraY translocase catalyzing the first membrane step of peptidoglycan biosynthesis. J. Biol. Chem. 2004, 279, 29974-29980. [CrossRef] [PubMed]

16. Ma, Y.; Münch, D.; Schneider, T.; Sahl, H.-G.; Bouhss, A.; Ghoshdastider, U.; Wang, J.; Dötsch, V.; Wang, X.; Bernhard, F. Preparative scale cell-free production and quality optimization of MraY homologues in different expression modes. J. Biol. Chem. 2011, 286, 38844-38853. [CrossRef] [PubMed]

17. Henrich, E.; Ma, Y.; Engels, I.; Münch, D.; Otten, C.; Schneider, T.; Henrichfreise, B.; Sahl, H.-G.; Dötsch, V.; Bernhard, F. Lipid requirements for the enzymatic activity of MraY translocases and in vitro reconstitution of the lipid II synthesis pathway. J. Biol. Chem. 2016, 291, 2535-2546. [CrossRef] [PubMed]

18. Winn, M.; Goss, R.J.M.; Kimura, K.; Bugg, T.D.H. Antimicrobial nucleoside antibiotics targeting cell wall assembly: Recent advances in structure-function studies and nucleoside biosynthesis. Nat. Prod. Rep. 2010, 27, 279-304. [CrossRef] [PubMed]

19. Ichikawa, S.; Yamaguchi, M.; Matsuda, A. Antibacterial nucleoside natural products inhibiting phospho-murnac-pentapeptide translocase; chemistry and structure-activity relationship. Curr. Med. Chem. 2015, 22, 3951-3979. [CrossRef] [PubMed]

20. Bugg, T.D.H.; Rodolis, M.T.; Mihalyi, A.; Jamshidi, S. Inhibition of phospho-MurNAc-pentapeptide translocase (MraY) by nucleoside natural product antibiotics, bacteriophage $\phi X 174$ lysis protein E, and cationic antibacterial peptides. Bioorg. Med. Chem. 2016, 24, 6340-6347. [CrossRef] [PubMed]

21. McDonald, L.A.; Barbieri, L.R.; Carter, G.T.; Lenoy, E.; Lotvin, J.; Petersen, P.J.; Siegel, M.M.; Singh, G.; Williamson, R.T. Structures of the muraymycins, novel peptidoglycan biosynthesis inhibitors. J. Am. Chem. Soc. 2002, 124, 10260-10261. [CrossRef] [PubMed]

22. Carter, G.T.; Lotvin, J.A.; McDonald, L.A. Antibiotics AA-896. Int. PCT Pub. No. WO02085310 A2. 31 October 2002.

23. Cui, Z.; Wang, X.; Koppermann, S.; Thorson, J.S.; Ducho, C.; Van Lanen, S.G. Antibacterial muraymycins from mutant strains of Streptomyces sp. NRRL 30471. J. Nat. Prod. 2018, 81, 942-948. [CrossRef] [PubMed] 
24. Spork, A.P.; Büschleb, M.; Ries, O.; Wiegmann, D.; Boettcher, S.; Mihalyi, A.; Bugg, T.D.; Ducho, C. Lead structures for new antibacterials: Stereocontrolled synthesis of a bioactive muraymycin analogue. Chem. Eur. J. 2014, 20, 15292-15297. [CrossRef] [PubMed]

25. Chung, B.C.; Mashalidis, E.H.; Tanino, T.; Kim, M.; Matsuda, A.; Hong, J.; Ichikawa, S.; Lee, S.-Y. Structural insights into inhibition of lipid I production in bacterial cell wall synthesis. Nature 2016, 533, 557-560. [CrossRef] [PubMed]

26. Koppermann, S.; Ducho, C. Natural products at work: Structural insights into inhibition of the bacterial membrane protein MraY. Angew. Chem. Int. Ed. 2016, 55, 11722-11724. [CrossRef] [PubMed]

27. Tanino, T.; Hirano, S.; Ichikawa, S.; Matsuda, A. Synthetic study of muraymycins using Ugi-four component reaction. Nucleic Acids Symp. Ser. 2008, 52, 557-558. [CrossRef] [PubMed]

28. Tanino, T.; Ichikawa, S.; Shiro, M.; Matsuda, A. Total synthesis of (-)-muraymycin D2 and its epimer. J. Org. Chem. 2010, 75, 1366-1377. [CrossRef] [PubMed]

29. Aleiwi, B.A.; Schneider, C.M.; Kurosu, M. Synthesis of ureido-muraymycidine derivatives for structure activity relationship studies of muraymycins. J. Org. Chem. 2012, 77, 3859-3867. [CrossRef] [PubMed]

30. Mitachi, K.; Aleiwi, B.A.; Schneider, C.M.; Siricilla, S.; Kurosu, M. Stereocontrolled total synthesis of muraymycin D1 having a dual mode of action against Mycobacterium tuberculosis. J. Am. Chem. Soc. 2016, 138, 12975-12980. [CrossRef] [PubMed]

31. Spork, A.P.; Koppermann, S.; Dittrich, B.; Herbst-Irmer, R.; Ducho, C. Efficient synthesis of the core structure of muraymycin and caprazamycin nucleoside antibiotics based on a stereochemically revised sulfur ylide reaction. Tetrahedron: Asymmetry 2010, 21, 763-766. [CrossRef]

32. Ries, O.; Ochmann, A.; Ducho, C. Synthesis of N-alkyl-N-hydroxyguanidines: A comparative study using different protecting group strategies. Synthesis 2011, 2011, 2357-2368.

33. Büschleb, M.; Granitzka, M.; Stalke, D.; Ducho, C. A biomimetic domino reaction for the concise synthesis of capreomycidine and epicapreomycidine. Amino Acids 2012, 43, 2313-2328. [CrossRef] [PubMed]

34. Ries, O.; Büschleb, M.; Granitzka, M.; Stalke, D.; Ducho, C. Amino acid motifs in natural products: Synthesis of O-acylated derivatives of (2S,3S)-3-hydroxyleucine. Beilstein J. Org. Chem. 2014, 10, 1135-1142. [CrossRef] [PubMed]

35. Lin, Y.-I.; Li, Z.; Francisco, G.D.; McDonald, L.A.; Davis, R.A.; Singh, G.; Yang, Y.; Mansour, T.S. Muraymycins, novel peptidoglycan biosynthesis inhibitors: Semisynthesis and SAR of their derivatives. Bioorg. Med. Chem. Lett. 2002, 12, 2341-2344. [CrossRef]

36. Yamashita, A.; Norton, E.; Petersen, P.J.; Rasmussen, B.A.; Singh, G.; Yang, Y.; Mansour, T.S.; Ho, D.M. Muraymycins, novel peptidoglycan biosynthesis inhibitors: Synthesis and SAR of their analogues. Bioorg. Med. Chem. Lett. 2003, 13, 3345-3350. [CrossRef]

37. Tanino, T.; Ichikawa, S.; Al-Dabbagh, B.; Bouhss, A.; Oyama, H.; Matsuda, A. Synthesis and Biological Evaluation of Muraymycin Analogues Active against Anti-Drug-Resistant Bacteria. ACS Med. Chem. Lett. 2010, 1, 258-262. [CrossRef] [PubMed]

38. Tanino, T.; Al-Dabbagh, B.; Mengin-Lecreulx, D.; Bouhss, A.; Oyama, H.; Ichikawa, S.; Matsuda, A. Mechanistic Analysis of Muraymycin Analogues: A Guide to the Design of MraY Inhibitors. J. Med. Chem. 2011, 54, 8421-8439. [CrossRef] [PubMed]

39. Takeoka, Y.; Tanino, T.; Sekiguchi, M.; Yonezawa, S.; Sakagami, M.; Takahashi, F.; Togame, H.; Tanaka, Y.; Takemoto, H.; Ichikawa, S.; et al. Expansion of Antibacterial Spectrum of Muraymycins toward Pseudomonas aeruginosa. ACS Med. Chem. Lett. 2014, 5, 556-560. [CrossRef] [PubMed]

40. Koppermann, S.; Cui, Z.; Fischer, P.D.; Wang, X.; Ludwig, J.; Thorson, J.S.; Van Lanen, S.G.; Ducho, C. Insights into the target interaction of naturally occurring muraymycin nucleoside antibiotics. ChemMedChem 2018, 13, 779-784. [CrossRef] [PubMed]

41. Spork, A.P.; Wiegmann, D.; Granitzka, M.; Stalke, D.; Ducho, C. Stereoselective synthesis of uridine-derived nucleosyl amino acids. J. Org. Chem. 2011, 76, 10083-10098. [CrossRef] [PubMed]

42. Spork, A.P.; Ducho, C. Novel 5'-deoxy nucleosyl amino acid scaffolds for the synthesis of muraymycin analogues. Org. Biomol. Chem. 2010, 8, 2323-2326. [CrossRef] [PubMed]

43. Brandish, P.E.; Burnham, M.K.; Lonsdale, J.T.; Southgate, R.; Inukai, M.; Bugg, T.D. Slow binding inhibition of phospho-N-acetylmuramyl-pentapeptide-translocase (Escherichia coli) by mureidomycin A. J. Biol. Chem. 1996, 271, 7609-7614. [CrossRef] [PubMed] 
44. Spork, A.; Ducho, C. Stereocontrolled synthesis of $5^{\prime}$ - and $6^{\prime}$-epimeric analogues of muraymycin nucleoside antibiotics. Synlett 2013, 24, 343-346. [CrossRef]

45. Spork, A.P.; Koppermann, S.; Ducho, C. Improved convergent synthesis of 5'-epi-analogues of muraymycin nucleoside antibiotics. Synlett 2009, 15, 2503-2507.

46. Sarabia, F.; Martín-Ortiz, L. Synthetic studies on nucleoside-type muraymycins antibiotics based on the use of sulfur ylides. Synthesis of bioactive 5'-epimuraymycin analogues. Tetrahedron 2005, 61, 11850-11865. [CrossRef]

47. Sarabia, F.; Vivar-García, C.; García-Ruiz, C.; Martín-Ortiz, L.; Romero-Carrasco, A. Exploring the Chemistry of Epoxy Amides for the Synthesis of the $2^{\prime \prime}$-epi-Diazepanone Core of Liposidomycins and Caprazamycins. J. Org. Chem. 2012, 77, 1328-1339. [CrossRef] [PubMed]

48. Wohnig, S.; Spork, A.P.; Koppermann, S.; Mieskes, G.; Gisch, N.; Jahn, R.; Ducho, C. Total synthesis of dansylated Park's nucleotide for high-throughput MraY assays. Chem. Eur. J. 2016, 22, 17813-17819. [CrossRef] [PubMed]

Sample Availability: Samples of the target compounds are available from the authors. 